\title{
Performance Enhancement of Automatic Generation Control by Developing a Detailed Load Frequency Control Model and an Adaptive Performance Index Criterion
}

\author{
Kaveh Rahimi \\ West Virginia University
}

Follow this and additional works at: https://researchrepository.wvu.edu/etd

\footnotetext{
Recommended Citation

Rahimi, Kaveh, "Performance Enhancement of Automatic Generation Control by Developing a Detailed Load Frequency Control Model and an Adaptive Performance Index Criterion" (2013). Graduate Theses, Dissertations, and Problem Reports. 4993.

https://researchrepository.wvu.edu/etd/4993

This Thesis is protected by copyright and/or related rights. It has been brought to you by the The Research Repository @ WVU with permission from the rights-holder(s). You are free to use this Thesis in any way that is permitted by the copyright and related rights legislation that applies to your use. For other uses you must obtain permission from the rights-holder(s) directly, unless additional rights are indicated by a Creative Commons license in the record and/ or on the work itself. This Thesis has been accepted for inclusion in WVU Graduate Theses, Dissertations, and Problem Reports collection by an authorized administrator of The Research Repository @ WVU. For more information, please contact researchrepository@mail.wvu.edu.
} 


\title{
Performance Enhancement of Automatic Generation Control by \\ Developing a Detailed Load Frequency Control Model and an Adaptive \\ Performance Index Criterion \\ By
}

\author{
KAVEH RAHIMI
}

Thesis submitted to the

Benjamin M. Statler College of Engineering and Mineral Resources

at West Virginia University

in partial fulfillment of the requirements for the degree of

\author{
Master of Science \\ in \\ ELECTRICAL ENGINEERING
}

\author{
Approved by \\ Parviz Famouri, Ph.D., Chair \\ Muhammad A. Choudhry, Ph.D. \\ Yaser P. Fallah, Ph.D. \\ Lane Department of Computer Science and Electrical Engineering \\ Morgantown, West Virginia \\ 2013
}

Copyright 2013 Kaveh Rahimi 


\begin{abstract}
Performance Enhancement of Automatic Generation Control by Developing a Detailed Load Frequency Control Model and an Adaptive Performance Index Criterion
\end{abstract}

\title{
Kaveh Rahimi
}

The imbalance between electrical loads and power supplied by the system generators causes the frequency deviations in a power system. Maintaining the frequency close to its nominal value as well as in its allowed deviation range is the first objective of the automatic generation control (AGC). Nowadays, in interconnected power systems, several control areas are connected to each other by tie-lines and power is transferred between control areas based on a specific schedule. The second objective of automatic generation control is to keep the tie-lines power flow close to their secluded values.

An accurate and realistic load frequency control (LFC) model is very essential to have an effective and adaptive AGC strategy. The first objective of this thesis is to present the importance of considering communication delay in LFC model missing in most of the studies investigating AGC and its performance using different methods and optimization techniques. The second objective of this thesis is to present a comprehensive LFC model, which contains all of the physical constraints such as governor dead-band, generation rate and delay of communication links. The third objective is to evaluate different controllers and performance index criteria used in conventional AGC. Finally, the last objective is to introduce an adaptive performance index criterion cable of defining settling time and overshoot which cannot be applied by other performance index criteria.

Different optimization methods have been used to optimize the performance of AGC such as genetic algorithm, fuzzy logic and neural networks. Genetic algorithm has been used widely in LFC studies so it is chosen to be employed in this study to optimize the performance of controllers in the utilized AGC scheme. Integrator controller is the most common controller employed in LFC 
studies because of its design simplicity, however, in this thesis proportional-integral-derivative (PID) controller is employed to obtain the best performance.

This study shows that without a precise and detailed LFC model, results of different techniques or strategies used in AGC will not be accurate and practical even when they are derived by optimization methods. Moreover, it is shown that PID controller has the best performance in comparison with other controllers used in LFC studies when physical constraints are not considered in the LFC model. Furthermore, a robust GA based control system is designed considering all of physical constraints for a three-area power system and the simulation results show that it can track the load change and restore the frequency of all control areas to the nominal value effectively. Different performance index criteria are evaluated and results show that in specific cases they cannot be completely accurate or reliable to assess the performance of AGC schemes. Finally, an effective and adaptive performance index is introduced and simulation results validate its effectiveness and reliability. 


\section{Acknowledgments}

I would like to express my deepest appreciation to my advisor, Dr. Parviz Famouri for giving me the opportunity to study at West Virginia University as well as work and research in his team. His knowledge and encouragement have been of utmost value throughout the course of my research.

Moreover, I wish to express my sincere thanks to my committee members, Dr. Muhammad Choudhry and Dr. Yaser Fallah for being in my committee, their constructive comments and invaluable materials which I learnt during their productive classes.

Most importantly, I would like to thank my family for their constant support and encouragement in every situation. I would not have made it this far without them.

Finally, I would like to thank all of my colleagues in our research lab. Special thanks go to Neda Nasiriani and Roopa Ramachandran. 


\section{List of Contents}

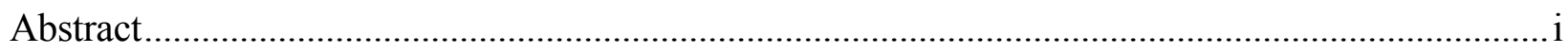

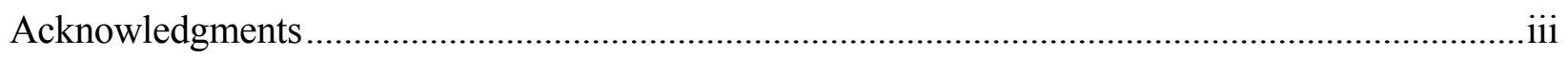

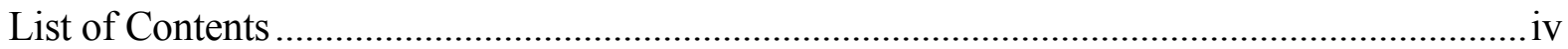

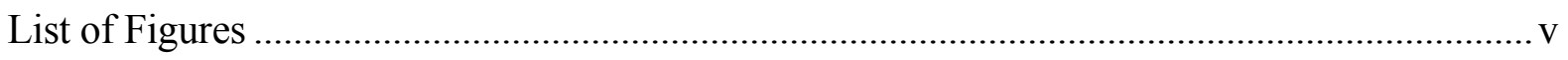

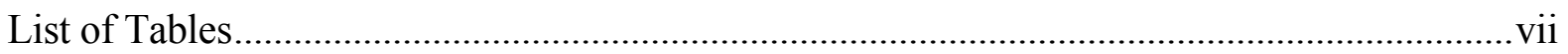

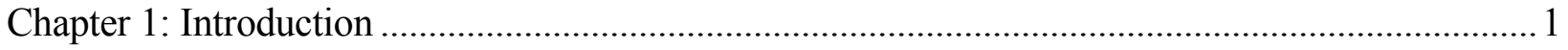

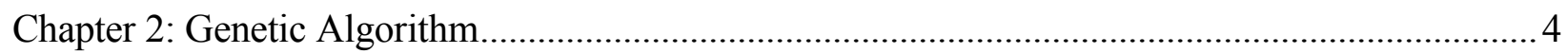

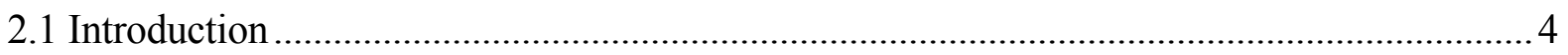

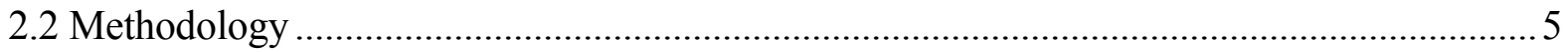

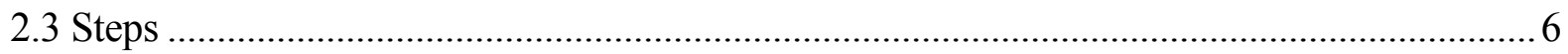

2.4 Genetic algorithm and its application in AGC .................................................................. 10

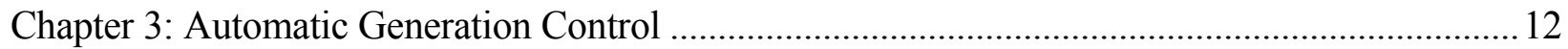

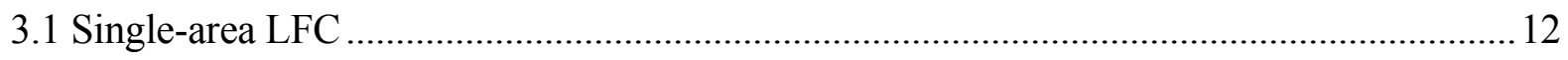

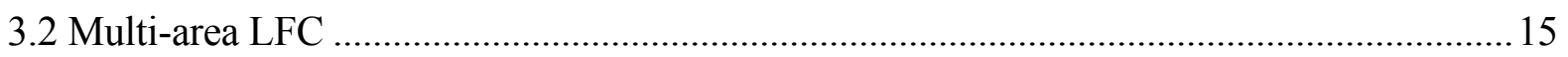

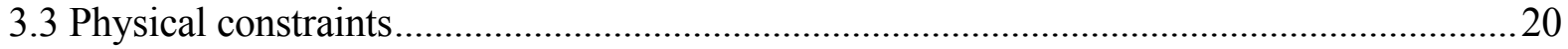

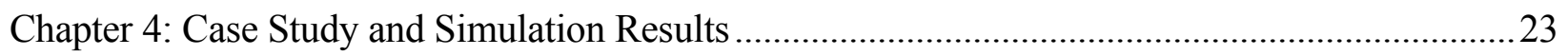

4.1 Effect of communication link delay on the performance of AGC …………………….........23

4.2 Detailed load frequency model and comparison between controllers.....................................32

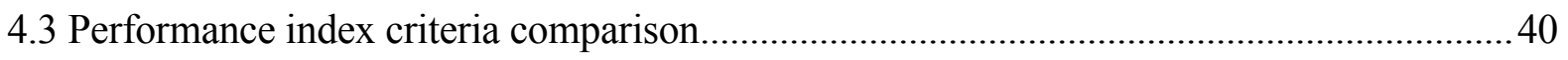

Chapter 5: Discussion and Future Direction ..................................................................................

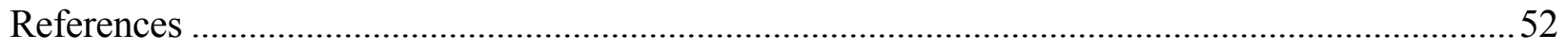

Appendix A: GA MATLAB Code (Multi-Area, PID Controller) ......................................................6

Appendix B: GA MATLAB Code (Single-Area, PID Controller).....................................................6

Appendix C: System parameters for three-area \& single-area power systems ..................................69 


\section{List of Figures}

\section{Chapter 2}

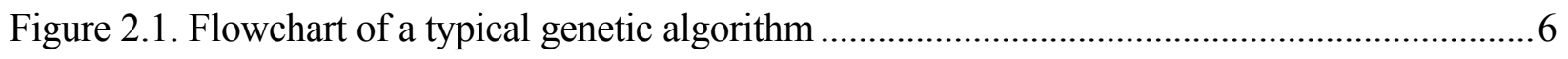

Figure 2.2. An example of roulette wheel selection.....................................................................

Figure 2.3. Single-point and two-point crossover ......................................................................

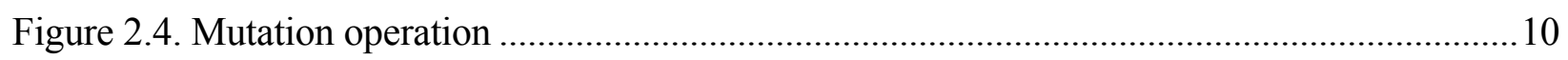

Figure 2. 5. Relation between GA implemented in MATLAB and simulations computed in

Simulink.

\section{Chapter 3}

Figure 3.1. Block diagram of a synchronous generator with basic frequency control loops.............13

Figure 3.2. Block diagram model of governor with frequency control loops ....................................14

Figure 3.3. Block diagram of turbine-governor system a reheat steam unit.....................................15

Figure 3.4. A multi-area power system ..................................................................................... 16

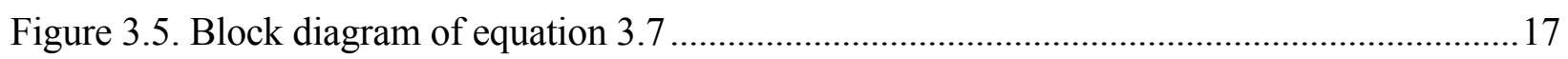

Figure 3.6. The combination of figure 3.3 and figure 3.5 ........................................................ 18

Figure 3.7. Block diagram model of multi-area load frequency control ..........................................19

Figure 3.8. The effect of governor dead band on the governor speed-droop characteristic .............20

Figure 3.9. Non-reheat generator unit model with GRC and dead band ..........................................21

Figure 3.10. Implementation of physical constraints ………….......................................................22

\section{Chapter 4}

Figure 4.1. Three-control area power system ..............................................................................

Figure 4.2. Designed PID controller in Simulink......................................................................2

Figure 4.3. Three-area power system implemented in Simulink ......................................................26

Figure 4.4. Frequency deviations in scenario A (no delay) .................................................................27

Figure 4.5. Frequency deviations in scenario $\mathrm{B}(0.5$ second delay $)$................................................2

Figure 4.6. Frequency deviations in scenario $\mathrm{C}$ (1.5 seconds delay) ................................................28

Figure 4.7. Frequency deviations in scenario $\mathrm{D}(0.5$ second delay $)$..................................................2 
Figure 4.8. Frequency deviations in scenario E (1.5 seconds delay) ..........................................29

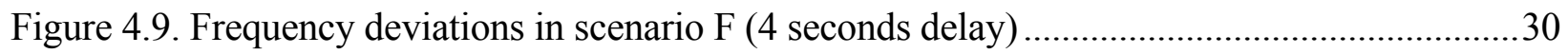

Figure 4.10. Response of PID controllers in three-area power system to 0.04 p.u. load change .....32

Figure 4. 11. Three-area power system considering all physical constraints ...................................33

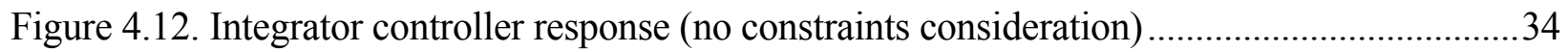

Figure 4.13. PI controller response (no constraints consideration) ..............................................35

Figure 4.14. PID controller response (no constraints consideration) ...........................................35

Figure 4.15. Comparison between integrator, PI and PID controllers (no constraints consideration)

Figure 4.16.Single-area LFC model considering physical constraints .........................................37

Figure 4.17. Response of integrator controller (constraints considered) .......................................38

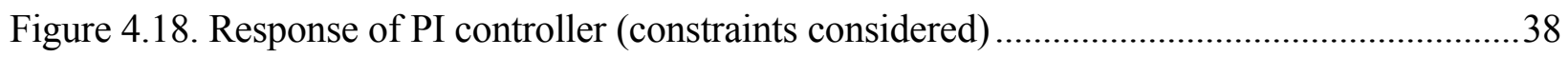

Figure 4. 19. Response of PID controller (constraints considered) ..............................................39

Figure 4. 20. Comparison between integrator, PI and PID controllers (constraints considered) .....39

Figure 4.21. Block diagram of computed performance criteria ...................................................41

Figure 4. 22. Response of PID controller with the least IAE .....................................................41

Figure 4. 23. Response of PID controller with the least ISE .....................................................42

Figure 4. 24. Comparing run \#3 and run \#4 (close ISE values) .................................................43

Figure 4. 25. Response of PID controller with the least ITAE .................................................43

Figure 4. 26. Response of PID controller with the least ITSE .....................................................44

Figure 4. 27. Response of PID controller with overshoot as the PIC ...........................................44

Figure 4. 28. Response of PID controller with settling time as the PIC ........................................48

Figure 4. 29. Response of PID controller with multi-objective function ......................................49

Figure 4. 30. Response of PID controller using developed adaptive PIC .....................................49 


\section{List of Tables}

\section{Chapter 2}

Table 2.1. Relations between concepts in natural evolution and genetic algorithms

\section{Chapter 4}

Table 4.1. GA Parameters . 30

Table 4.2. PID controllers gains in different scenarios

Table 4.3. Controllers' gains and their respective performance criteria (no physical constraints

consideration)

Table 4.4. Controllers' gains and their respective performance criteria (physical constraints

considered) 31

Table 4.5. Physical constraints imposed. .34

Table 4.6. Value of controllers' gains computed by GA .34

Table 4. 8. Result of GA runs using IAE as the performance index criterion .45

Table 4. 9. Result of GA runs using ISE as the performance index criterion ...............................45

Table 4. 10. Result of GA runs using ITAE as the performance index criterion ...........................46

Table 4. 11. Result of GA runs using ITSE as the performance index criterion............................46

Table 4. 12. Result of GA runs using overshoot as the performance index criterion ......................47

Table 4. 13. Result of GA runs using settling time as the performance index criterion ..................47

Table 4. 14. Result of GA using multi-objective function with weighting coefficients ..................47

Table 4. 15. Result of GA using adaptive performance index ceriterion .......................................47 


\section{Chapter 1: Introduction}

The frequency of a power system should be almost constant to keep its satisfactory operation. Frequency deviations originate from the imbalance between the electric loads and the active power generated by the system generators. A considerable drop in frequency might lead to a huge magnetizing current in system's motors and generators. Moreover, extended use of electric clocks and frequency in timing applications requires accurate control of system frequency and its integral [1]. Therefore, the maintenance of frequency close to its nominal value is an inevitable necessity.

The control of frequency and keeping the balance between electric loads and active power is commonly called Load Frequency Control (LFC) and the model used for LFC studies is commonly referred as load frequency control model. The control system and mechanism which performs the load frequency control is called Automatic Generation Control (AGC) [2]. In today's bulk power system, interconnected areas exchange power based on a specific schedule to satisfy their demands. It provides continuity of service, reliability, and reduces the total number of generators working under no-load conditions [3]. Keeping the frequency deviations in its allowed range and tie-lines power in their scheduled values are the main roles of automatic generation control [4].

A LFC model consists of governor, turbine (reheat/non-reheat), and rotational inertia and load models plus two control loops; primary control loop and supplementary control loop [1]. However, it is very important to consider the physical constraints in the LFC model to obtain an accurate model. Physical constraints such as governor dead-band [5], generation rate [6] and communication link delays [7] may have a significant effect on performance of AGC. The physical constraints have been ignored in most of the LFC studies evaluating the AGC performance especially the communication link delays. This work first shows the importance of considering communication delay in LFC model and how it can affect the performance of AGC and then proposed a detailed LFC model including the mentioned physical constraints.

The most common controller employed in LFC studies is integrator controller [8]. An integrator controller can be designed simply so its design simplicity is the reason of its popularity. Proportional-integral (PI) controllers have been also used in many researches assessing the 
performance of AGC mechanism [9]. PID controllers have the best performance but the most complex design [10]. In some cases, using PID controllers increases the dimensions of the problem and by having so many parameters and variables, the LFC problem turns into a complicated problem to solve. This work performs a comparison between mentioned controllers in two cases; when physical constraints are ignored and when they are considered in the LFC model.

Solving the optimization problems with many parameters may not be feasible by classical optimization techniques. However, time consumption and inaccuracy of classical, experiencebased and trial and error methods made non-classical optimization methods such as neural networks [11], fuzzy logic [12], and genetic algorithm [13] effective tools for solving the mentioned problems. Design of the controllers employed in an AGC scheme with optimal performance might be a huge problem to solve, but by employing non-classical optimization methods finding a solution can be fairly feasible. In this work, genetic algorithm is selected to compute the optimal gains of the utilized controllers. The LFC model is implemented in Simulink and the GA is computed in MATLAB.

To evaluate and assess the performance of control loops different performance index criteria have been used. In LFC studies, the integral of the absolute value of the error (IAE) [14], the integral of time-multiplied absolute value of the error (ITAE) [15], the integral of the square of the error (ISE) [16], and the integral of time-multiplied square of the error (ITSE) [17] criteria have been used mostly. This work compares these performance index criteria and shows the cases which these performance index criteria cannot be definitely accurate and reliable.

As mentioned, the performance index criteria used in LFC studies may not be capable of defining and computing the desire setting time and overshoot in a specific AGC scheme. Therefore, an adaptive and robust performance index is introduced in this study so that the settling time and overshoot can be defined in their possible margins. This proposed performance index does not have the disadvantage of the mentioned performance index criteria and is computed by a multiobjective function which can be calculated by different optimization techniques. Although, the proposed performance index criterion is not limited to be computed by GA, in this work GA is chosen to obtain the optimal gains of the controllers. 
Briefly, the main objectives of this study are:

- Presenting the effect of communication links delay on performance of AGC

- Presenting a detailed and practical LFC model considering physical constraints

- Assessment of different controllers and performance index criteria used in LFC studies

- Presenting an adaptive and robust AGC performance index criterion

The rest of this thesis is organized as follows. Chapter 2 is devoted to genetic algorithm and expressing the GA employed in this study. Chapter 3 discusses load frequency control model and automatic generation in details as well as introducing the comprehensive LFC model considering the physical constraints. In Chapter 4, case study and simulation results are presented. Finally the last chapter discusses the results and concludes the thesis. 


\section{Chapter 2: Genetic Algorithm}

\subsection{Introduction}

Genetic Algorithm (GA) is an evolutionary optimization method which is derived from the nature and capable of being applied to a wide range of optimization problems [18]. First proposed and investigated by John Holland at the University of Michigan in 1975 [19]. Easy speaking, it is an intelligent trial and error method which uses the best current solutions to find the best solution for a problem in a recursive scheme. It simulates the natural selection mechanism of biologic systems such as reproduction, crossover and mutation. The basic idea of genetic algorithms was revealed by a number of biologists when they used computers to perform simulations of natural genetic systems [20]. Genetic algorithm can be used for solving the problems which standard optimization algorithms cannot be used such as problems with discrete objective functions, non-derivative, stochastic and very non-linear problems.

Genetic algorithm popularity for solving optimization problems originates from the following advantages [20]:

- GA does not need the derivative information

- GA is stochastic and less likely to get trapped in local minima

- GA can be used for either continuous or discrete problems

- GA is a parallel-search procedure which can be performed on parallel machines to speed up the computation significantly

As mentioned before, GA employs natural evolution concepts. The relations between concepts in natural evolution and genetic algorithm are given in Table 2.1. Since GA is utilized as the solver in this study to compute optimal gains of the controllers in the AGC scheme, this chapter briefly discusses GA and how GA is employed as the solver of the LFC problem. 
Table 2.1. Relations between concepts in natural evolution and genetic algorithms

\begin{tabular}{|c|c|}
\hline Concepts in Natural Evolution & Concepts in Genetic Algorithm \\
\hline Chromosome & String \\
\hline Gene & Features in the string \\
\hline Locus & Position in the string \\
\hline Allele & Position value \\
\hline Genotype & String structure \\
\hline Phenotype & Set of characteristics (features) \\
\hline
\end{tabular}

\subsection{Methodology}

The GA starts with a set of initial population which can be random or deterministic represented in forms of chromosomes. These chromosomes (probable solutions) made of genes are needed to be decoded appropriately to solve the optimization problem. A fitness function is employed to evaluate the solutions and according to the fitness value assigned to each chromosome, the fittest chromosomes are sorted. Genetic operators (selection, crossover and mutation) are then applied to the chromosomes to make an improved new generation form the fittest chromosomes. Therefore, it is expected to achieve a better solution after each iteration. Mutation operation prevents GA form getting trapped in local minima. This process continues until the termination condition is met which can be reaching either a specific fitness value or a specific number of iterations [21]. Major steps of genetic algorithm are:

- Initialization

- Evaluation

- Selection

- Crossover

- Mutation

- Termination

Figure 2.1 shows the flowchart of a typical genetic algorithm. 


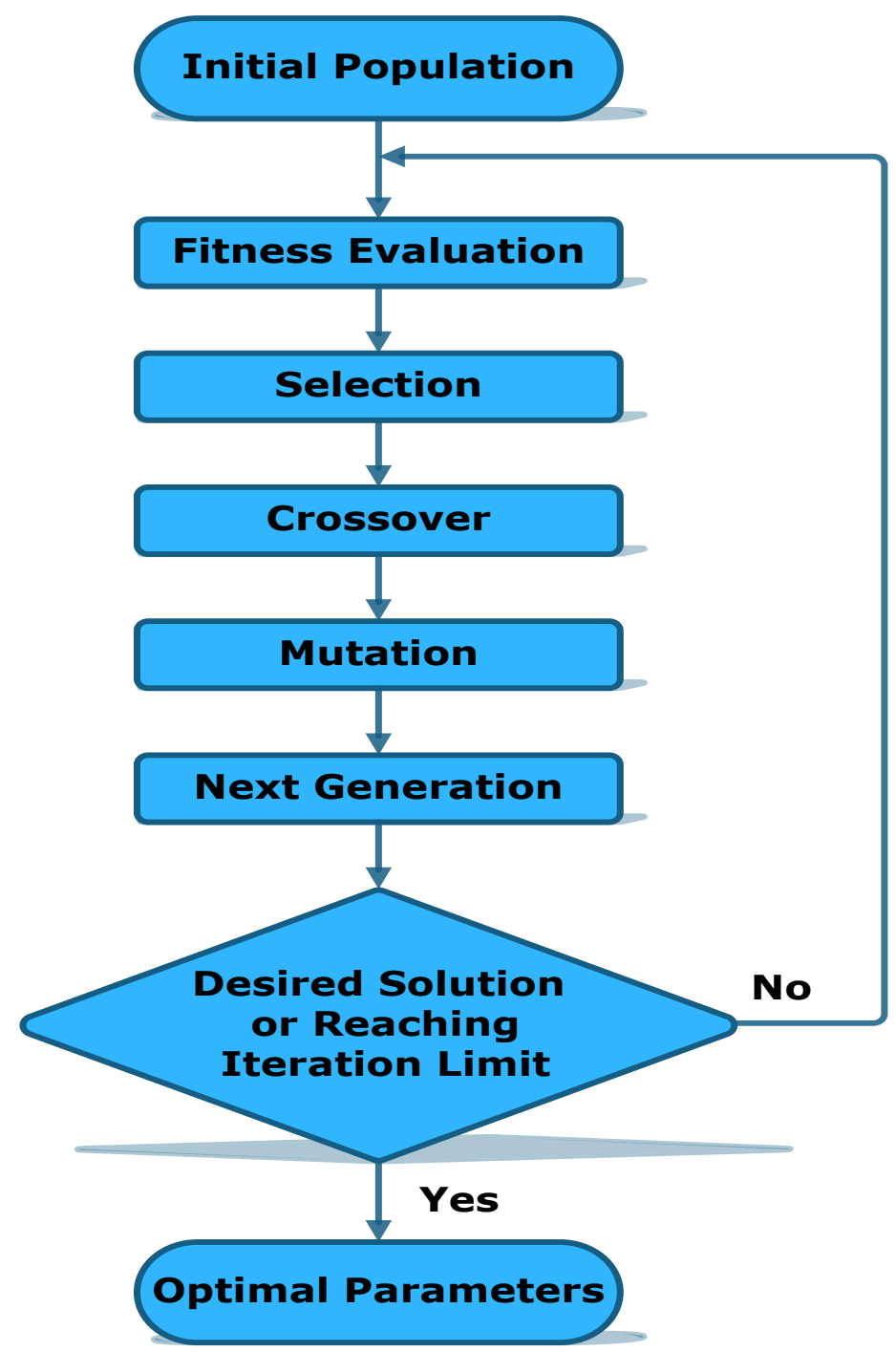

Figure 2.1. Flowchart of a typical genetic algorithm

\subsection{Steps}

In this part GA's steps are discussed briefly to explain the overall performance of GA.

\section{Initialization}

Usually, individuals (Chromosomes) are randomly generated to make an initial population covering the entire range of possible solutions, however there are other methods to generate initial population (deterministic initialization). Population size depends on the nature of the problem and typically contains several hundred or thousands individuals [22]. 


\section{Evaluation}

According to the objective function which has been defined for the problem, individuals are evaluated and the fitness value for each individual is computed and assigned. If a solution satisfies the termination condition the algorithm will terminate and that individual is announced as the solution for the problem. In the case that the termination condition is reaching a specific number of iterations, GA continues until termination condition is met. The assigned fitness values are used in the next steps to make better and fitter solutions. Defining an appropriate and smart objective function is very effective to reach the solution quickly [23].

To find the optimal gains of the controller employed in this thesis, objective function is computed according to the selected performance index criterion. In chapter 4, the importance and effect of different objective functions (in other word performance index criteria) are assessed and discussed in details.

\section{Selection}

Selection is the step where individuals are chosen from a population for later breeding. Each individual has been evaluated based on the fitness value assigned in the evaluation step. In selection step, fitter solutions are typically more likely to be selected. There are several methods

for selecting individuals such as roulette wheel selection, Boltzman selection, tournament rank selection, elitism and steady-state selection [24]. Roulette wheel selection is used in this thesis as the selection method. Figure 2.2 presents an example of roulette wheel selection. It is obvious the chromosome with higher fitness is more likely to be selected.

\section{Crossover}

In crossover step, new children (new individuals) are generated from two or more parents (old individuals) which typically shares many of the characteristics of their parents. The idea behind 


\begin{tabular}{|l|l|}
\hline Chromosome & Fitness \\
\hline 10110110 & 20 \\
\hline 10000000 & 5 \\
\hline 11101110 & 15 \\
\hline 10010011 & 8 \\
\hline 10100010 & 12 \\
\hline
\end{tabular}

\section{Chromosome Fitness on a Roulette Wheel}

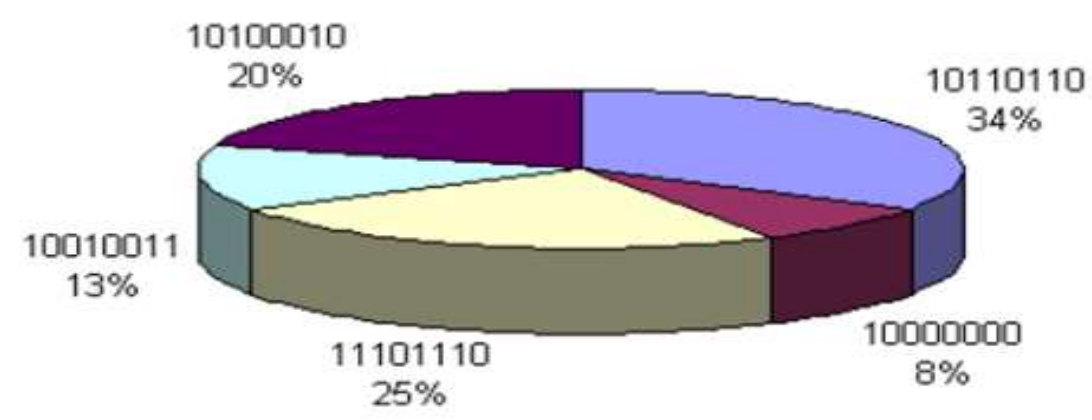

Figure 2.2. An example of roulette wheel selection

crossover is that the new chromosomes may be better than both of the parents if they inherit the best characteristics from their parents. There are different types of crossover operation such as single-point crossover, two-point crossover, multi-point crossover, uniform crossover and arithmetic crossover [25]. In single-point crossover, a point on both parents is selected randomly and all data beyond that point in either parent is swapped. In two-point crossover, two points on both parents are selected and all data is swapped between the parents. It should be mentioned that single point crossover is employed in this study. Single-point and two-point crossover can be seen in figure 2.3 


\section{Children}

Parent A

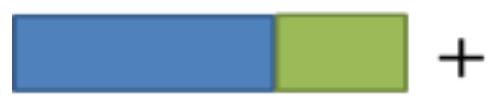

Single-Point Crossover

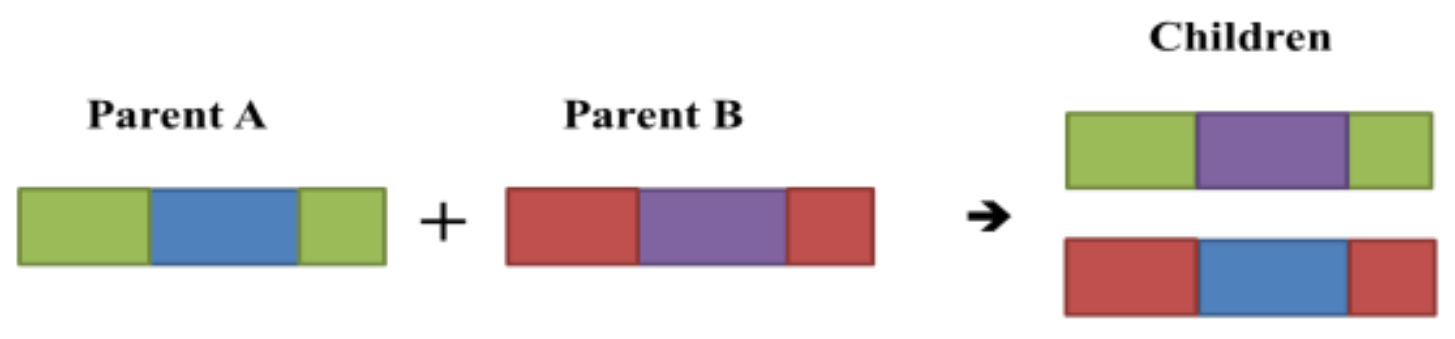

Parent B
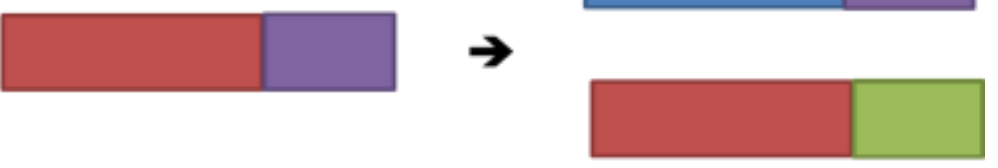

Two-Point Crossover

Figure 2.3. Single-point and two-point crossover

\section{Mutation}

This operation plays an important role in genetic algorithm. It prevents GA form getting trapped in local minima [26]. Moreover, in some cases there might be the same data in a specific location of the whole population so regeneration and crossover are not useful to change it. However, those cases can be recovered by mutation operation. For example in the following population, the second left bit is always one and crossover and reproduction cannot change it. This might lead to not obtaining the satisfying solution. Mutation operator can solve the issue and as it mentioned before it prevents GA from getting trapped in local minima. The mutation operator selects an individual randomly and selects a random bit of the chosen individual and complements that bit. In this study mutation is defined in another way but uses the same concept. It means instead of complementing a bit, a new random number (in the allowable range) is generated and replaced by the old value. Figure 2.4 presents how mutation operator works in a case where the second left bit of the whole population is always one. 


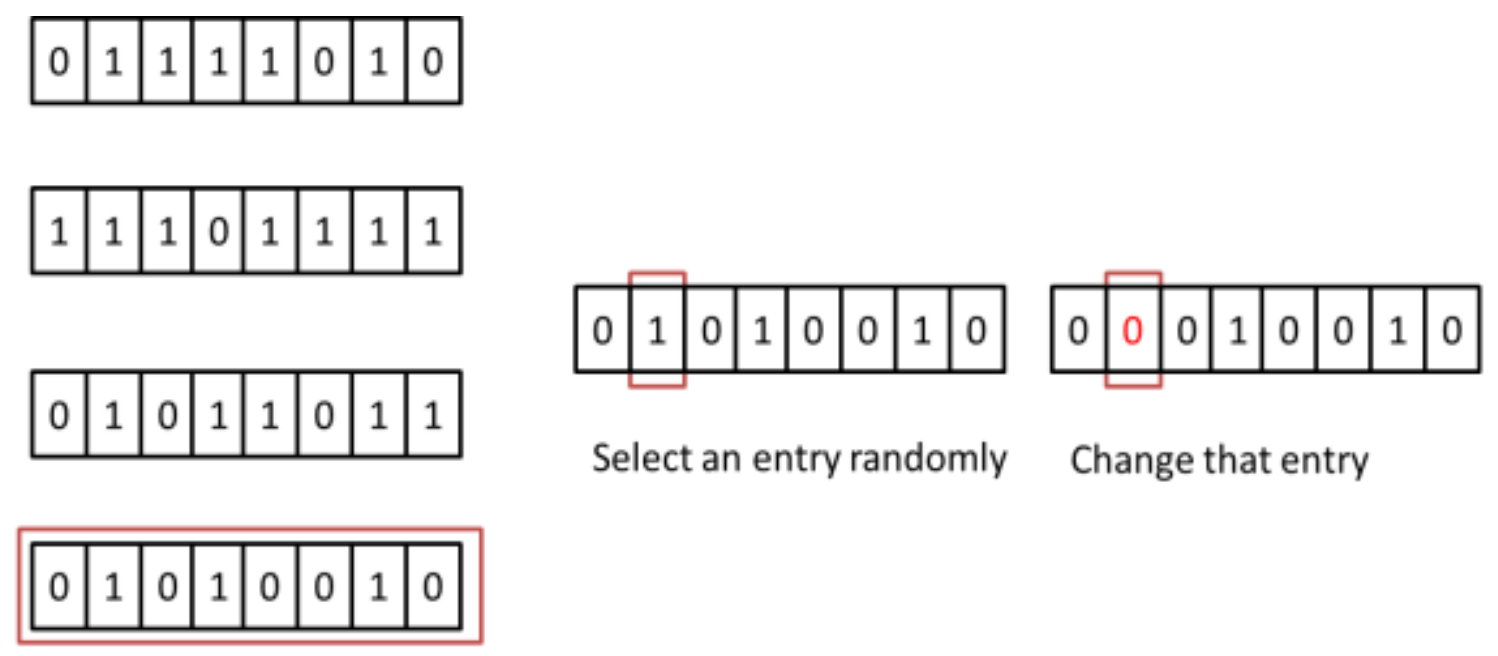

Select an individual randomly

Figure 2.4. Mutation operation

\section{Termination}

The generational process is repeated until a termination condition has been reached [27]. Common terminating conditions are:

- A solution is reached which satisfies minimum criteria

- Specific number of iterations reached

- Allocated budget (computation time or money) reached

- Combinations of the above

\subsection{Genetic algorithm and its application in AGC}

Genetic algorithm is an evolutionary optimization algorithm capable of being applied to a wide range of optimization problems. Generally, classical optimization methods are not applicable to large optimization problems because of neither being quick nor grantee to converge to a solution. However, GA has become so interesting for researchers in solving huge optimization problems in scientific and engineering fields because of its unique advantages [28]. GA as one of the main optimization techniques in field of control engineering and control system design has proved to be an effective and practical means in the field of power system operation and control [29], [30]. GA can be used in AGC to determine the optimal gains of PI or PID controllers to achieve the optimal 
solutions for LFC problems [13], [31]-[35] but still effect of communication delays has not been considered in those GA based researches. In this study, GA is employed to find the optimal gains of integrator, PI and PID controllers used in different AGC schemes. The simulation is performed in Simulink and performance index criterion is computed and then by using the computed performance index the fitness value for each individual is calculated and GA uses it to find a better solutions and finally delivering the optimal solution. Figure 2.5 shows the relation between GA implemented in MATLAB and simulations computed in Simulink. The developed GA codes in MATLAB are presented in appendix A and B.

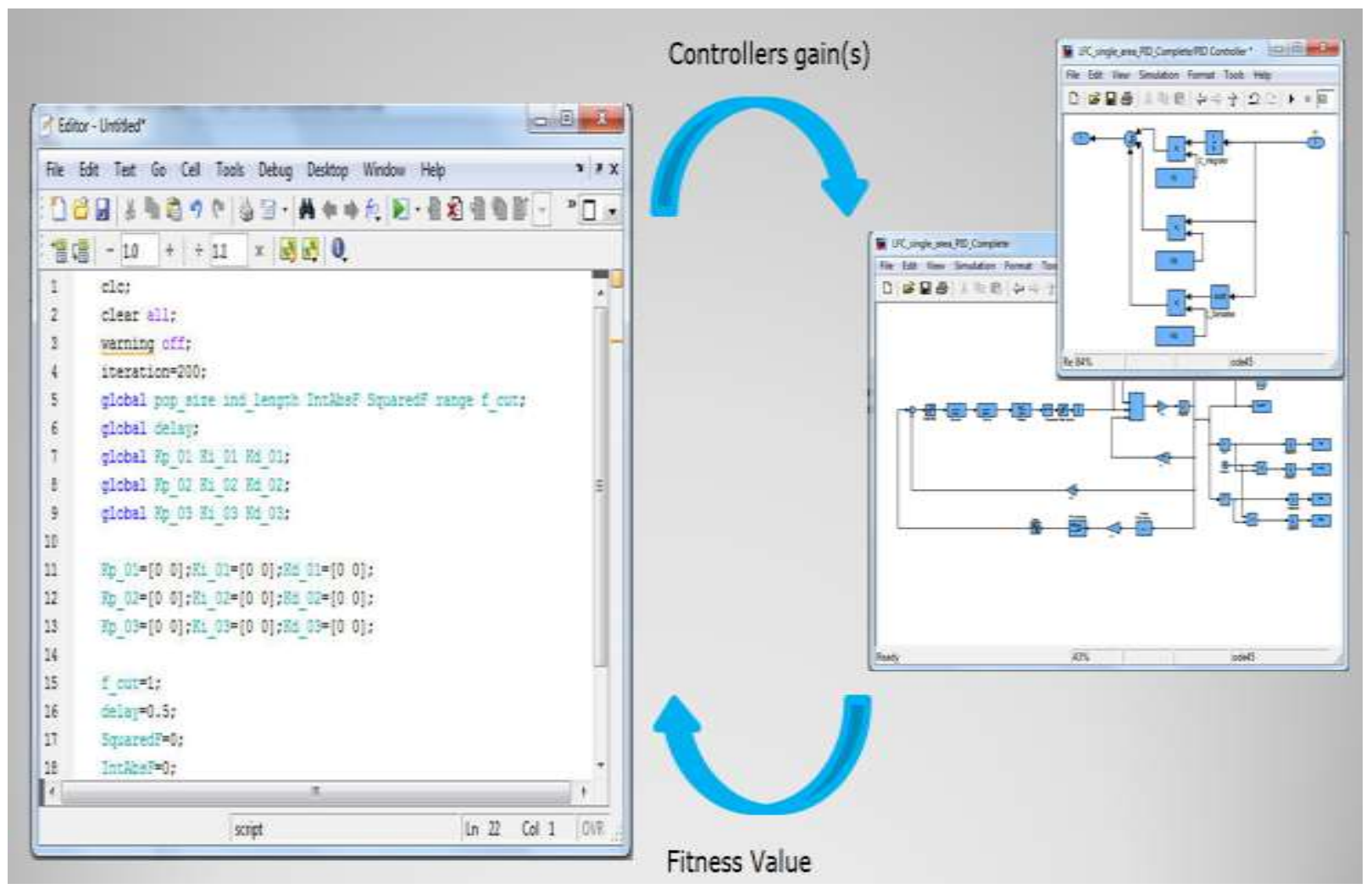

Figure 2. 5. Relation between GA implemented in MATLAB and simulations computed in Simulink 


\section{Chapter 3: Automatic Generation Control}

Source of frequency deviations in power system is the imbalance between electrical loads and real power generated by system generators [1]. Although frequency deviations should be minimized in a power system, it can provide a useful index to show the system generation and load imbalance. Moreover, Nowadays interconnected power systems exchange power between their areas through the lie-lines based on a timing schedule. According to what mentioned, minimizing the frequency and tie-lines power flow deviations from their allowed and scheduled values are the two main objectives of automatic generation control [4].

Load frequency control has been studied and considered as one of the most important problems in power system studies for decades [36]-[43]. However, increase in power exchange between interconnected areas through the tie lines and renewable energies integration has made the AGC design strategies an emerging research area. It should be mentioned that AGC is designed for small changes in real power and the consequent frequency deviations. AGC systems are not capable of dealing with large imbalances associated with rapid frequency changes during a fault condition [44]. This chapter first discusses the single-area LFC model and then covers the multi-area LFC model. In the end, physical constraints are introduced and modeled.

\subsection{Single-area LFC}

There are two control loops in the classic automatic generation control scheme of a single control area; primary control loop and supplementary control loop [1]. Real power is controlled by the mechanical power output of a prime mover, which can be a hydro, gas or steam turbine [43]. By regulating the water flow or amount of steam entering the turbine, the balance between electrical and mechanical power can be achieved and consequently the frequency regulation. Because of physical constraints effect the response of primary frequency control is not quick. Most large synchronous generators are equipped with a supplementary frequency control loop in addition to a primary frequency control [44]. Block diagram of a synchronous generator equipped with frequency control loops is shown in figure 3.1. 


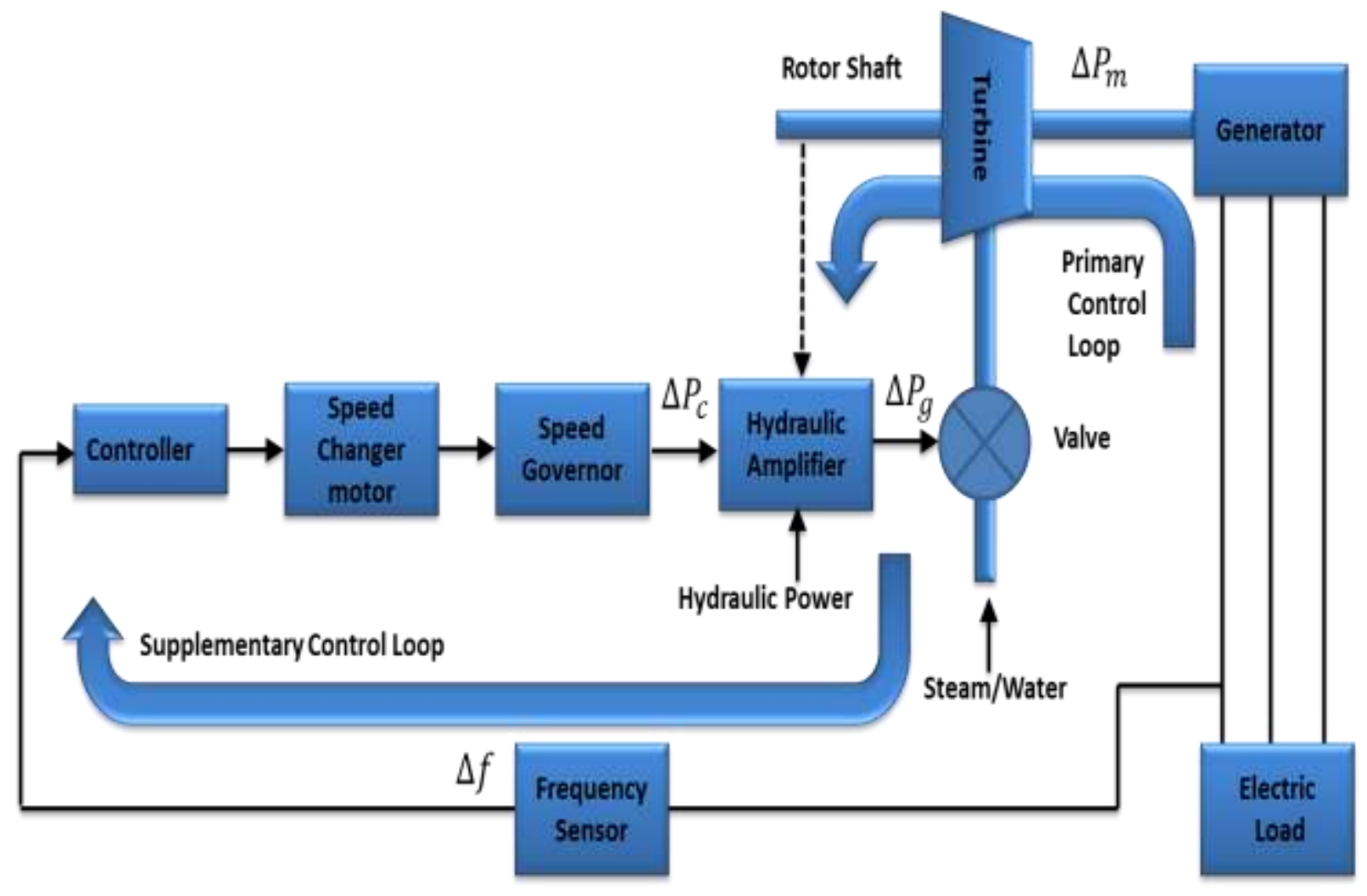

Figure 3.1. Block diagram of a synchronous generator with basic frequency control loops

As it can be seen that in figure 3.1, the speed governor provides the primary speed control. It senses the changes in speed (which means changes in frequency) and essential mechanical forces to position the main valve which is provided by hydraulic amplifier [44]. Then the speed changer provides a steady-state power set point for the turbine and the primary frequency control loop is reached. However, primary control loop is not solely sufficient to restore system frequency so it is the duty of supplementary control loop to restore the frequency to its nominal value [45].

Supplementary control loop uses the feedback of frequency deviations. Then the controller defines a new set point through the speed changer. The computed signal $\left(\Delta P_{c}\right)$ is used to regulate the frequency [44]. Usually, an integrator or a PI controller is used in real-world power systems [46], [47]. The combination of primary control loop and supplementary control loop provides frequency regulation. 
By modeling the governor, turbine, generator and load deviation, a simplified frequency response model (single-area) can be obtained which is shown in figure 3.2 [48]. Moreover, figure 3.3 shows the turbine-governor system of a reheat steam unit.

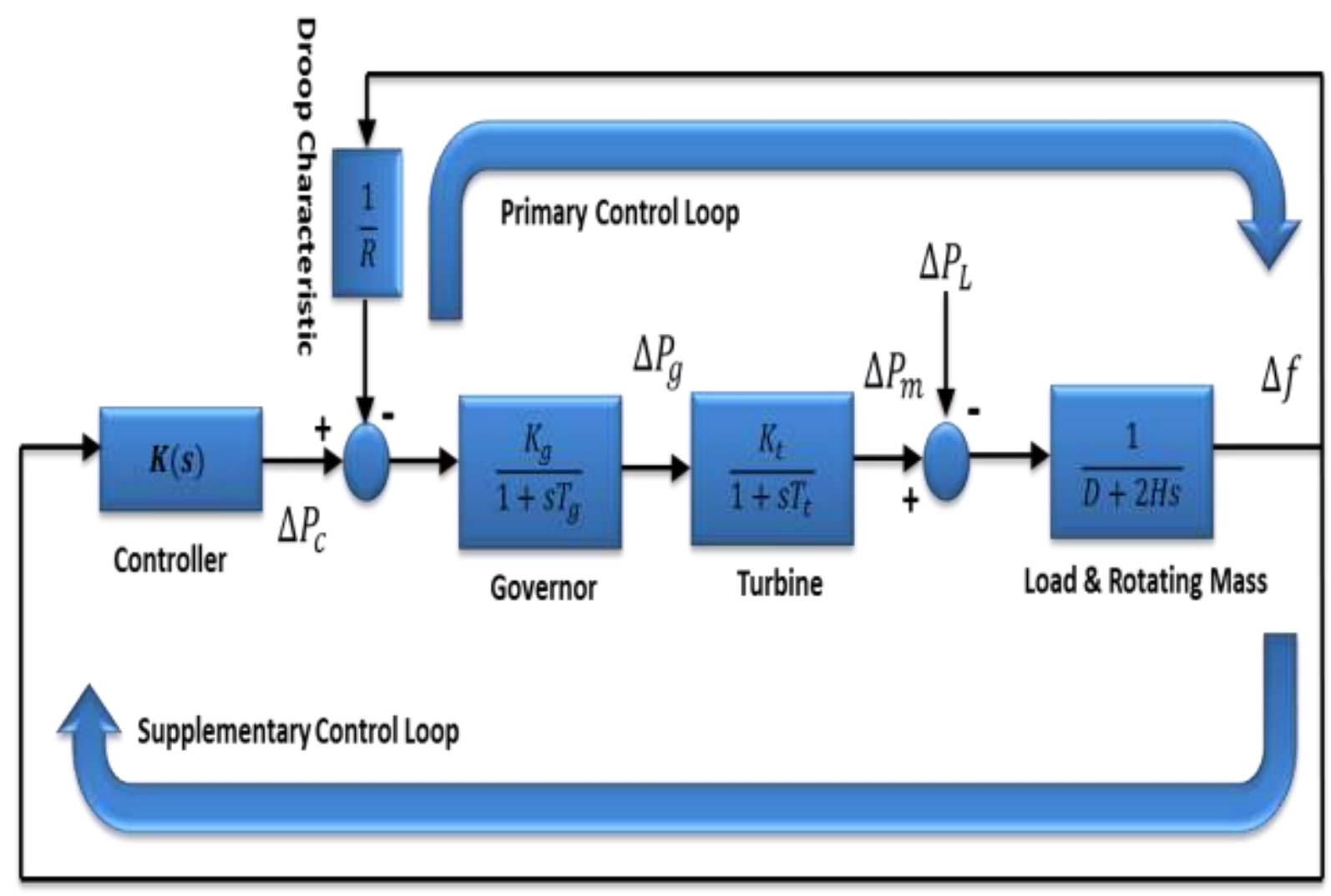

Figure 3.2. Block diagram model of governor with frequency control loops

Where $\mathrm{R}$ is the droop characteristic, $\mathrm{D}$ is load damping coefficient, $\mathrm{H}$ is inertia constant, $T_{g} T_{t}, T_{r}$, and $T_{t r}$ are the time constants of the governor and turbine. Load and rotating mass model is derived from the equation 3.1 which is expressing the Laplace transform of the relationship between incremental mismatch power and frequency deviation.

$$
\Delta P_{m}(s)-\Delta P_{L}(s)=2 H s \Delta f(s)+D \Delta f(s)
$$




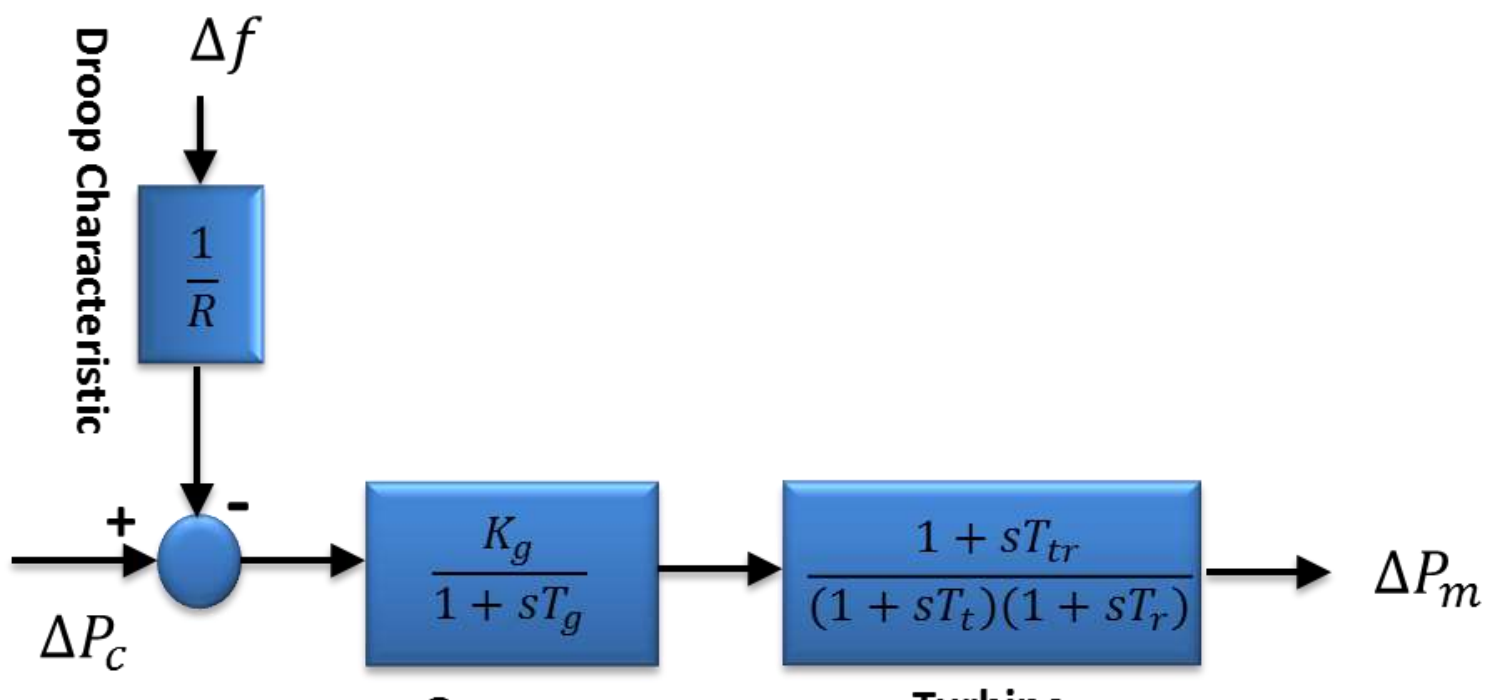

Governor

Turbine

Figure 3.3. Block diagram of turbine-governor system for a reheat steam unit.

\subsection{Multi-area LFC}

A multi-area power system is made of several control areas which are interconnected by highvoltage transmission lines or tie-lines [48]. In a multi-area control scheme, minimizing the frequency deviations is not the only objective to reach. Since control areas exchange power based on a timing schedule, tie-lines power flow should be close to the scheduled values. Therefore, in a multi-area load frequency control model, The AGC system in each area should control the interchange power with the other areas as well as its local frequency [50]-[52]. Therefore, for multi-area power systems the concept of Area Control Error (ACE) is used to achieve the mentioned objectives [53]. Figure 3.4 shows an example of a multi-area power system. The power exchanged between areas $i$ and $j$ can be computed by the equation 3.2 [44].

$$
P_{t i e, i j}=\frac{V_{i} V_{j}}{X_{i j}} \sin \left(\delta_{i}-\delta_{j}\right)
$$


Where $X_{i j}$ is the reactance of tie-line between areas i and $\mathrm{j}, \delta_{i}$ and $\delta_{j}$ are the voltage angles and $V_{i}$ and $V_{j}$ are the magnitudes of voltage in areas $\mathrm{i}$ and $\mathrm{j}$. By linearizing equation 3.2 about an equilibrium point ( $\delta_{i}^{0}$ and $\delta_{j}^{0}$ ), equation 3.3 is reached.

$$
\Delta P_{t i e, i j}=T_{i j}\left(\Delta \delta_{i}-\Delta \delta_{j}\right)
$$

Where $T_{i j}$ is the synchronizing coefficient given by equation 3.4 .

$$
T_{i j}=\frac{\left|V_{i}\right|\left|V_{j}\right|}{X_{i j}} \cos \left(\delta_{i}^{0}-\delta_{j}^{0}\right)
$$

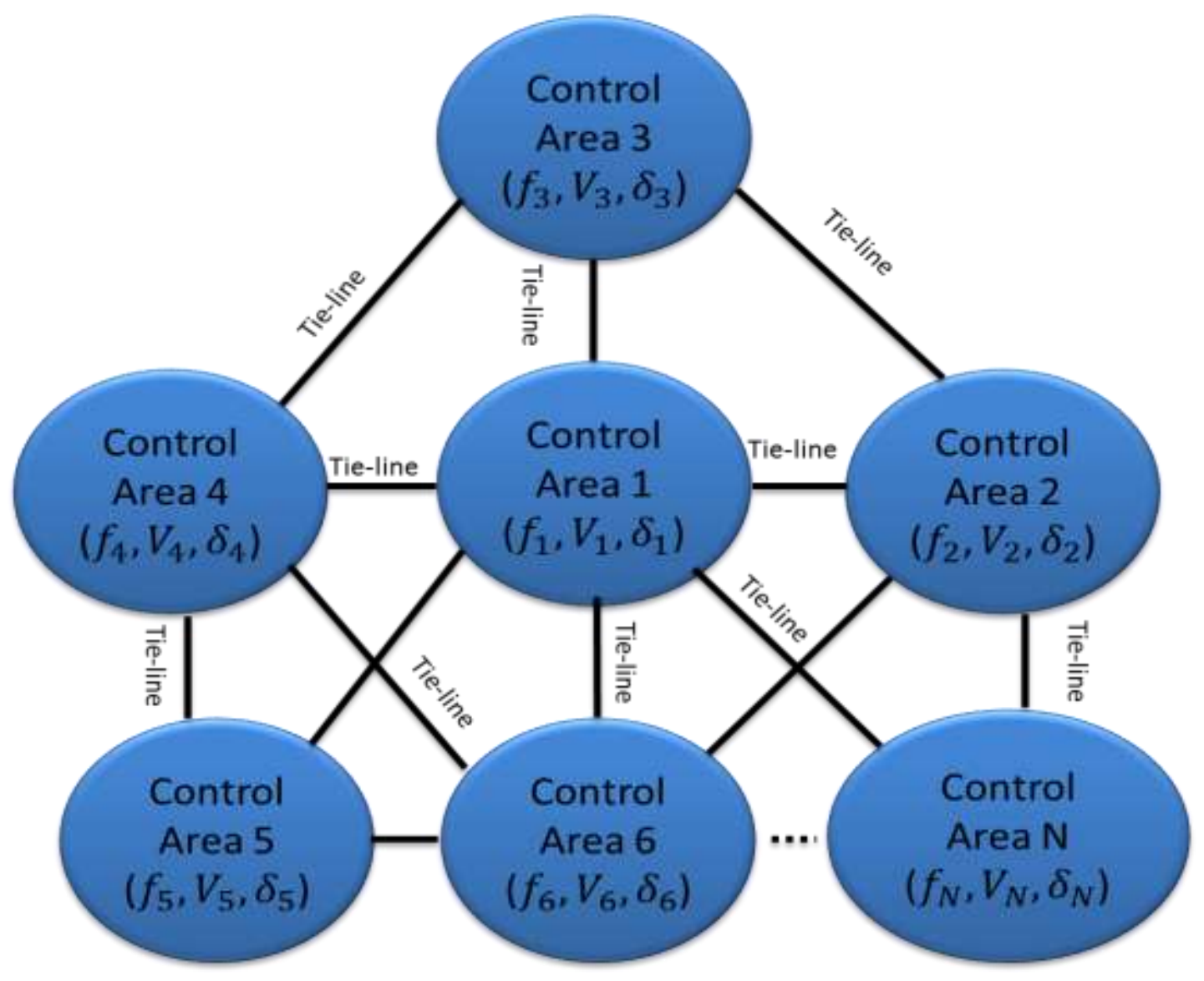

Figure 3.4. A multi-area power system

By considering the relationship between power angle and frequency, equation 3.3 is written as equation 3.5. In addition, by using Laplace transform equation 3.6 is obtained. 


$$
\begin{aligned}
& \Delta P_{t i e, i j}=2 \pi T_{i j}\left(\int \Delta f_{i}-\int \Delta f_{j}\right) \\
& \Delta P_{t i e, i j}(s)=\frac{2 \pi}{s} T_{i j}\left(\Delta f_{i}-\Delta f_{j}\right)
\end{aligned}
$$

Now by adding all the tie-lines power flow for an area (area i) equation 3.7 is reached. Figure 3.5 show the block diagram of equation 3.7 .

$$
\Delta P_{t i e, i}=\sum_{\substack{j=1 \\ j \neq i}}^{N} \Delta P_{t i e, i j}=\frac{2 \pi}{s}\left[\sum_{\substack{j=1 \\ j \neq i}}^{N} T_{i j} \Delta f_{i}-\sum_{\substack{j=1 \\ j \neq i}}^{N} T_{i j} \Delta f_{j}\right]
$$

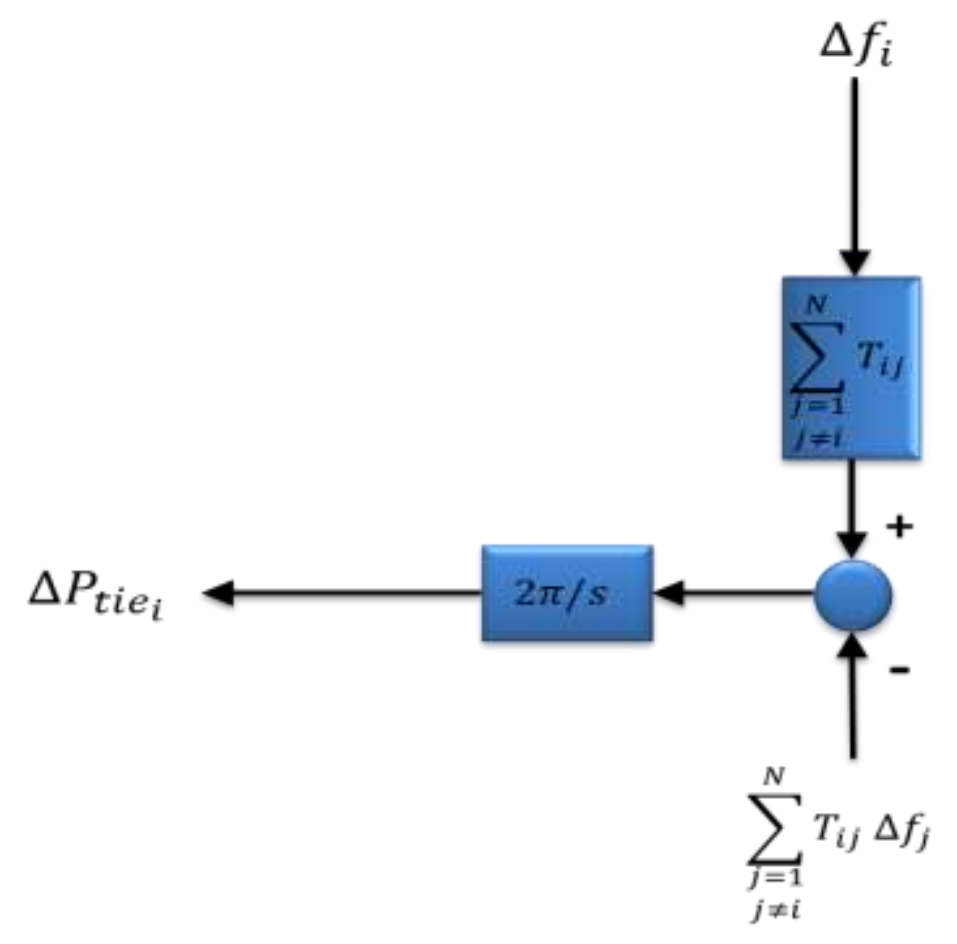

Figure 3.5. Block diagram of equation 3.7

The combination of figure 3.3 and figure 3.5 provide a simplified block diagram for control area $i$ in an $\mathrm{N}$-control area power system which is shown in figure 3.6 [44]. 


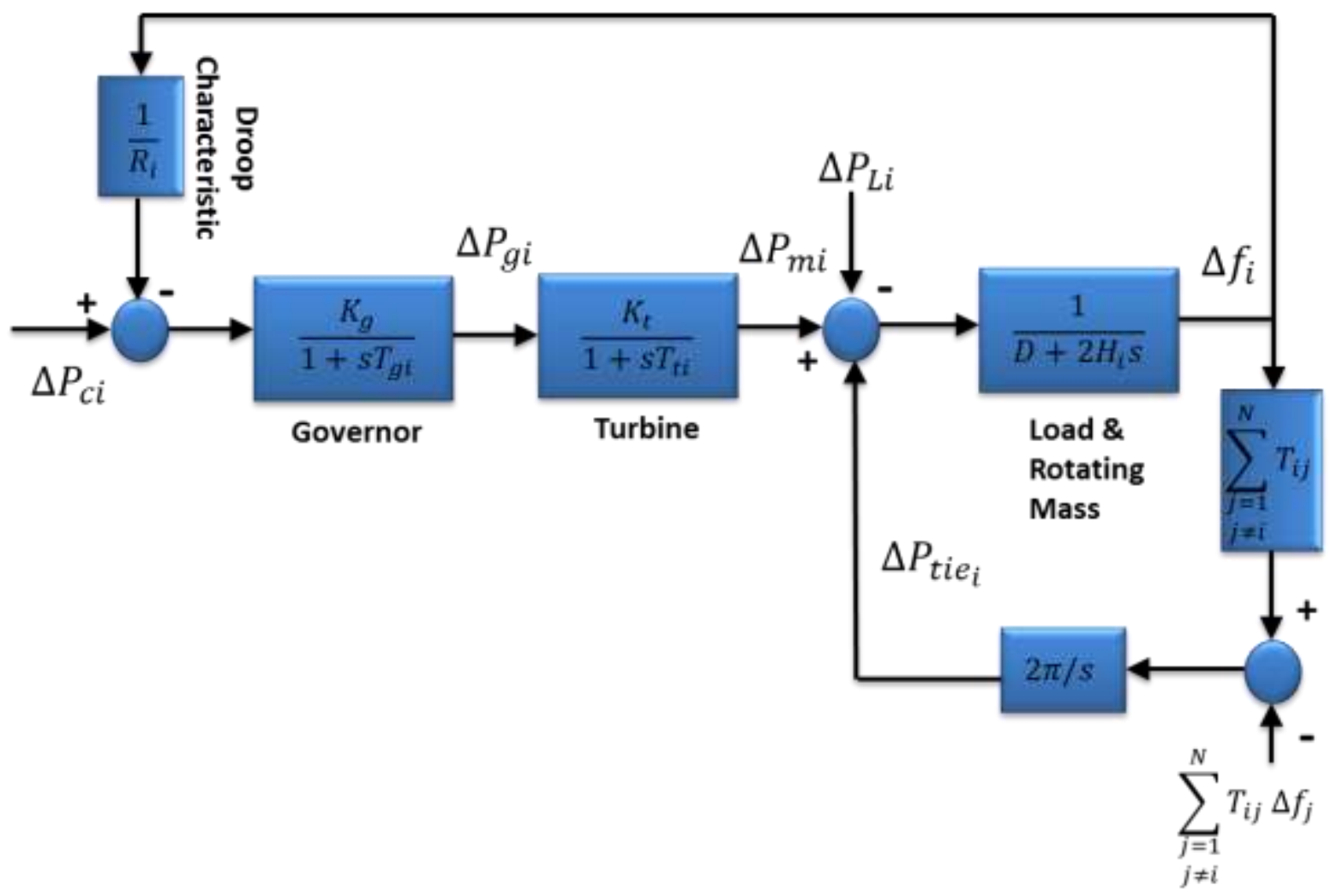

Figure 3.6. The combination of figure 3.3 and figure 3.5

In this way, the effect of tie-lines power flow deviations in the frequency of other control areas can be implemented. The other point needed to be taken into consideration is the supplementary control in presence of tie-lines power flow. In an interconnected power system, the supplementary control should maintain the frequency in each area close to the nominal value plus the net interchange power with neighbor areas at scheduled values. To achieve this goal tie-line power flow deviation is added to frequency deviation in supplementary feedback loop. A linear combination of frequency and tie-lines power flow deviations is called Area Control Error (ACE) [1], [44], [54]. For Area i, the ACE is calculated by equation 3.8.

$$
A C E_{i}=\Delta P_{t i e, i}+B_{i} \Delta f_{i}
$$

Commonly, $B_{i}$ (bias factor) is chosen equal to $\beta_{i}$ (frequency-response characteristic of area i) which can be computed by equation 3.9. 


$$
\beta_{i}=\frac{1}{R_{i}}+D_{i}
$$

Several studies have assessed the effect of choosing different B in performance of AGC [55]-[57].

By employing ACE the effect of load changes and power exchange with other areas can be monitored by the AGC system. Therefore, each control area is able to reach its AGC objectives. Figure 3.7 presents the block diagram of a multi-area LFC model. ACE signal is computed and allocated to the controller in each area and the controller action is reflected to the governor-turbine unit.

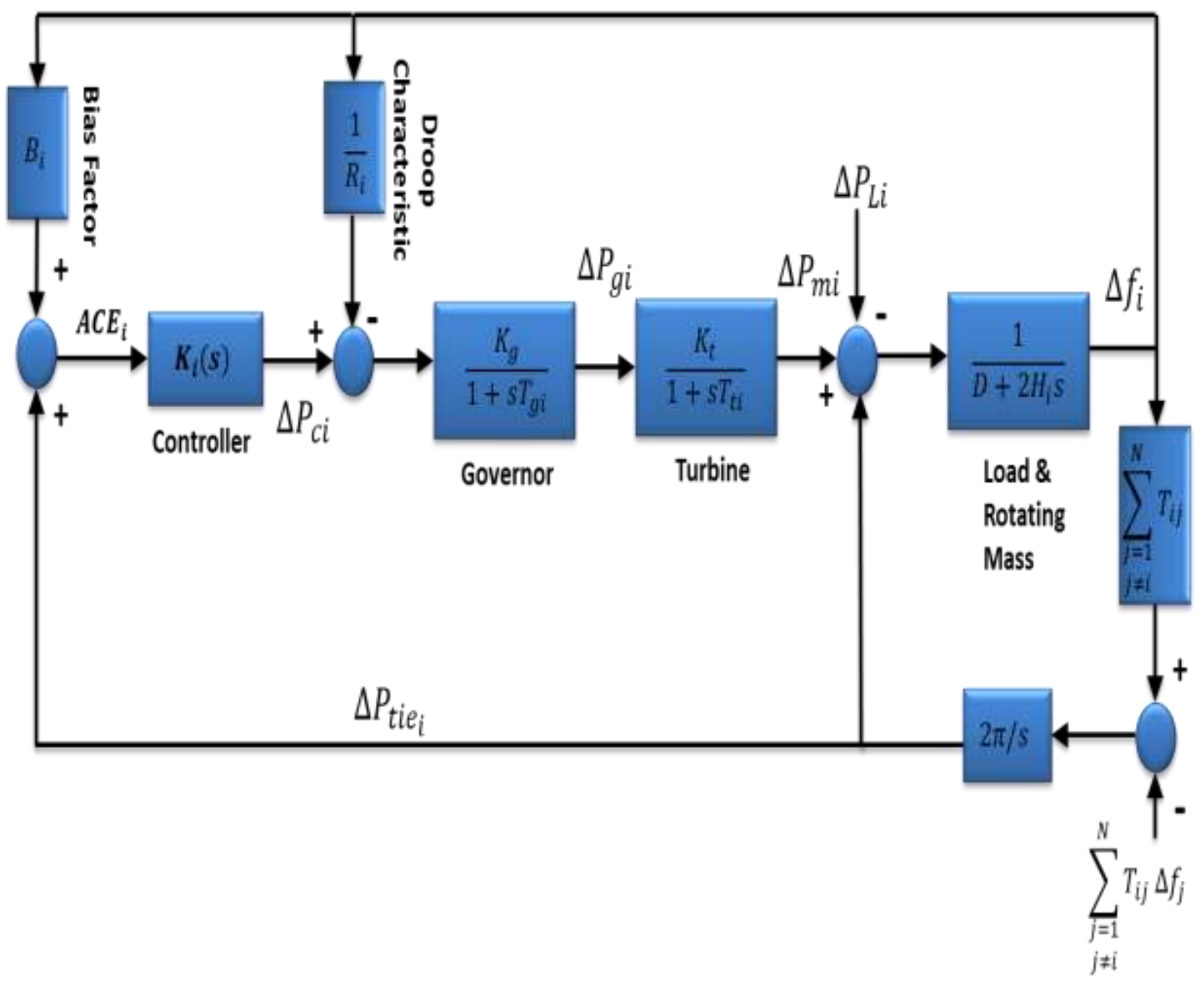

Figure 3.7. Block diagram model of multi-area load frequency control 


\subsection{Physical constraints}

Performance of AGC systems is dependent on physical constraints imposed to the system. The physical constraints can affect the dynamics of the system and performance of the system controllers significantly by increasing the settling time and overshoot and consequently degrading the system response to load changes [44], [58]. In this part, physical constraints in load frequency control are discussed and their proper models are introduced to have a precise and realistic LFC model. This model provides a realistic test-bench to evaluate different AGC strategies' performance.

\section{Governor dead band}

Governor dead band of a speed governor is defined as "the total magnitude of the change in steadystate speed within which there is no resulting measurable change in the position of the governorcontrolled valves or gates" [59] and it is expressed in term of rated speed [1]. The effect of governor dead band on the governor speed-droop characteristic can be seen in figure 3.8.

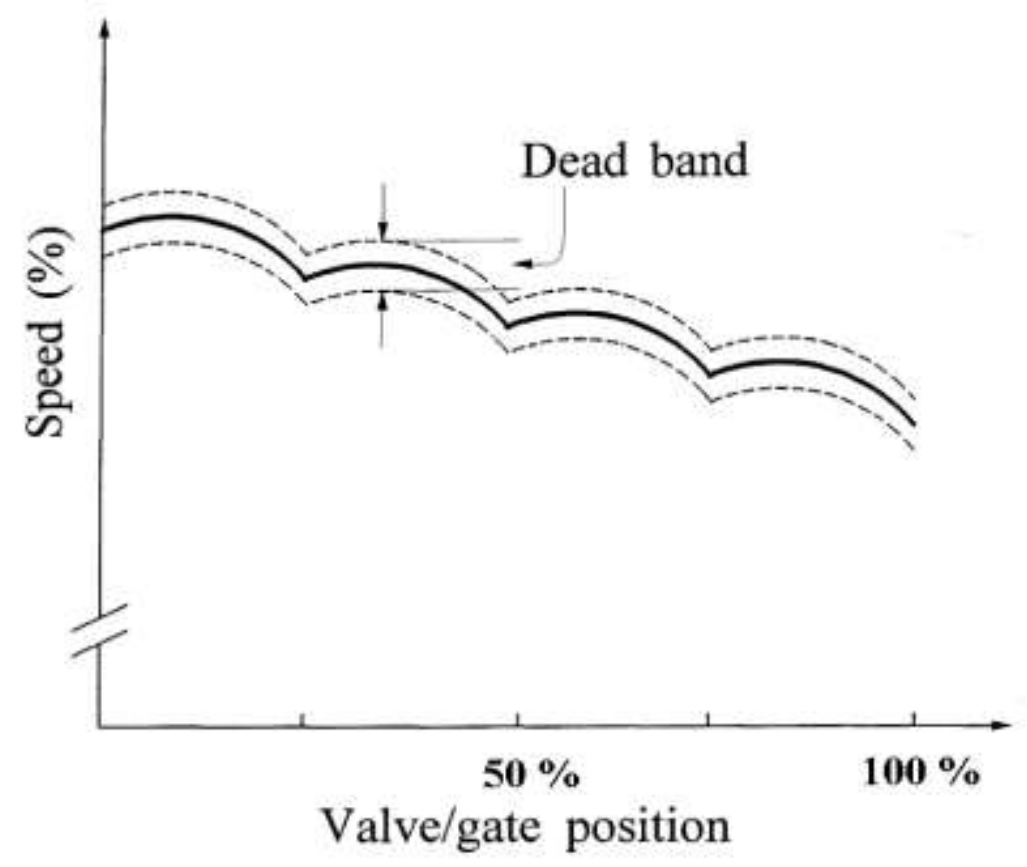

Figure 3.8. The effect of governor dead band on the governor speed-droop characteristic 
Dead band is caused by coulomb friction and backlash effect in various governor linkages as well as valve overlap in the hydraulic relays [1], [60]. Governor dead band increases the apparent steady-state speed regulation [61]. However, the impact of dead band on the speed governor response depends on the magnitude of frequency changes. If frequency deviation is small, it might remain within the dead band so no speed control action will be performed [1]. The maximum value of dead band for governors of large steam turbines is specified as $0.06 \%(0.036 \mathrm{~Hz})$ [62]. Standards recommend a maximum speed dead band of $0.02 \%$ for governor of hydraulic turbines. The new electrohydraulic governors have much smaller dead band [1], [63].

\section{Generation rate limit}

Each generating unit had a generation rate constraint (GRC) which is the maximum unit's output rate of change. This limitation is imposed by the mechanical and thermal stresses. The maximum generation rate for thermal units is on the order of $2 \%$ maximum continues rating (MCR) per minute. The hydro units have the generation rate on the order of $100 \%$ MCR per minute [1]. Several studies assessed the effect of generation rate limit on the performance of AGC [64]-[66]. The block diagram of a non-reheat unit with governor dead band and generation rate limit is shown in figure 3.9.

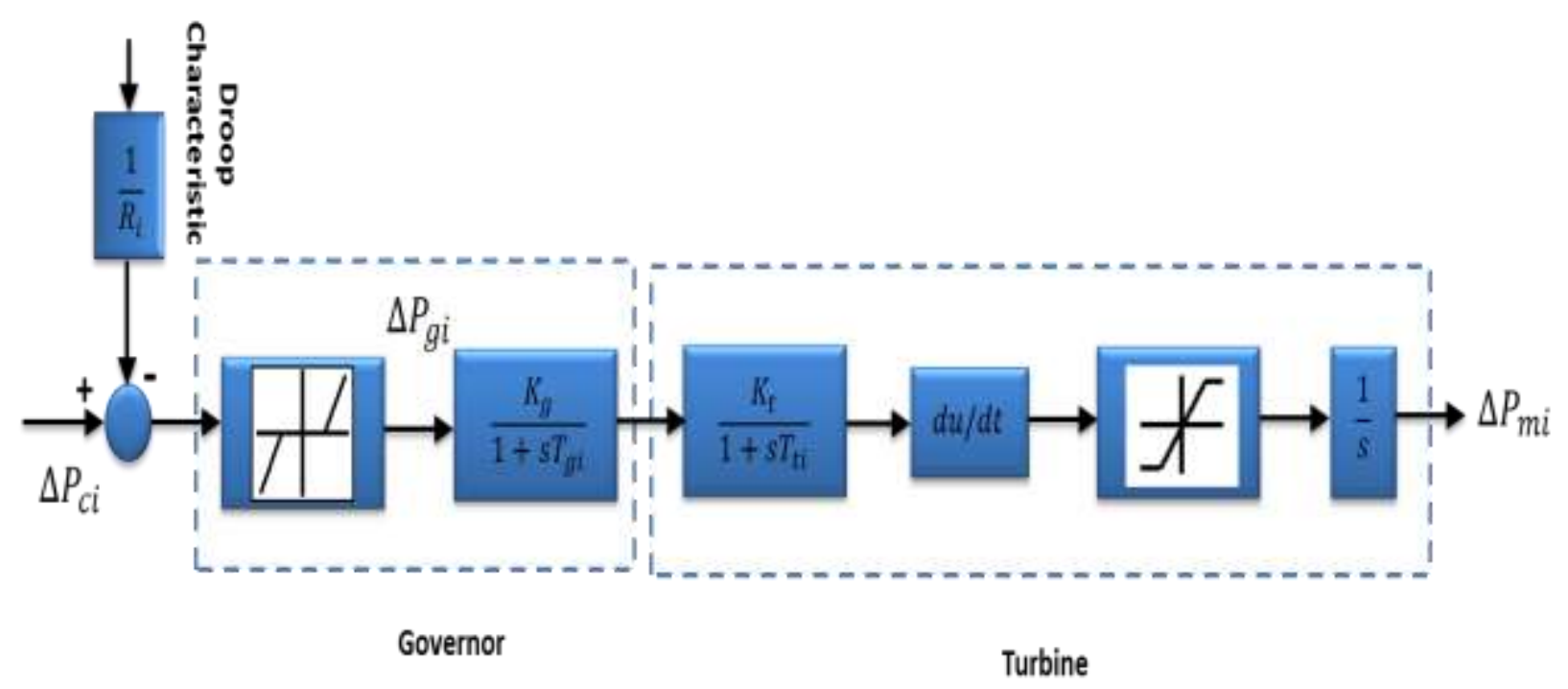

Figure 3.9. Non-reheat generator unit model with GRC and dead band 


\section{Time delays}

Future of power system and smart grid has tied in open communication infrastructures and study of power system without considering communication link parameters will not be practical, realistic and precise. Effect of communication parameters such as delay of communication link and packet loss has not been considered in most of the studies investigating automatic generation control and its performance. Communication delay as one of the physical constraints can affect the performance of AGC significantly [67], [68]. Most LFC studies ignored considering the effect of communication delay on AGC performance and have ignored communication delay in their LFC model. Amount of communication delay depends on how congested the communication network is and which communication protocol is employed. Implementation of communication delay can be seen in figure 3.10 as well as other physical constraints.

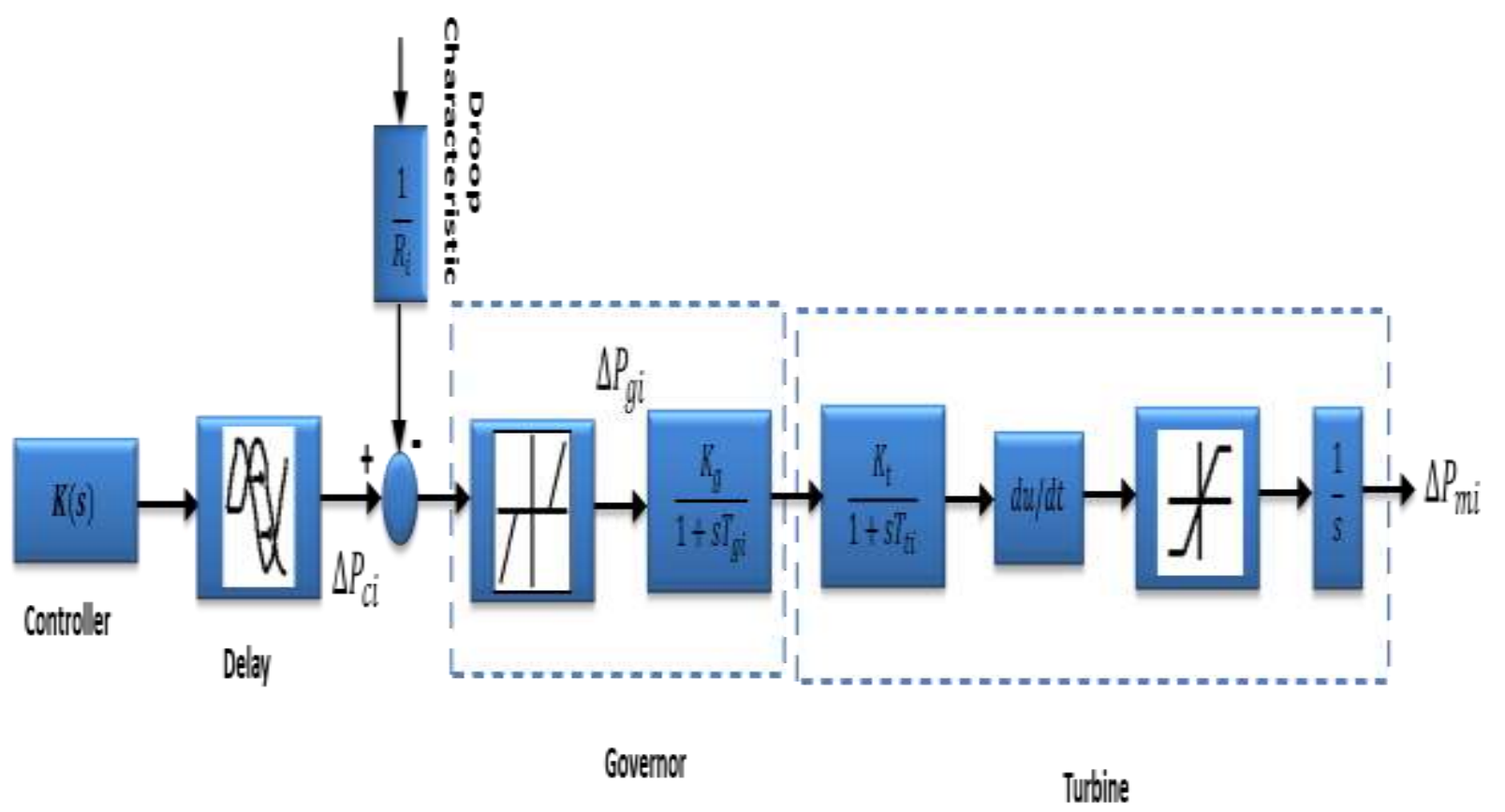

Figure 3.10. Implementation of physical constraints 


\section{Chapter 4: Case Study and Simulation Results}

In this chapter simulation results for single-area and multi-area AGC schemes are presented. At the first section, effect of communication delay on performance of automatic generation control in a three-area power system is introduced and simulation results for different scenarios are provided. The second section is devoted to introducing a detailed and comprehensive LFC model containing all physical constrains mentioned in chapter 3. A robust control scheme for the three-area power system considering all physical constraints is designed by genetic algorithm. In the second section, a caparison between controllers with and without considering physical constraints is also performed. Finally at the last section, different performance index criteria are evaluated and an adaptive and effective performance index criterion is introduced. Simulation results show that by using the introduced performance index criterion, desired settling time and overshoot can be defined for the used AGC scheme.

\subsection{Effect of communication link delay on the performance of AGC}

In LFC studies, to quantify the performance of AGC systems and evaluating the optimality of designed controllers several criteria have been used such as the integral of the absolute value of the error (IAE) [14], the integral of time-multiplied absolute value of the error (ITAE) [15], the integral of the square of the error (ISE) [16], and the integral of time-multiplied square of the error (ITSE) [17]. This part of the study utilizes IAE for calculating the fitness values and the objective is minimizing the frequency and tie-lines power flow deviations in all areas.

The case study used is the three-area power system, which has been used commonly in decentralized LFC studies and literature [69]-[72]. Figure 4.1 shows the configuration of the control areas and how they are connected. System parameters are provided in the appendix C. As mentioned before, IAE is used as the criterion to evaluate the performance of AGC. Therefore, the objective function can be described as equation 4.1 .

$I A E=\int_{0}^{t=\text { Simulation time }}\left(\left|\Delta f_{1}\right|+\left|\Delta f_{2}\right|+\left|\Delta f_{3}\right|+\left|\Delta P_{12}\right|+\left|\Delta P_{13}\right|+\left|\Delta P_{23}\right|\right) d t$ 
Where $\Delta \mathrm{f}_{\mathrm{i}}$ is frequency deviation in area $\mathrm{i}$ and $\Delta \mathrm{P}_{\mathrm{ij}}$ is the tie power deviation between area $\mathrm{i}$ and $\mathrm{j}$.

Each control area has a PID controller which has three gains to be tuned, so nine gains of the controllers are the variables of the LFC optimization problem in this case. Using PID controllers improves the performance of AGC scheme, on the other hand, it increases number of optimization variables. Solving an optimization problem in this order (nine variables) may not be feasible and practical with classic optimization methods, but by employing GA as a useful tool applicable to many problems, the solutions for different scenarios can be easily attained. Therefore, accuracy, efficiency and feasibility all together can be reached by considering the communication delay and use of GA as the solver.

Figure 4.2 shows the implemented PID controller in MATLAB/Simulink. A low pass filter is employed to remove the negative effect of noise on the derivative portion of the PID controllers as well as reducing the tear and wear on the governor and turbine valves. The three-area power system which is also developed in MATLAB/Simulink can be seen in figure 4.3.

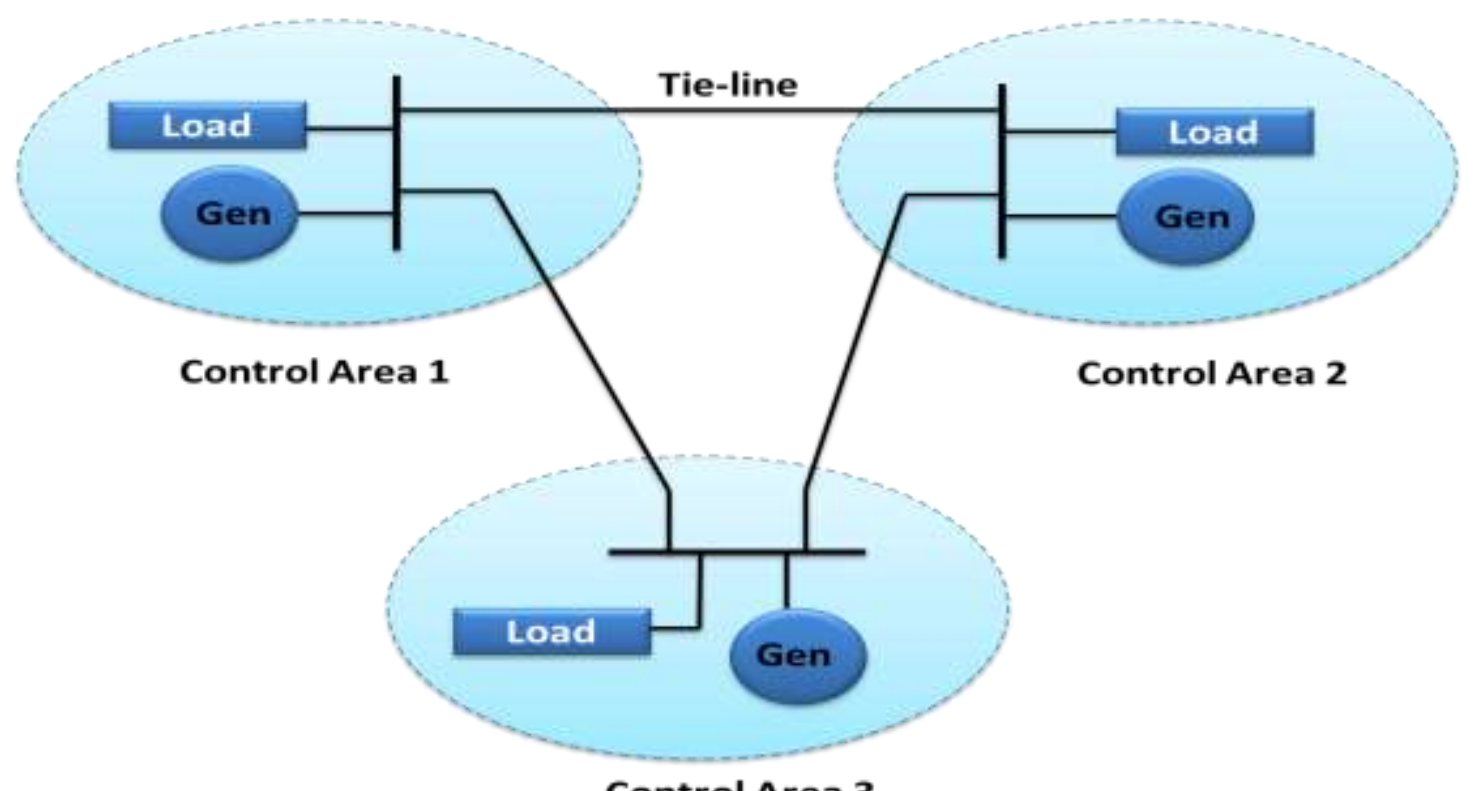

Figure 4.1. Three-control area power system 


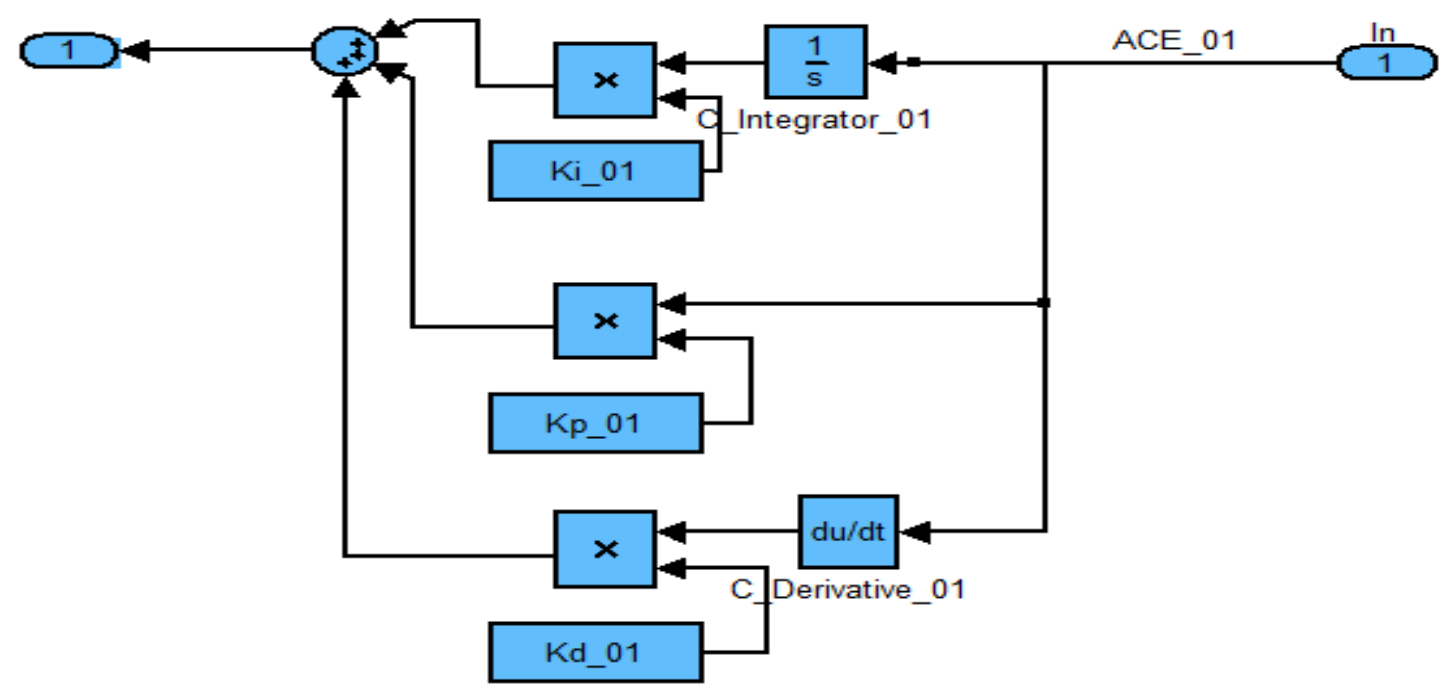

Figure 4.2. Designed PID controller in Simulink

Six scenarios are presented and evaluated. In the first three scenarios communication delay is not considered in the LFC model but in the last three scenarios delay is considered. In the first scenario (scenario A), a load change of 0.04 p.u. is applied to control area 1 (at $\mathrm{t}=1 \mathrm{~s}$ ) without considering the delay imposed by communication link. GA is used to find the optimal parameter of the PID controllers in each area. Figure 4.4 presents the frequency deviations in each area. In the second scenario (scenario B) the same load changed is applied to area 1 , but 0.5 second delay is applied to all control areas. Frequency deviations in all areas can be seen in figure 4.5. The effect of communication delay in degrading the response of the system can be seen obviously. In the third scenario (scenario C), delay of 1.5 seconds is applied to the system. Figure 4.6 presents frequency deviations in all areas. It can be seen that the communication delay make the system almost unstable even if optimal controllers are used. The effect of communication link delay has not been considered in many LFC studies. However, this study addresses it and emphasizes on its importance. Performance of AGC and response of the system can be significantly improved by considering the delay in the applied GA technique. Three scenarios have been considered for different delays and it can be seen that by considering the delay in the LFC model, system still can keep track of load change efficiently. 

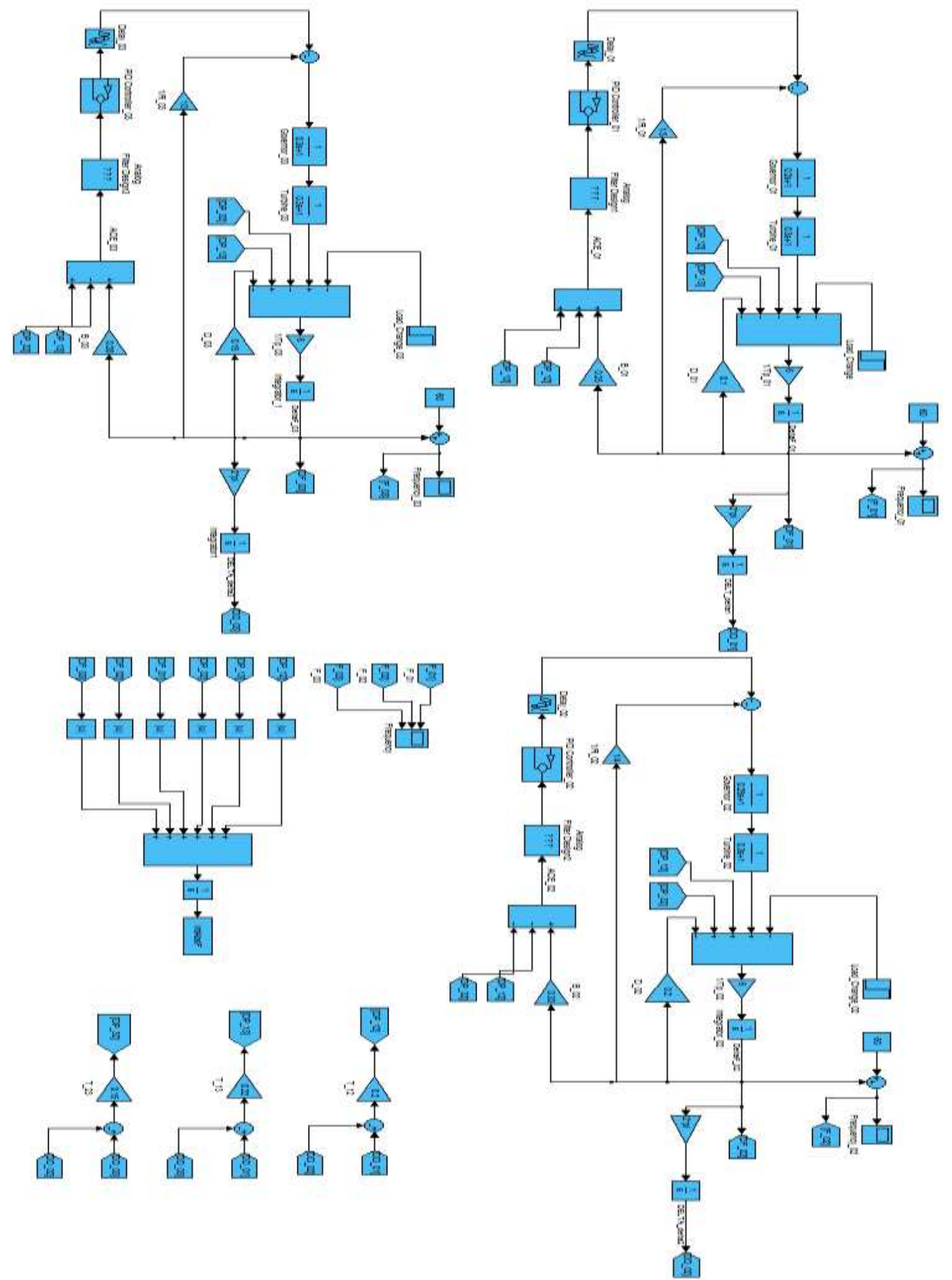

Figure 4.3. Three-area power system implemented in Simulink 


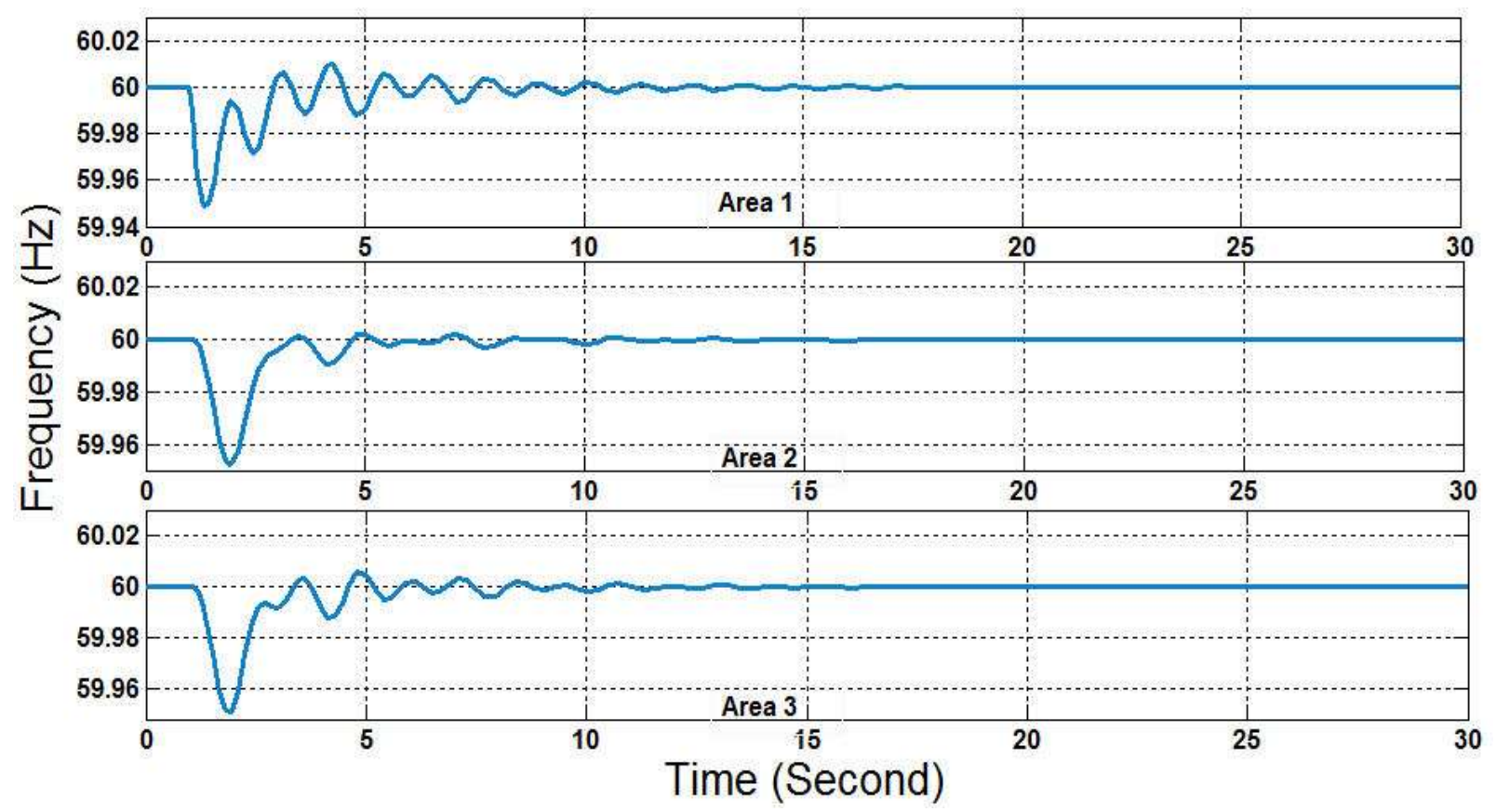

Figure 4.4. Frequency deviations in scenario A (no delay)

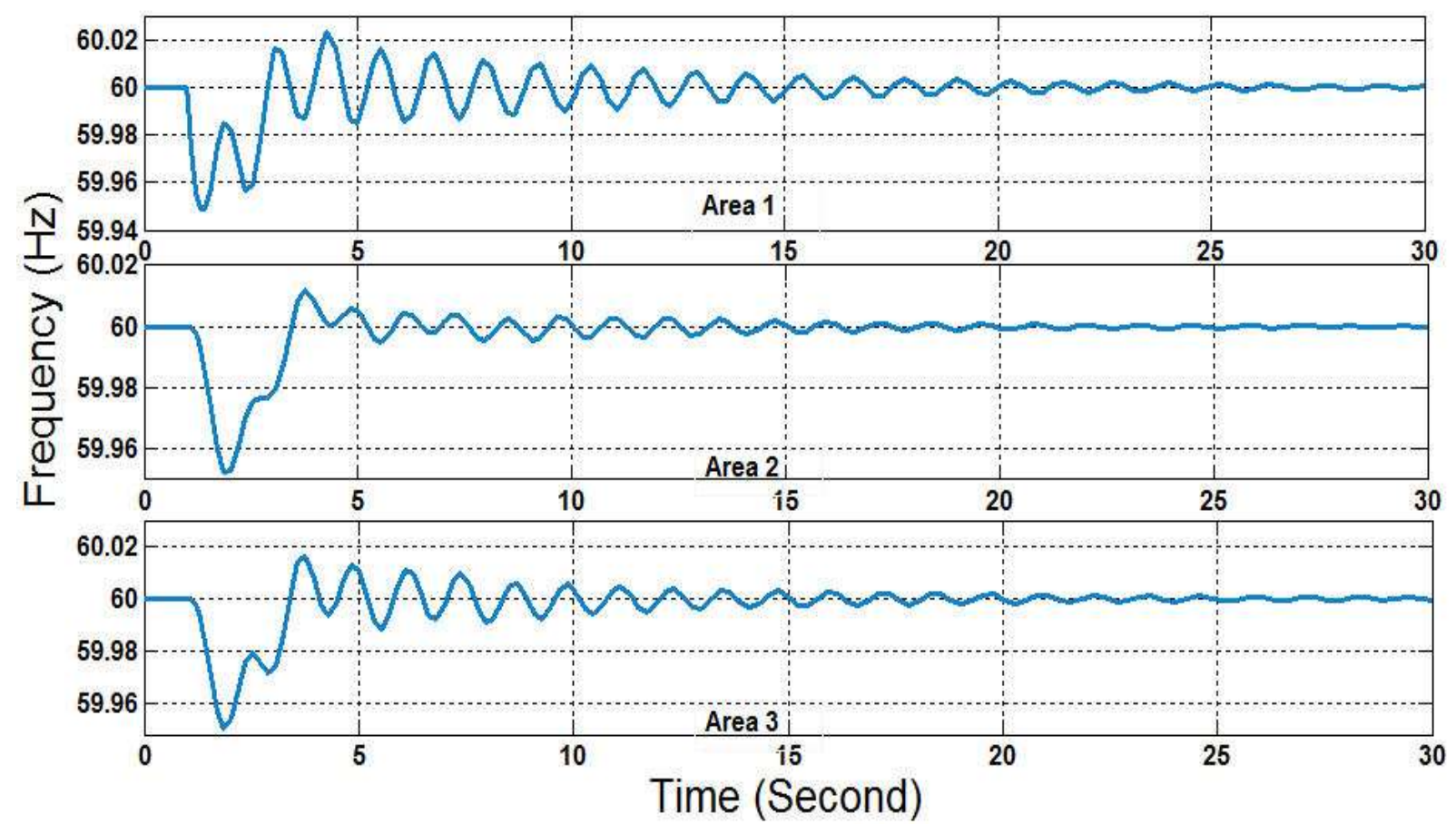

Figure 4.5. Frequency deviations in scenario B ( 0.5 second delay) 


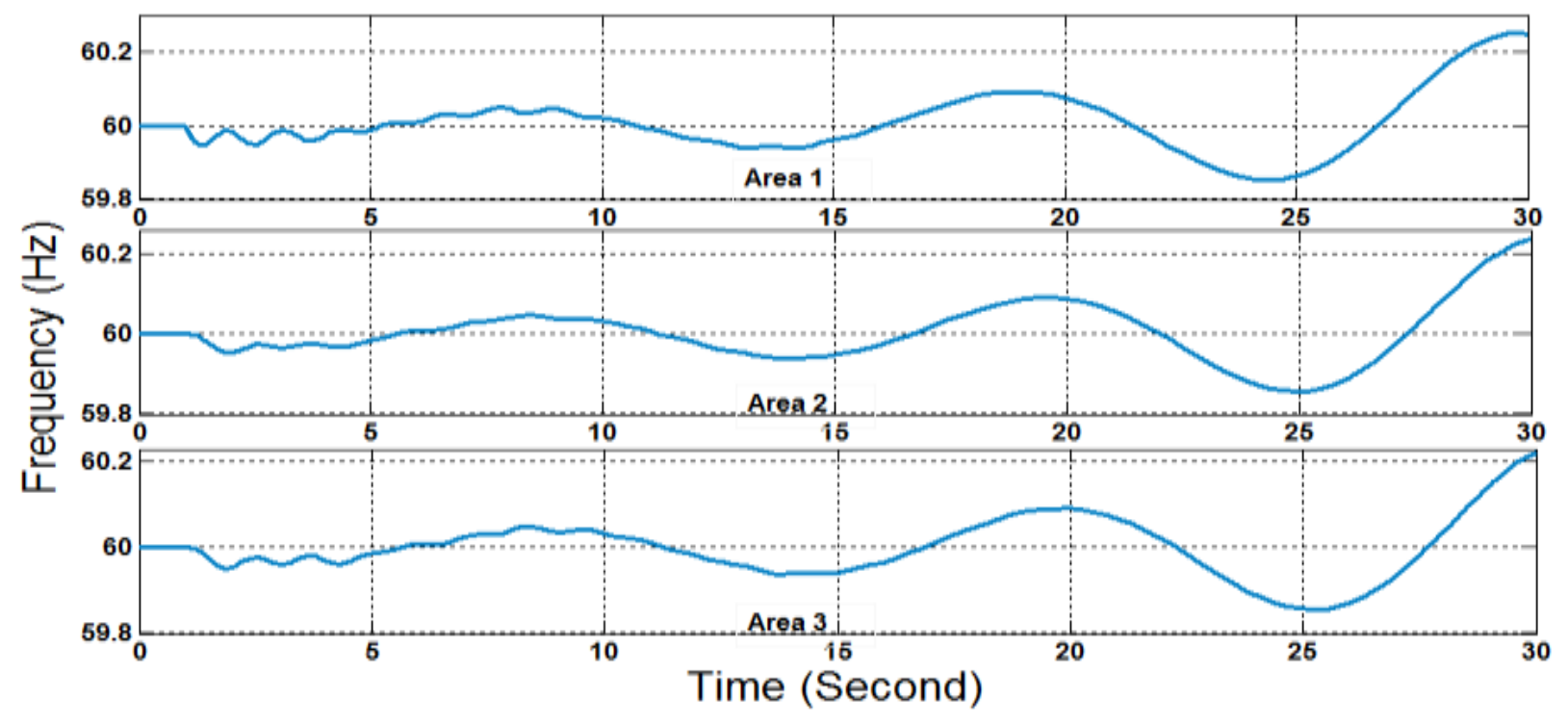

Figure 4.6. Frequency deviations in scenario C (1.5 seconds delay)

In the fourth scenario (scenario D) 0.04 p.u. load change and 0.5 second delay are applied to the system but the delay is also considered in the LFC model. Figure 4.7 shows the response of the whole system to the load change. It can be seen that the system could handle the load change easily even with 0.5 second delay. The fifth scenario has a delay of 1.5 seconds. Figure 4.8 presents the frequency deviations and it can be seen that the system can track the load change and has an acceptable response. It should be mentioned that in the scenario $\mathrm{C}$, the amount of delay was the same, but since the delay was not considered in the LFC model, the system became almost unstable. Finally, in the last scenario (scenario F) 4 seconds delay is applied to the system. Figure 4.9 presents the frequency deviations in the last case. The amount of delay is more than twice of scenario $\mathrm{C}$, but still system is stable and can damp the load change. By performing the same procedure and increasing the amount of delay, it is observed that system can stand delay of 7.3 seconds without being unstable.

It is necessary to highlight that the amount of delay a system can stand is very dependent of system parameters and certainly will be variable for different cases. Sources of delay can be communication links delay (sending the measurements to the control center and then sending the control signals form the control center to each area), delay originated from filters used in the AGC scheme and the delay of control center during commuting the control signals. Moreover, to have a realistic model for communication delays, a discrete communication model should be employed. 
The GA parameters are presented in Table 4.1. Gains of the PID controllers for all scenarios plus IAE values can be seen in Table 4.2.

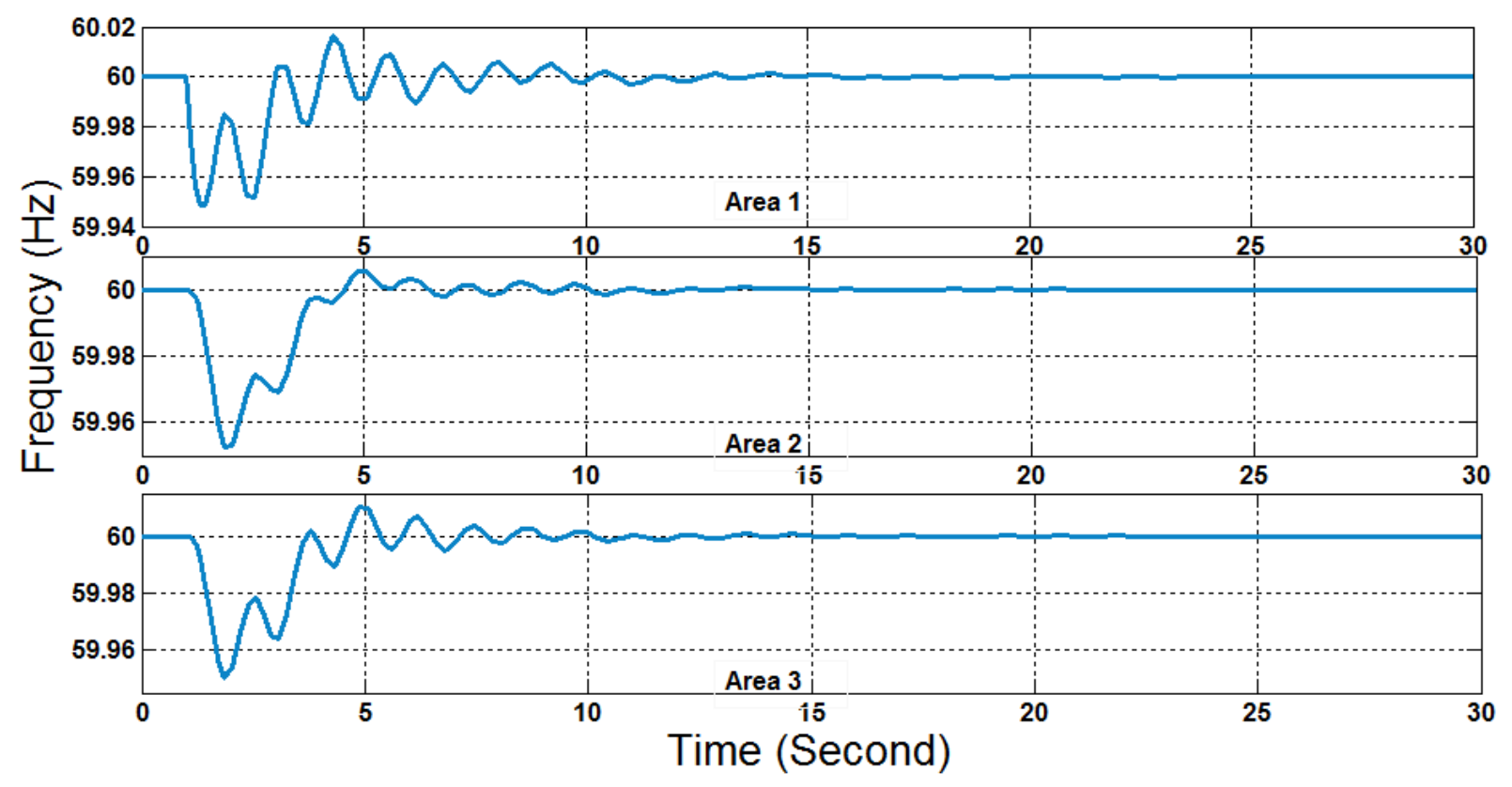

Figure 4.7. Frequency deviations in scenario $\mathrm{D}$ ( 0.5 second delay)

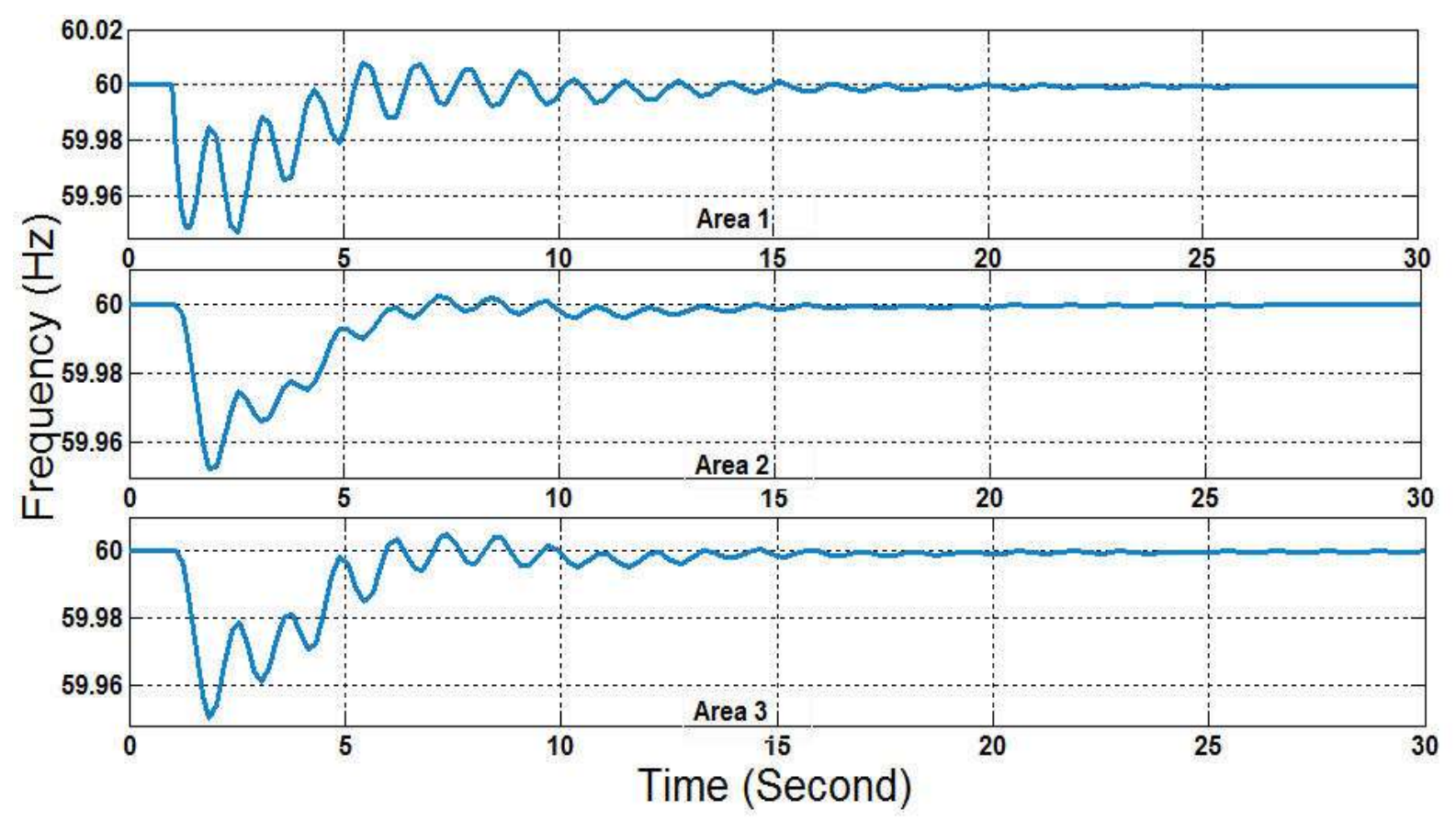

Figure 4.8. Frequency deviations in scenario E (1.5 seconds delay) 


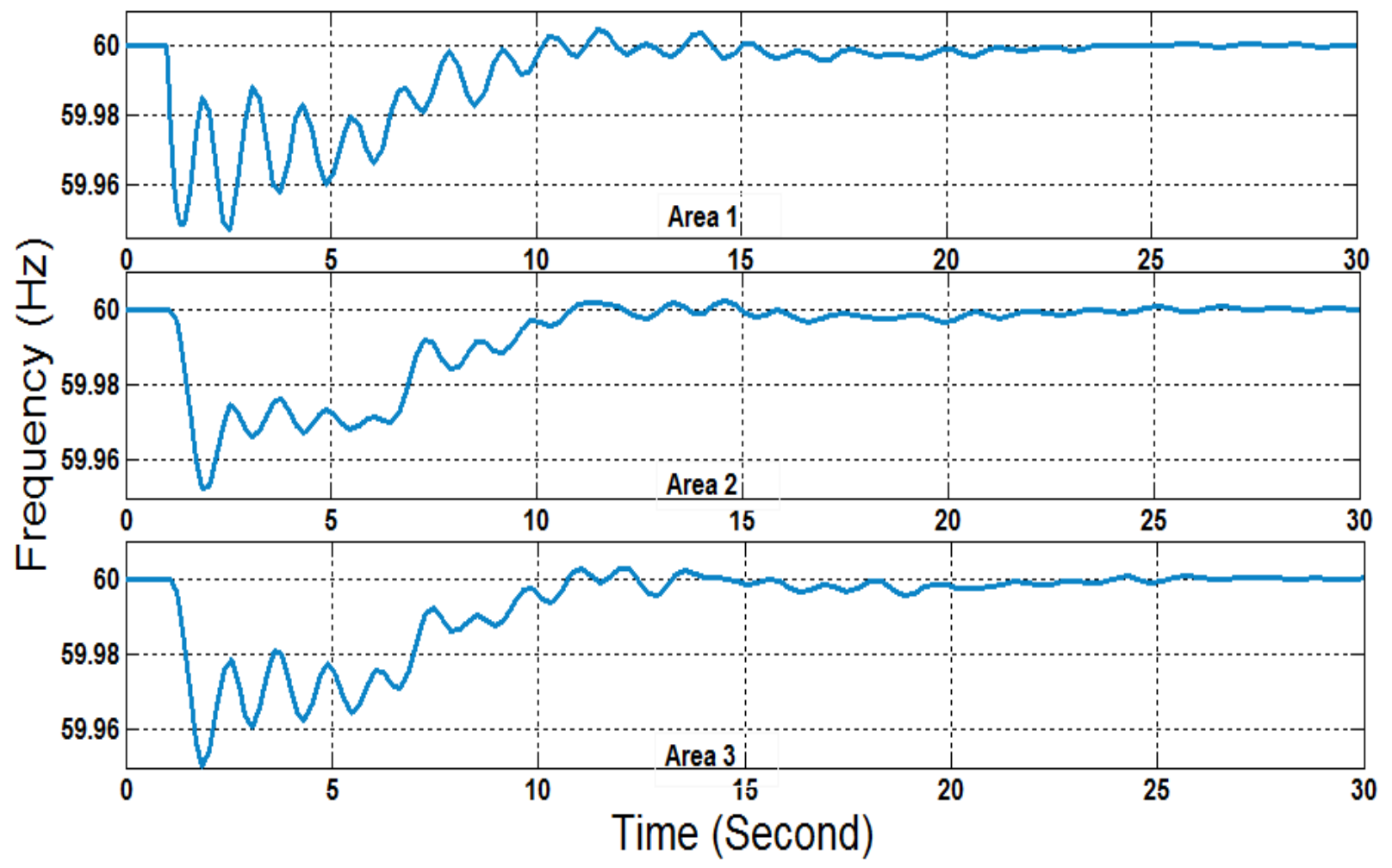

Figure 4.9. Frequency deviations in scenario $\mathrm{F}$ (4 seconds delay)

Table 4.1. GA Parameters

\begin{tabular}{|c|c|}
\hline Population size & 500 \\
\hline Selection Method & Roulette Wheel \\
\hline Crossover Method & Single Point (Random Point) \\
\hline Crossover Rate & 0.8 \\
\hline Mutation Method & Single Point (Random Point) \\
\hline Mutation Rate & 0.05 \\
\hline Termination & GA terminates after 200 iterations \\
\hline
\end{tabular}


Table 4.2. PID controllers gains in different scenarios

\begin{tabular}{|c|c|c|c|c|c|c|c|c|c|c|c|c|}
\hline $\begin{array}{l}\text { Load } \\
\text { Change }\end{array}$ & Scenario & $\begin{array}{l}\text { Delay } \\
(\mathrm{Sec})\end{array}$ & $\mathrm{K}_{\mathrm{p}} 1$ & Ki_1 & Kd_1 & Kp_2 & $\mathrm{Ki} \_2$ & Kd_2 & $\mathrm{Kp} \_3$ & $\mathrm{Ki} 3$ & $\mathrm{Kd}$ _3 & IAE \\
\hline 0.04 p.u & A & 0.0 & 0.519921 & 0.965742 & 0.280493 & 0.318080 & 0.205402 & 0.107374 & 0.470425 & 0.738477 & 0.202136 & 0.265695 \\
\hline 0.04 p.u. & $\mathrm{B}$ & 0.5 & 0.519921 & 0.965742 & 0.280493 & 0.318080 & 0.205402 & 0.107374 & 0.470425 & 0.738477 & 0.202136 & 0.544942 \\
\hline 0.04 p.u & $\mathrm{C}$ & 1.5 & 0.519921 & 0.965742 & 0.280493 & 0.318080 & 0.205402 & 0.107374 & 0.470425 & 0.738477 & 0.202136 & 4.144059 \\
\hline 0.04 p.u. & $\mathrm{D}$ & 0.5 & 0.424382 & 0.714985 & 0.012732 & 0.310091 & 0.822985 & 0.037651 & 0.473990 & 0.777665 & 0.016607 & 0.386303 \\
\hline 0.04 p.u. & $\mathrm{E}$ & 1.5 & 0.411075 & 0.369043 & 0.044742 & 0.192560 & 0.138695 & 0.043199 & 0.638830 & 0.157458 & 0.010893 & 0.546371 \\
\hline 0.04 p.u. & F & 4 & 0.410244 & 0.190001 & 0.005731 & 0.209097 & 0.194308 & 0.314999 & 0.063477 & 0.016793 & 0.090441 & 0.902766 \\
\hline
\end{tabular}

Table 4.3. Controllers' gains and their respective performance criteria (no physical constraints consideration)

\begin{tabular}{|c|c|c|c|c|c|c|c|c|c|c|c|c|}
\hline Controller & $\begin{array}{c}\text { Load } \\
\text { Change } \\
\text { (p.u.) }\end{array}$ & $\begin{array}{r}\text { Delay } \\
(\mathrm{sec})\end{array}$ & $\mathrm{Kp}$ & $\mathrm{Ki}$ & $\mathrm{Kd}$ & IAE & ISE & ITAE & ITSE & $\begin{array}{l}\text { Overshoot } \\
(\%)\end{array}$ & $\begin{array}{c}\text { Undershoot } \\
(\%)\end{array}$ & $\begin{array}{l}\text { Settling } \\
\text { Time } \\
(\mathrm{Sec})\end{array}$ \\
\hline PID & 0.04 & 0.00 & 2.985599 & 2.998149 & 0.662650 & 0.030897 & 0.000599 & 0.111993 & 0.000847 & 0.131515 & 4.030627 & 8.174992 \\
\hline PI & 0.04 & 0.00 & 1.344858 & 0.758352 & & 0.113739 & 0.003979 & 0.485190 & 0.007517 & 1.368154 & 7.590060 & 12.424174 \\
\hline I & 0.04 & 0.00 & & 0.501054 & & 0.280504 & 0.019104 & 1.048000 & 0.046033 & 4.132535 & 11.784188 & 11.173212 \\
\hline
\end{tabular}

Table 4.4. Controllers' gains and their respective performance criteria (physical constraints considered)

\begin{tabular}{|c|c|c|c|c|c|c|c|c|c|c|c|c|}
\hline Controller & $\begin{array}{c}\text { Load } \\
\text { Change } \\
\text { (p.u.) }\end{array}$ & $\begin{array}{l}\text { Delay } \\
(\mathrm{sec})\end{array}$ & $\mathrm{Kp}$ & $\mathrm{Ki}$ & $\mathrm{Kd}$ & IAE & ISE & ITAE & ITSE & $\begin{array}{l}\text { Overshoot } \\
(\%)\end{array}$ & $\begin{array}{l}\text { Undershoot } \\
(\%)\end{array}$ & $\begin{array}{l}\text { Settling } \\
\text { Time } \\
(\mathrm{Sec})\end{array}$ \\
\hline PID & 0.04 & 0.00 & 0.506346 & 0.185852 & 0.202323 & 1.384730 & 0.186394 & 9.763985 & 0.853512 & 1.264489 & 20.297646 & 29.739746 \\
\hline PI & 0.04 & 0.00 & 0.458188 & 0.175677 & & 1.439721 & 0.200712 & 10.195718 & 0.928658 & 1.337420 & 20.927334 & 29.574229 \\
\hline I & 0.04 & 0.00 & & 0.089213 & & 1.489319 & 0.202964 & 10.869464 & 0.959746 & 1.654815 & 20.911327 & 29.160322 \\
\hline
\end{tabular}




\subsection{Detailed load frequency model and comparison between controllers}

In this part a detailed LFC model containing all of the physical constraints is developed. Governor dead band and turbine generation rate constraints plus the communication delay are implemented in the LFC model to have an accurate and realistic model. First, the LFC problem for the three-area power system is solved by GA considering all of physical constants. Second the proposed comprehensive LFC model is used to perform a comparison between different controllers and performance index criteria.

\section{Three-area power system with physical constraints consideration}

The same procedure which was computed to address the effect of communication delay is performed for the three-area power system but this time all physical constraints are considered. IAE is used as the performance index criterion. It can be seen that the physical constraints degrade the response of AGC system. Figure 4.10 shows the response of PID controllers to the load change of 0.04 p.u. (at $\mathrm{t}=1 \mathrm{~s}$ ). Figure 4.11 presents the simulated system in Simulink.

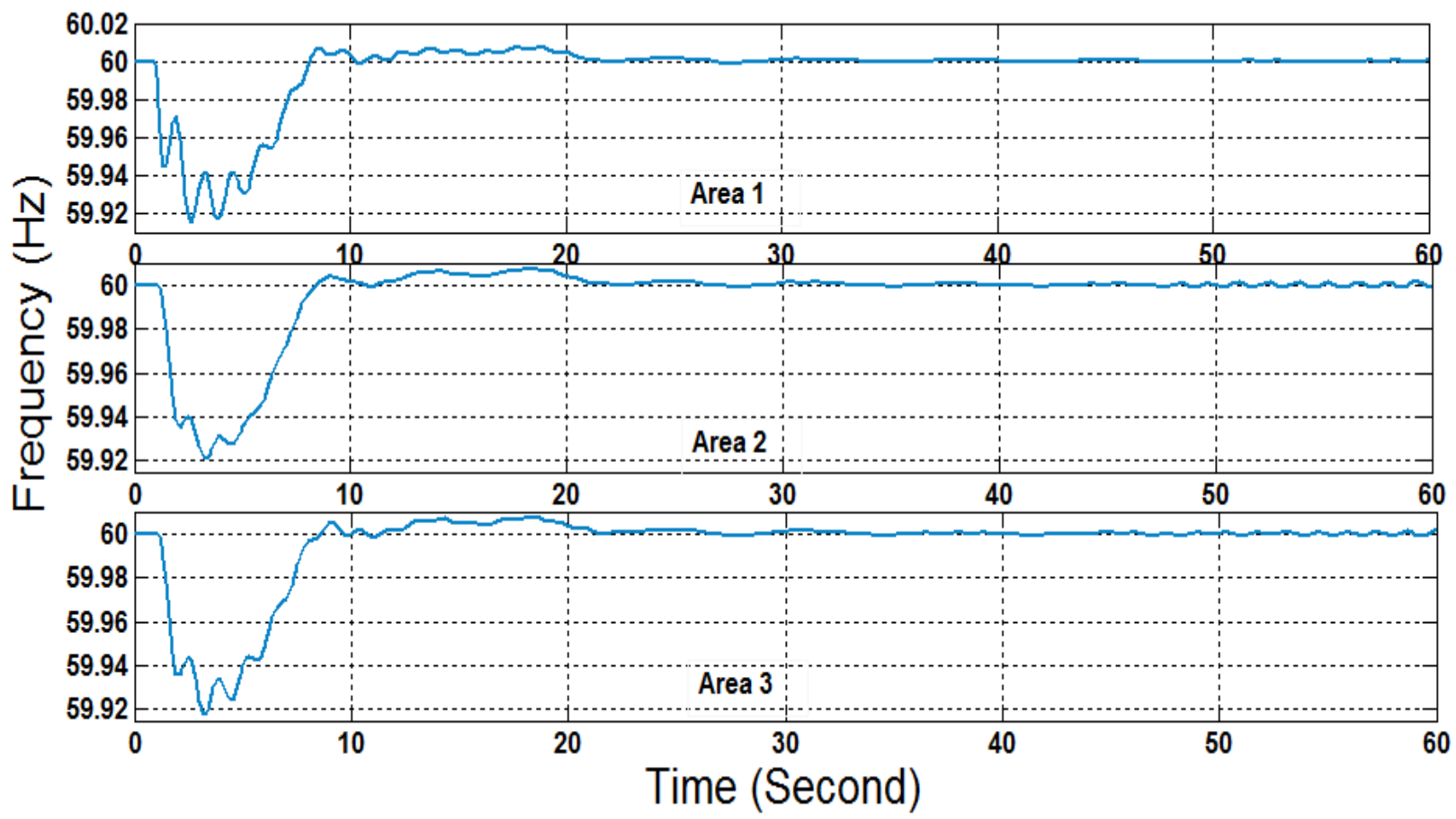

Figure 4.10. Response of PID controllers in three-area power system to 0.04 p.u. load change 


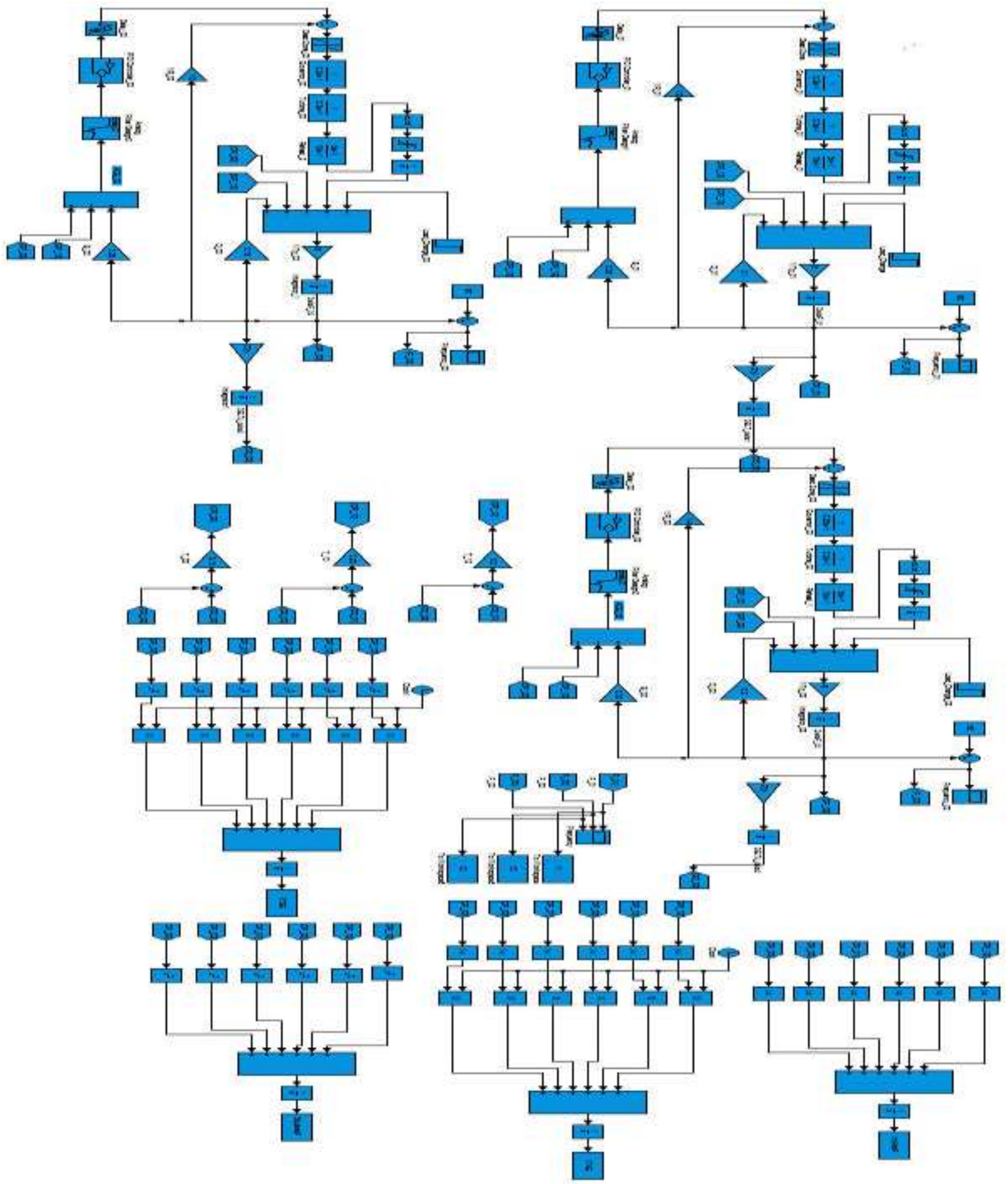

Figure 4.11. Three-area power system considering all physical constraints

Table 4.5 presents the value of physical constraint imposed to the system and Table 4.6 shows the GA results and the IAE value. System parameters are presented in Appendix C. 
Table 4.5. Physical constraints imposed

\begin{tabular}{|c|c|c|}
\hline Generation rate limit & Governor dead band & Delay \\
\hline $3 \%$ p.u. MW/min & $0.036 \mathrm{~Hz}$ & $0.5 \mathrm{Sec}$ \\
\hline
\end{tabular}

Table 4.6. Value of controllers' gains computed by GA

\begin{tabular}{|c|c|c|c|c|c|c|c|c|c|}
\hline Kp1 & Kp_1 & Ki_1 & Kd_1 & Kp_2 & Ki_2 & Kd_2 & Kp_3 & Ki_3 & IAE \\
\hline 1.638011 & 0.897703 & 0.178942 & 1.332821 & 2.189337 & 1.331725 & 0.787086 & 2.386130 & 0.872473 & 1.515901 \\
\hline
\end{tabular}

\section{Comparison between conventional controllers employed in LFC problem}

Different performance index criteria have been used in control studies such as IAE, ITAE, ISE and ITSE. In this part of the thesis all of them are calculated for two cases, however, only IAE is used for computing the fitness value for each individual. A comparison between integrator, PI and PID controllers is performed when no physical constraints are considered. For better understanding of the comparison, simulations and GA optimization are computed for a single control area. System parameters are provided in appendix C. The results show that PID controller has the best performance significantly when physical constraints are ignored. Figures 4.12-14 show the frequency deviations for the load change of 0.04 p.u. (at $\mathrm{t}=1 \mathrm{~s}$ ) and response of integrator, PI and PID controllers respectively.

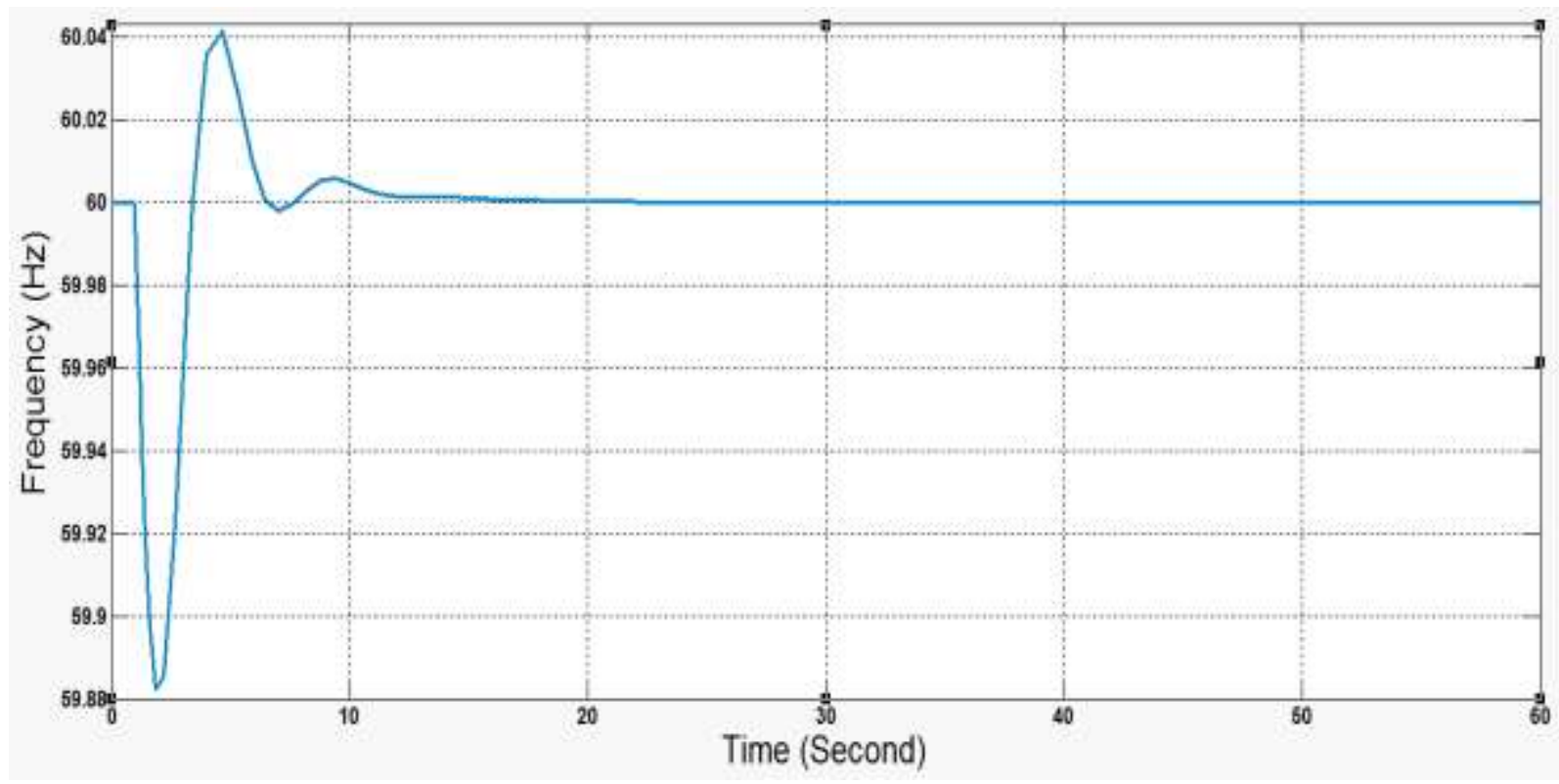

Figure 4.12. Integrator controller response (no constraints consideration) 


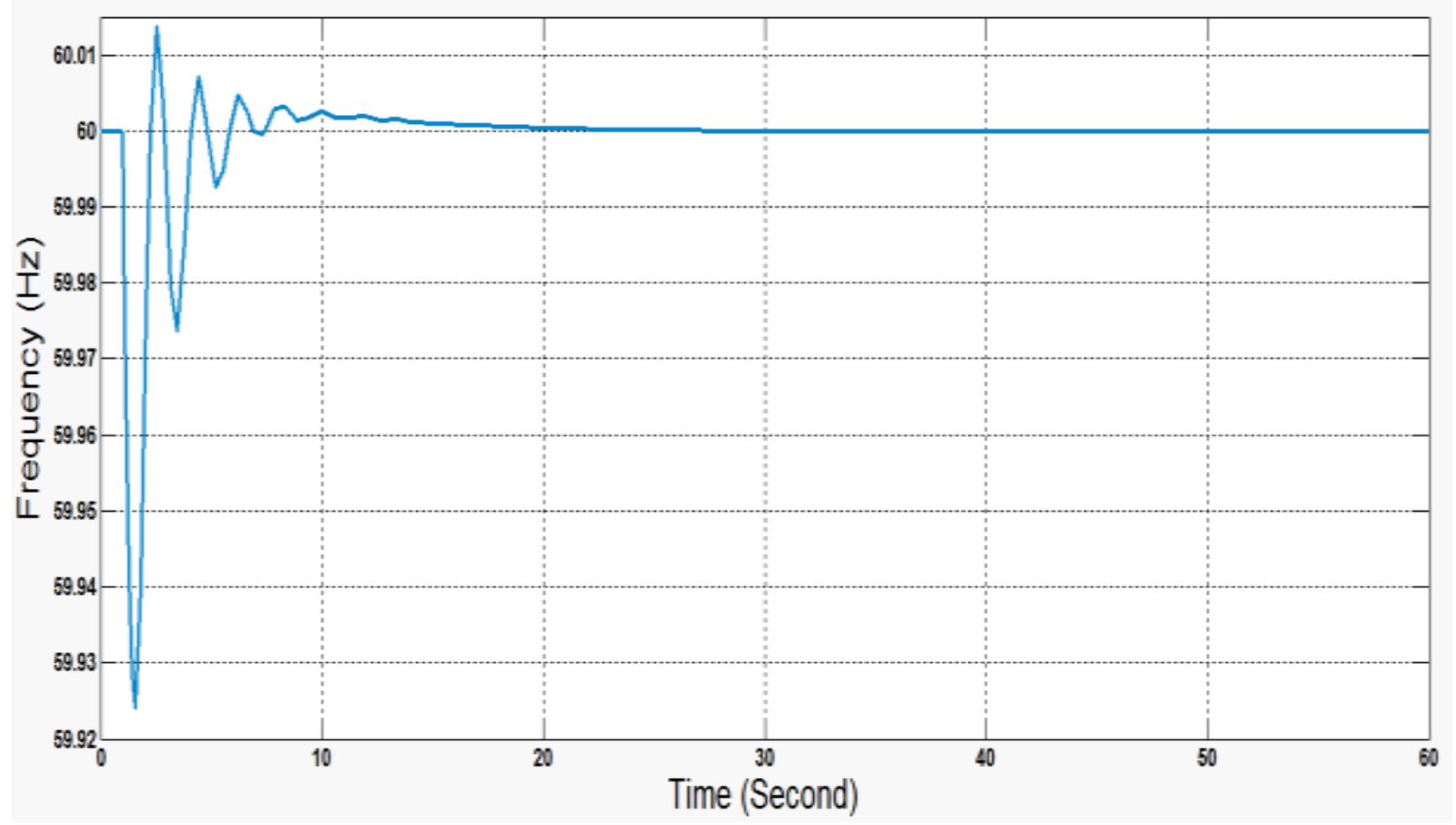

Figure 4.13. PI controller response (no constraints consideration)

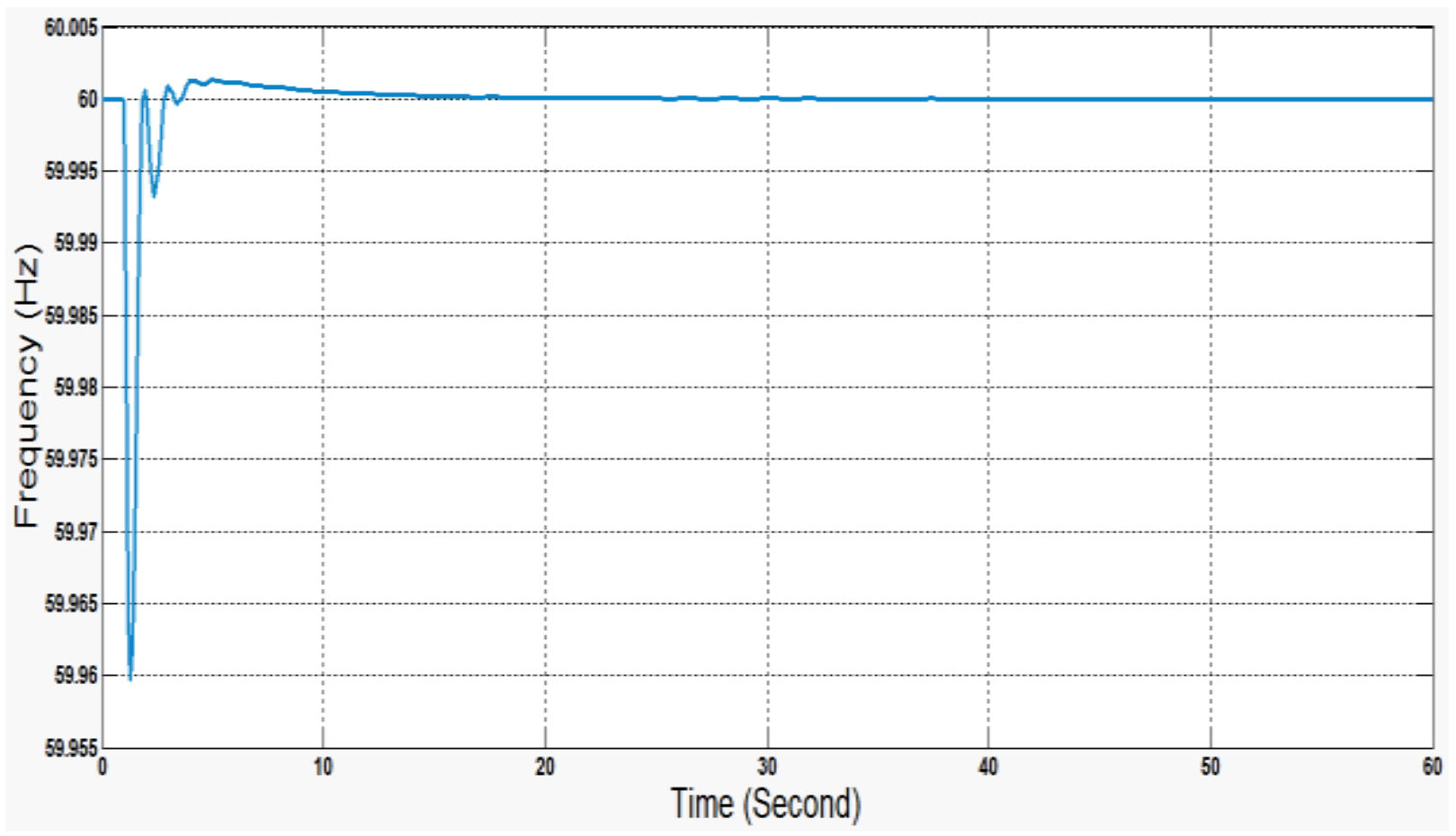

Figure 4.14. PID controller response (no constraints consideration) 
Table 4.3 shows the value of controllers' gains and their respective performance index criteria. It is necessary to mention that IAE is chosen to calculate the fitness value and performing the GA. Obviously, it can be seen that the PID controller has a better and faster response to the same load change in terms of performance index criteria, overshoot and settling time. Figure 4.15 shows the difference very clearly.

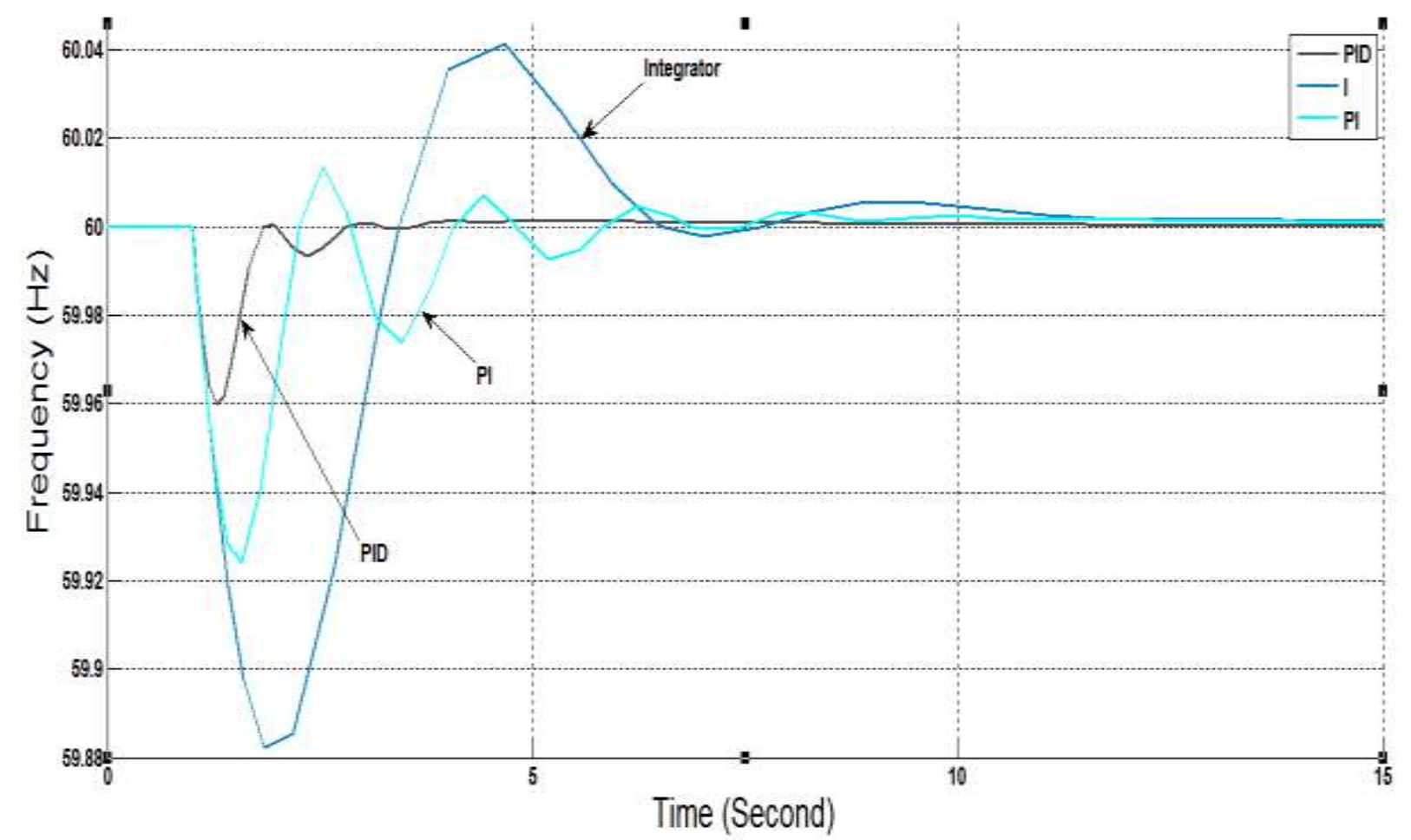

Figure 4.15. Comparison between integrator, PI and PID controllers (no constraints consideration)

Having the comprehensive model, a comparison between controllers is performed and this time PID controller represents a slight better performance. The developed model in Simulink is presented in figure 4.16. A load change of 0.04 p.u. (at $\mathrm{t}=1 \mathrm{~s}$ ) is applied and figures 4.17-19 show the response of integrator, PI and PID controllers respectively. Figure 4.20 shows all of the responses together and table 4.4 shows the value of controllers' gains and their respective performance index criteria. It is observed that there is not a significant difference between responses of the controllers when physical constraints are considered. However, it is important to point out that IAE is employed as the performance index criterion and PID controller has the least value of IAE. 


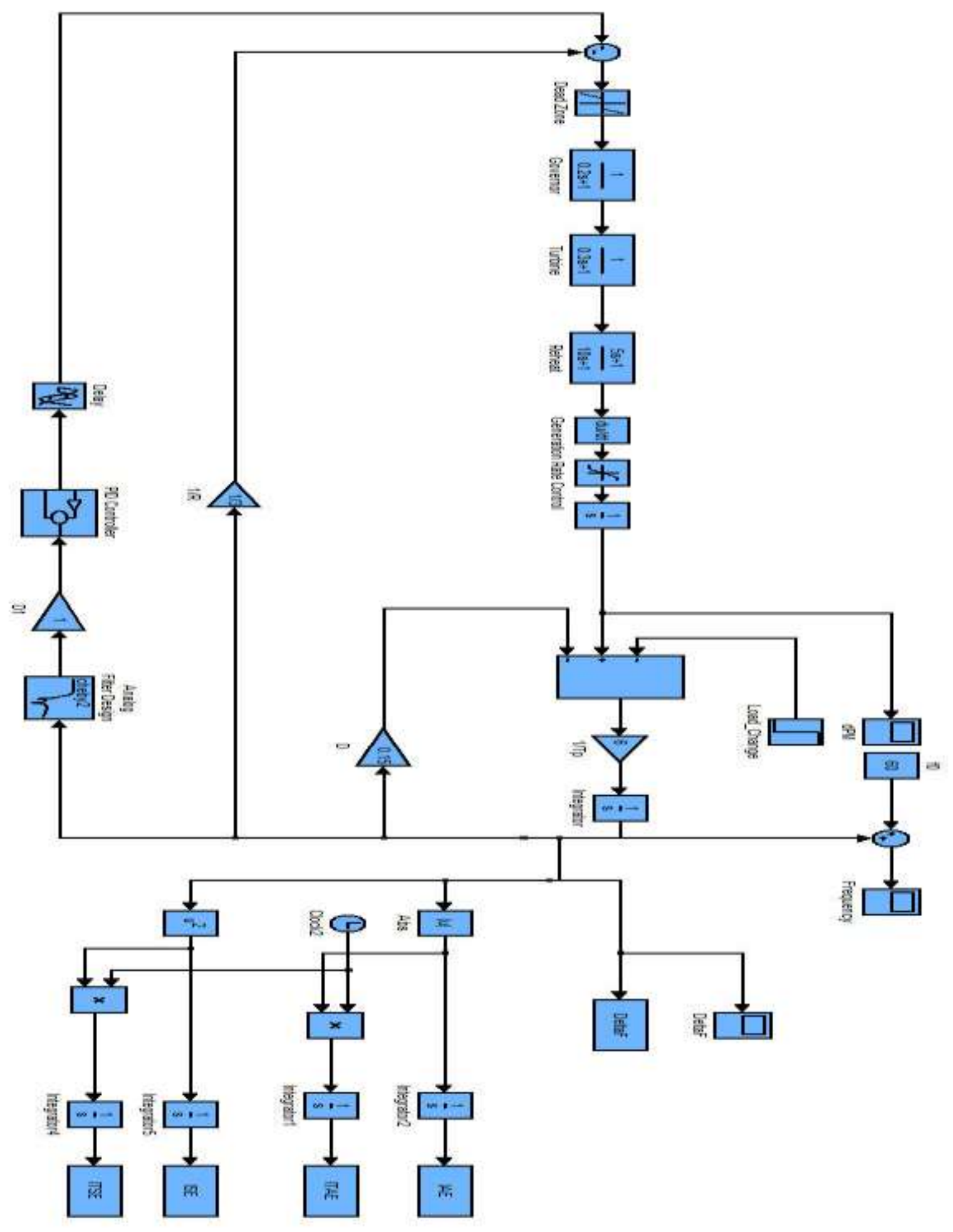

Figure 4.16.Single-area LFC model considering physical constraints 


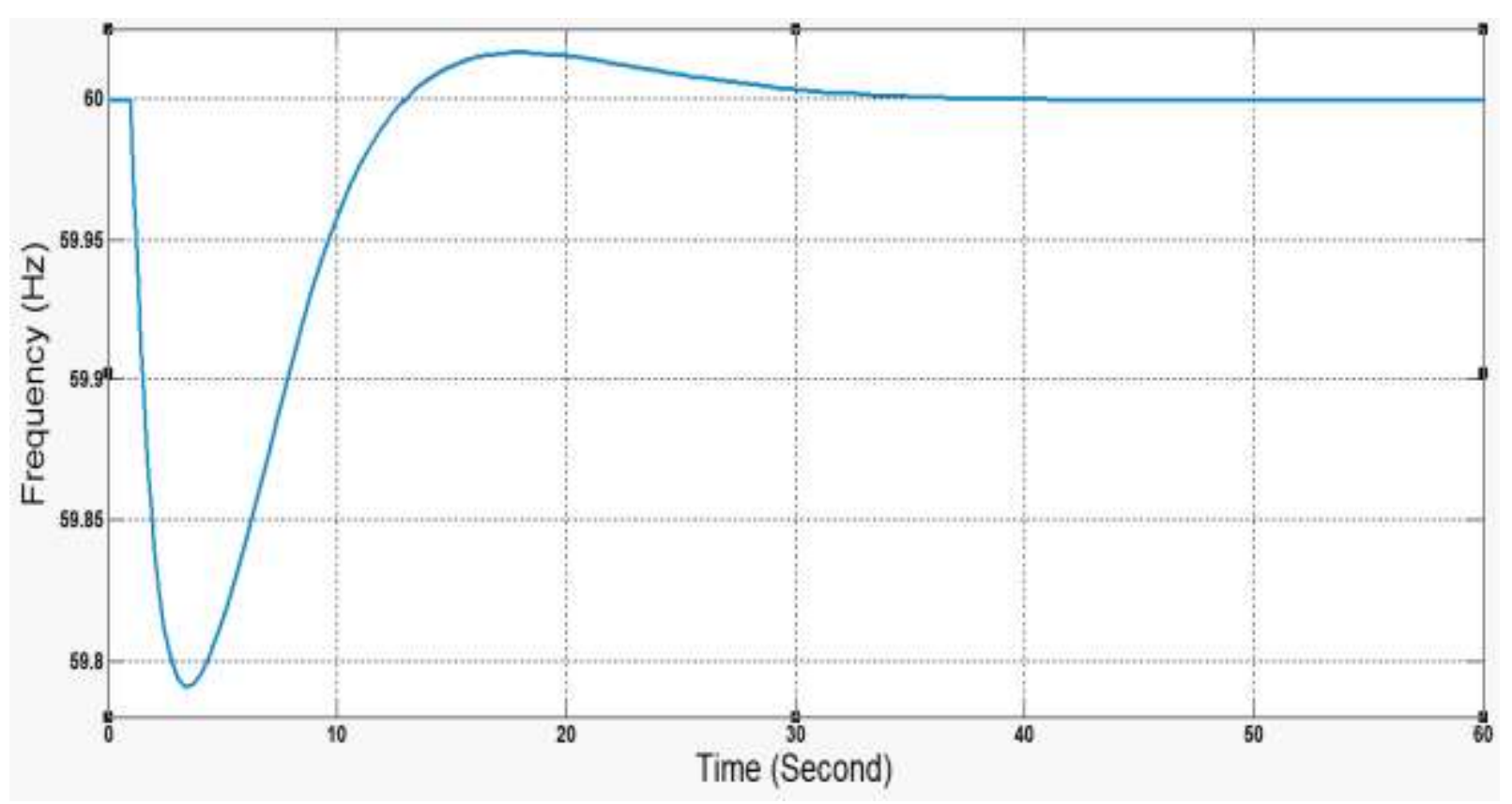

Figure 4.17. Response of integrator controller (constraints considered)

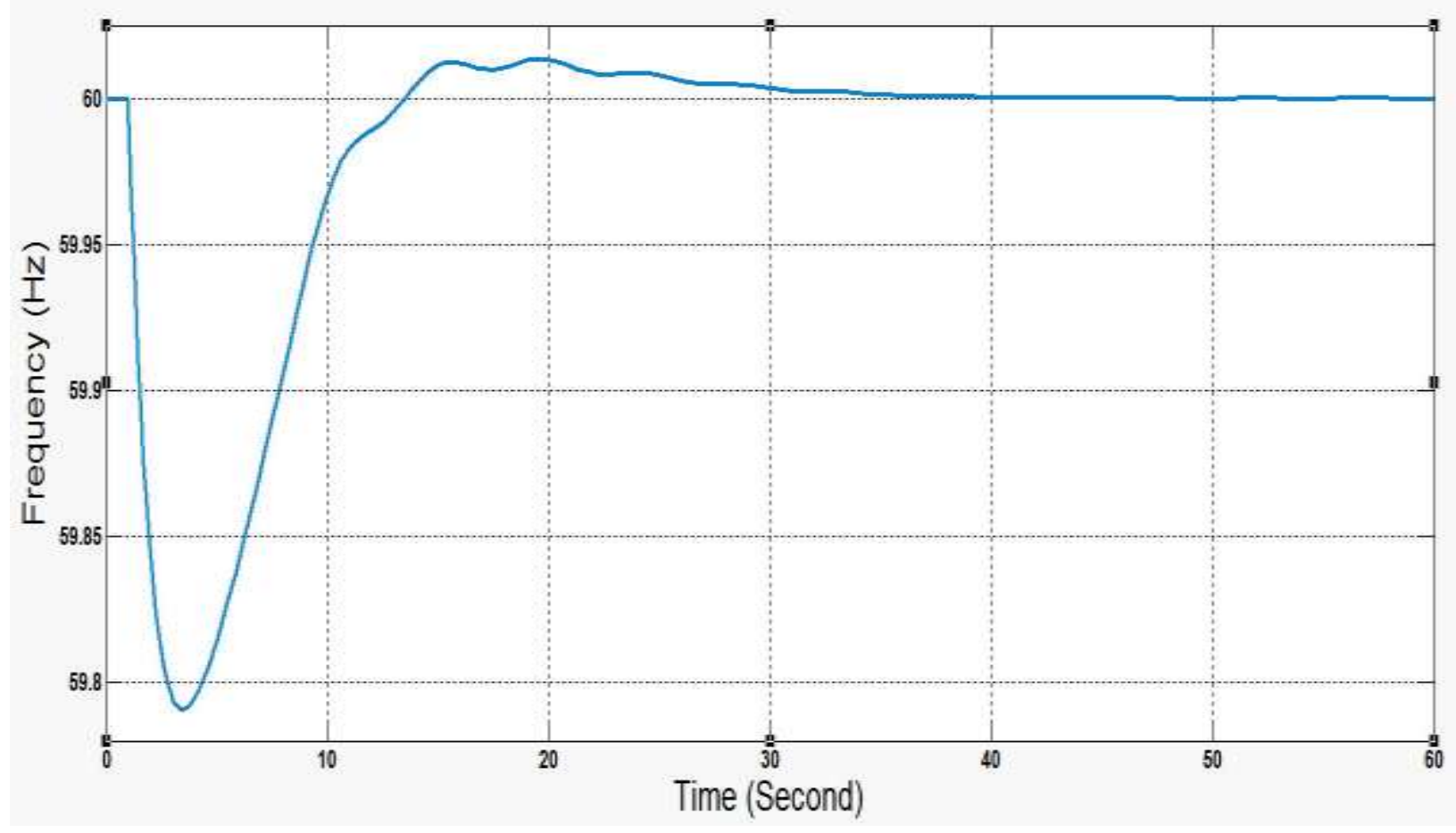

Figure 4.18. Response of PI controller (constraints considered) 


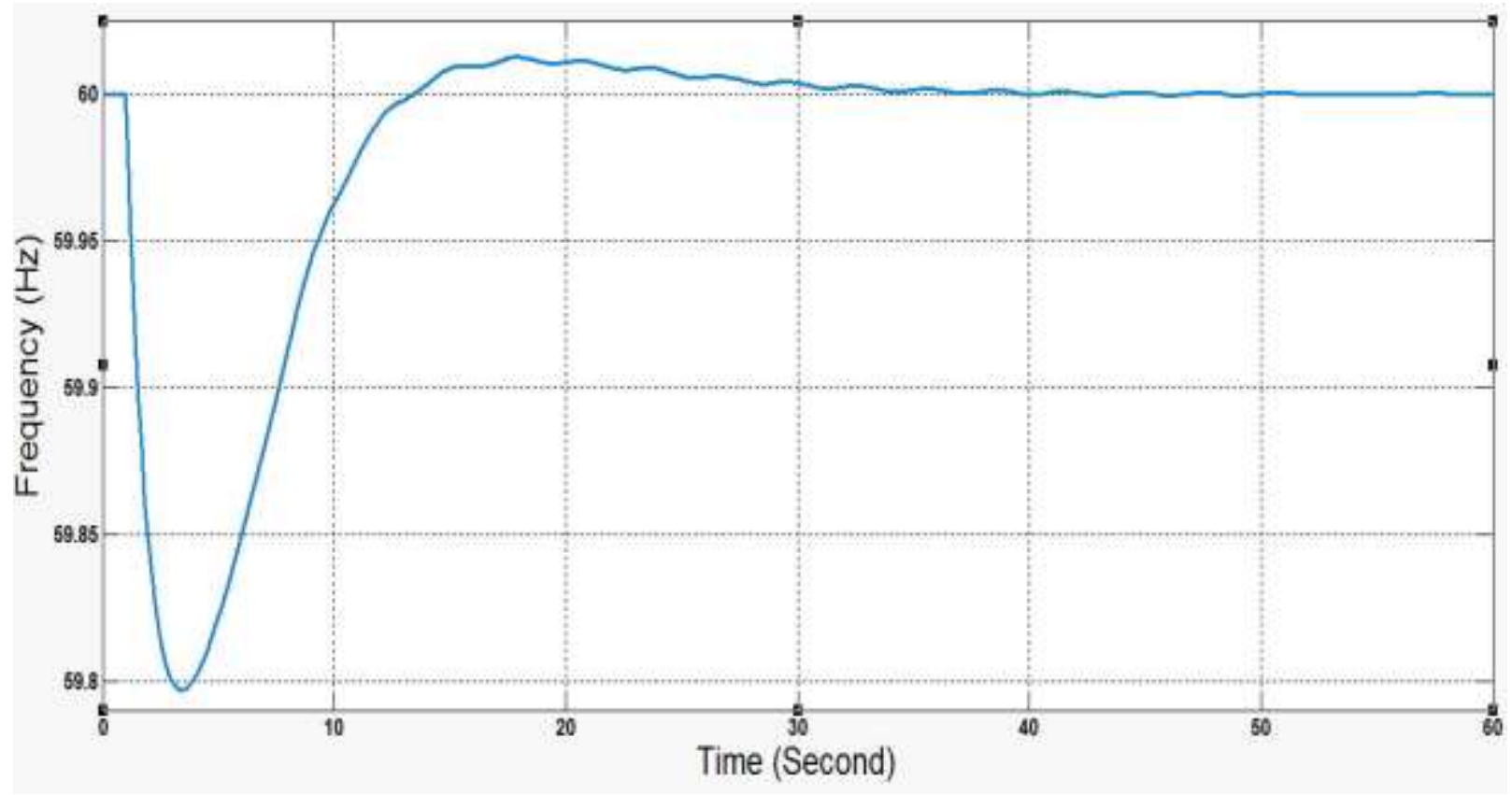

Figure 4.19. Response of PID controller (constraints considered)

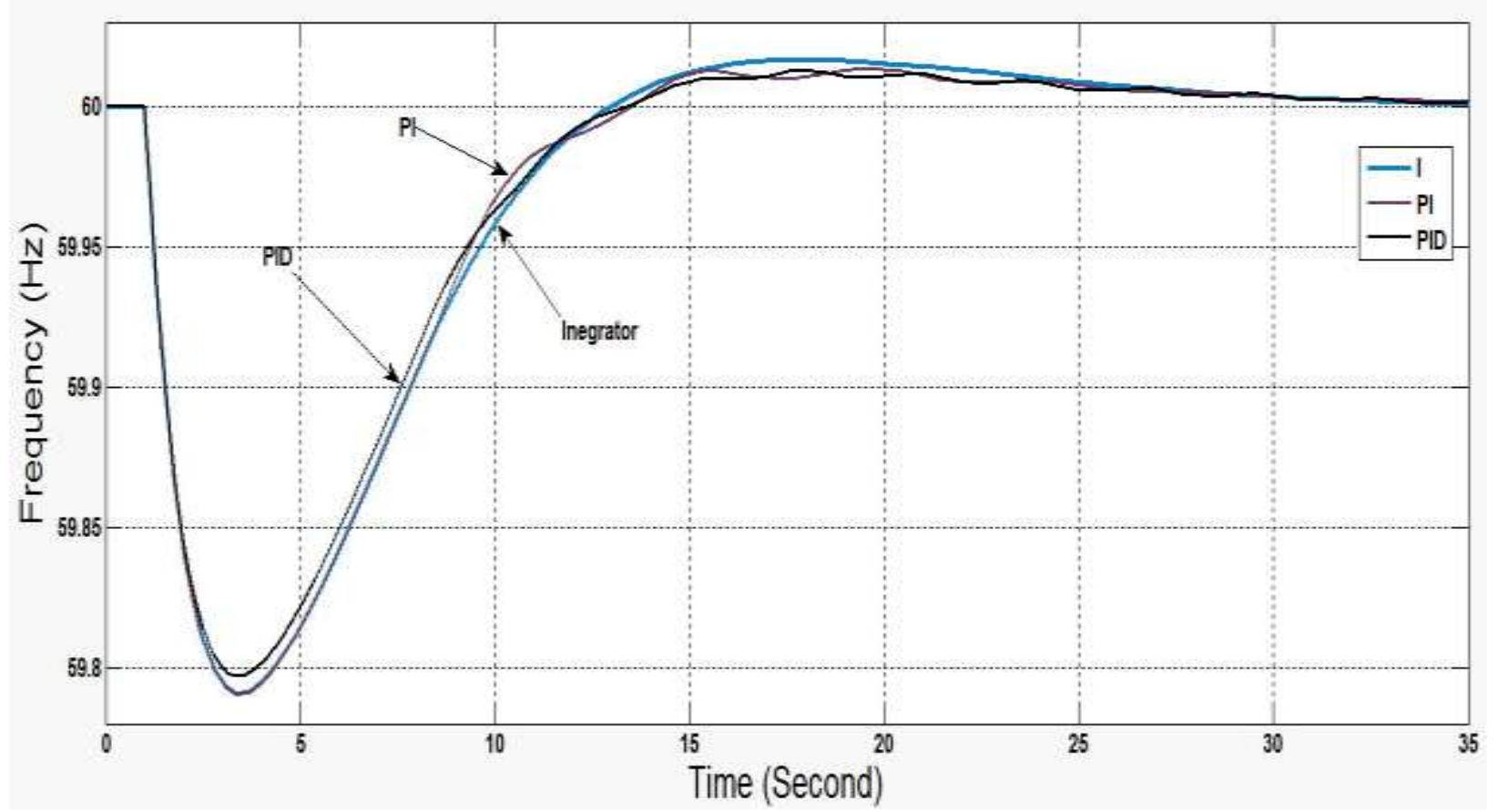

Figure 4.20. Comparison between integrator, PI and PID controllers (constraints considered) 


\subsection{Performance index criteria comparison}

This section begins with a brief description of commonly used performance index criteria (PIC) in LFC and control literature such as the integral of the absolute value of the error (IAE), the integral of time-multiplied absolute value of the error (ITAE), the integral of the square of the error (ISE), and the integral of time-multiplied square of the error (ITSE). Then a comparison between them is presented which is obtained from a single-area power system. Equations 4.2- 4.5 describe different employed performance index criteria.

$$
\begin{gathered}
I A E=\int_{0}^{t=\text { Simulation time }}|e(t)| d t \\
I S E=\int_{0}^{t=\text { Simulation time }} e(t)^{2} d t \\
\text { ITAE }=\int_{0}^{t=\text { Simulation time }} t|e(t)| d t \\
\text { ITSE }=\int_{0}^{t=\text { Simulation time }} t e(t)^{2} d t
\end{gathered}
$$

Where $e(t)$ in single-area LFC problem is $\Delta f$ (frequency deviation). Therefore, equations 4.2-4.5 are modified to 4.6-.4-9.

$$
\begin{aligned}
& I A E=\int_{0}^{t=\text { Simulation time }}|\Delta f| d t \\
& I S E=\int_{0}^{t=\text { Simulation time }} \Delta f^{2} d t \\
& I T A E=\int_{0}^{t=\text { Simulation time }} t|\Delta f| d t \\
& \text { ITSE }=\int_{0}^{t=\text { Simulation time }} t \Delta f^{2} d t
\end{aligned}
$$

Figure 4.21 shows how mentioned performance index criteria are computed. 


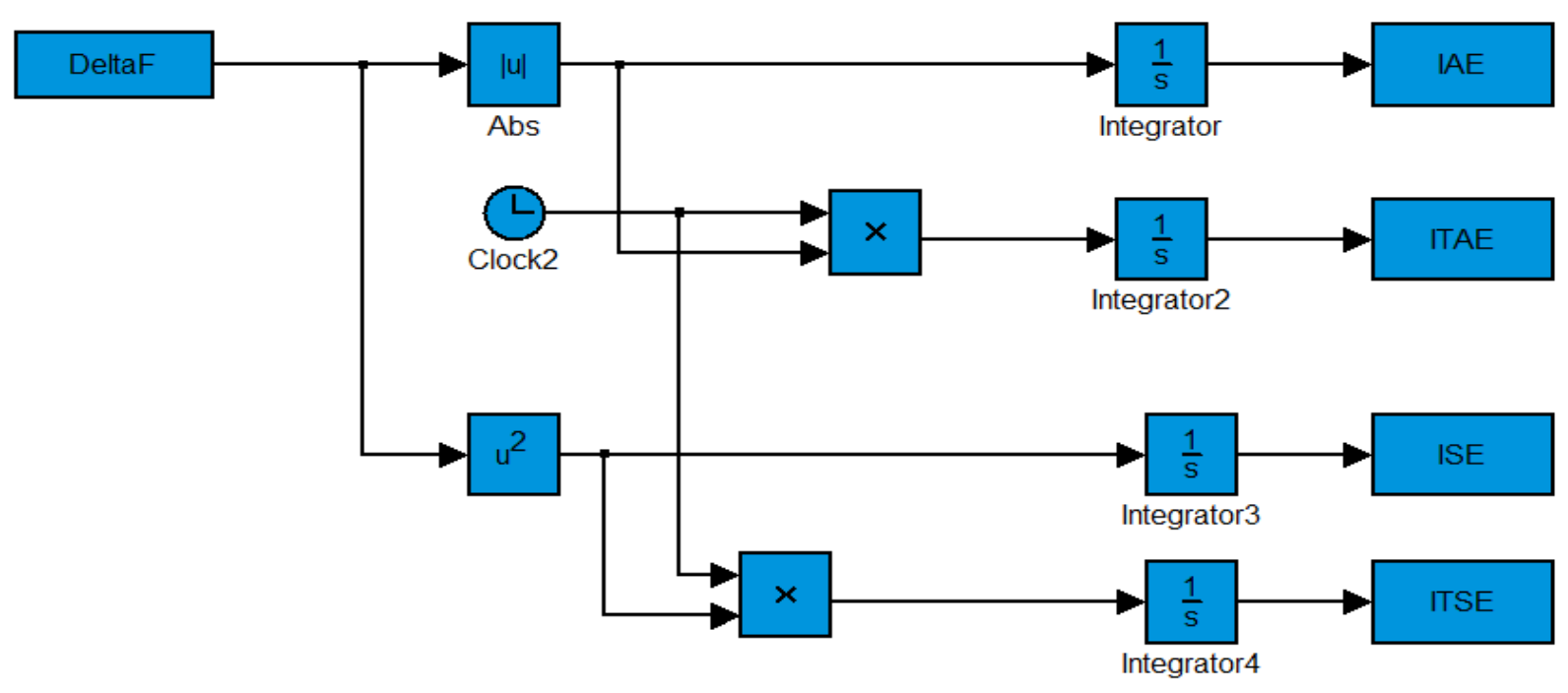

Figure 4.21. Block diagram of computed performance criteria

For each performance index criterion GA is run 10 times. The average values of performance index criterion, overshoot, and settling time can provide a very good understanding about the behavior and effectiveness of each performance index criterion. All discussed physical constraints are considered (the LFC model can be seen in figure 4.16) and physical constraints presented in table 4.5 are employed. The first PIC assessed is IAE. The results of GA runs can be seen in Table 4.7. The response of system to the least IAE found (best solution- run \#9) can be seen in figure 4 . 22.

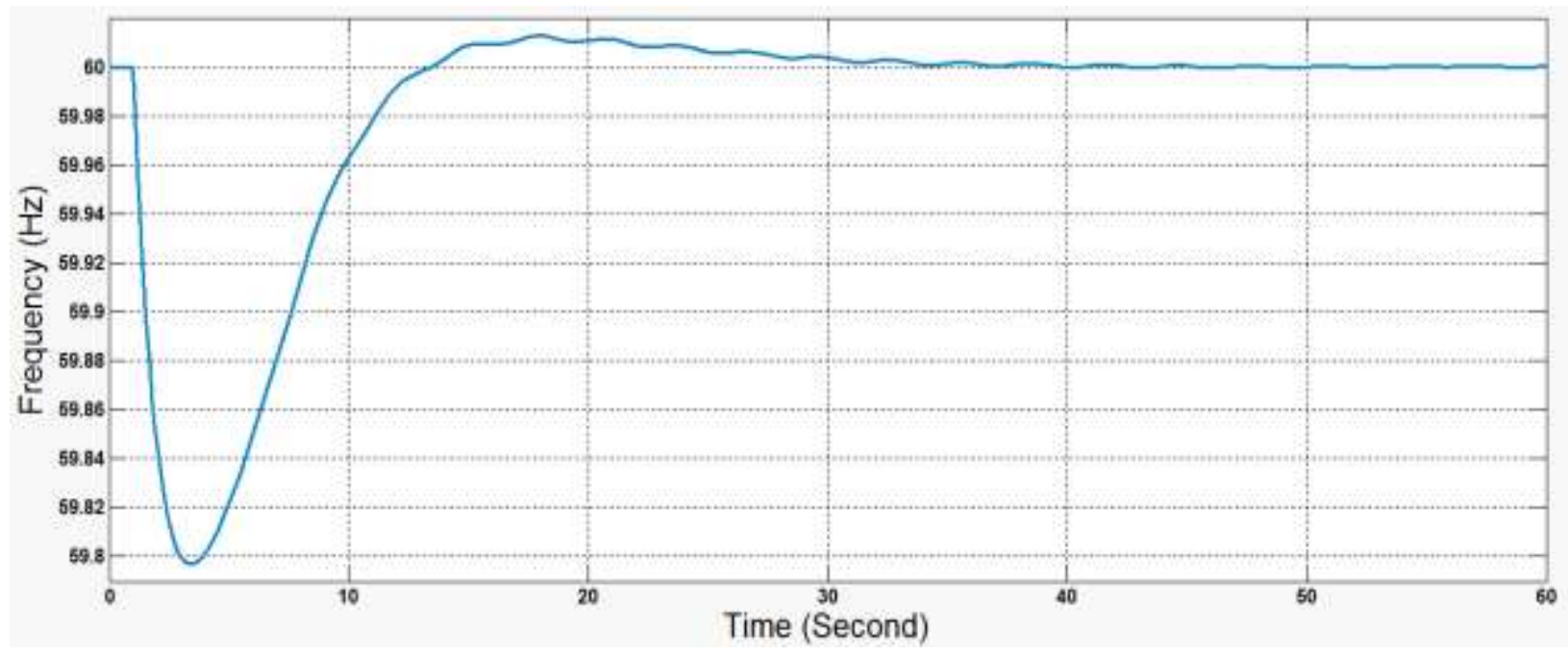

Figure 4.22. Response of PID controller with the least IAE 
ISE is the second PIC studied. The results of GA runs can be seen in Table 4.8. The response of system to the least ISE found (best solution- run \#10) can be seen in figure 4. 23. It should be pointed out that the best solution found using ISE performance index criterion cannot eliminate the steady-state error completely and still deviates around the steady-stat point $(60 \mathrm{~Hz})$. ISE has been used widely in LFC studies and this is an important issue that should be considered when using ISE criterion. There are cases which ISE has the least value, but the AGC system cannot eliminate steady-state error completely. Figure 4. 23 shows the response of system during the simulation. Moreover, there are cases with very close ISE values but different gains values and consequently different behavior of the AGC system. The third and fourth runs can be good examples for that case. Figure 4.24 presents their responses.

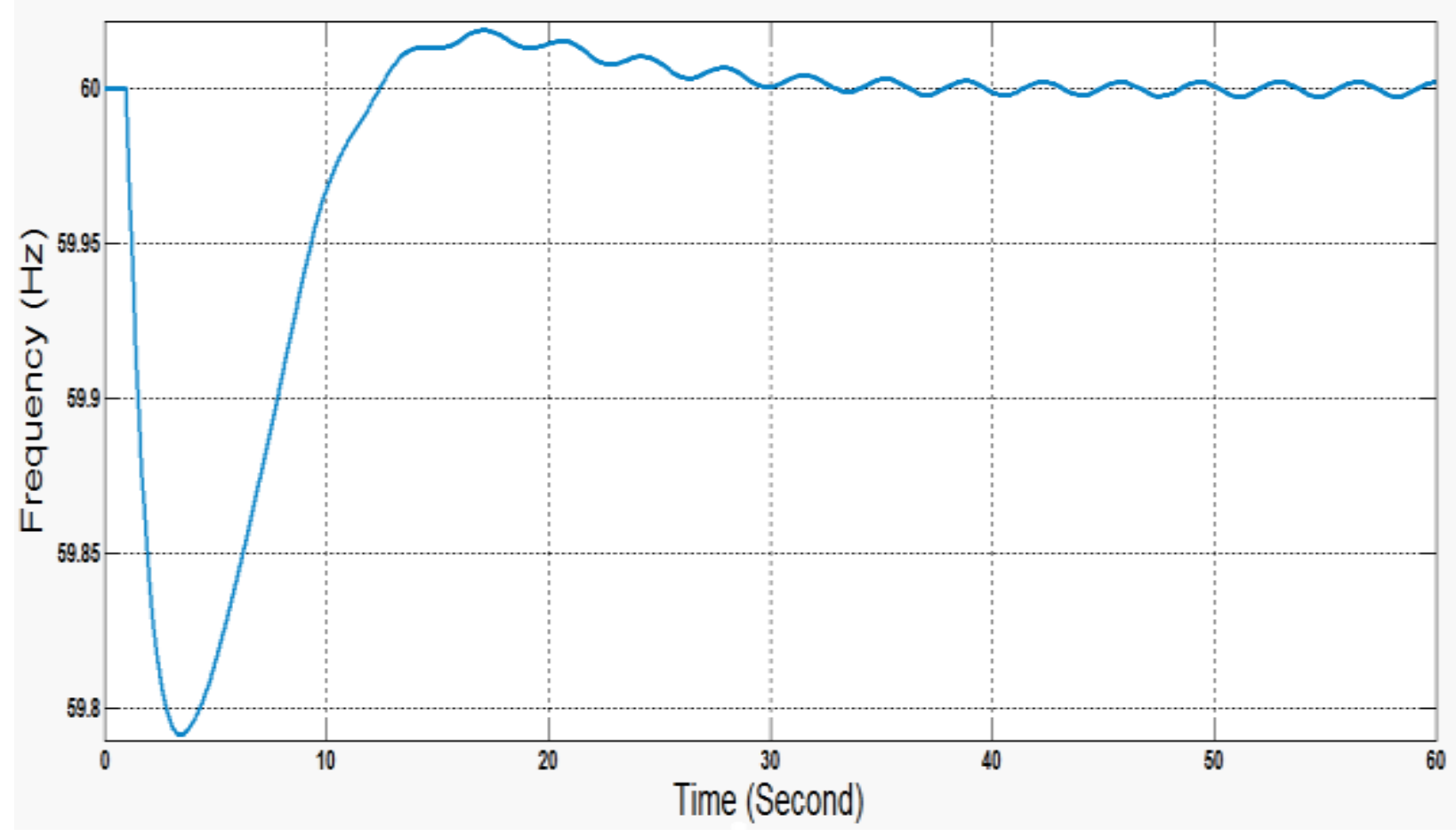

Figure 4.23. Response of PID controller with the least ISE 
The third PIC studied is ITAE. The results of GA runs can be seen in Table 4. 9. The response of system to the least ISE found (best solution- run \#10) can be seen in figure 4.25.

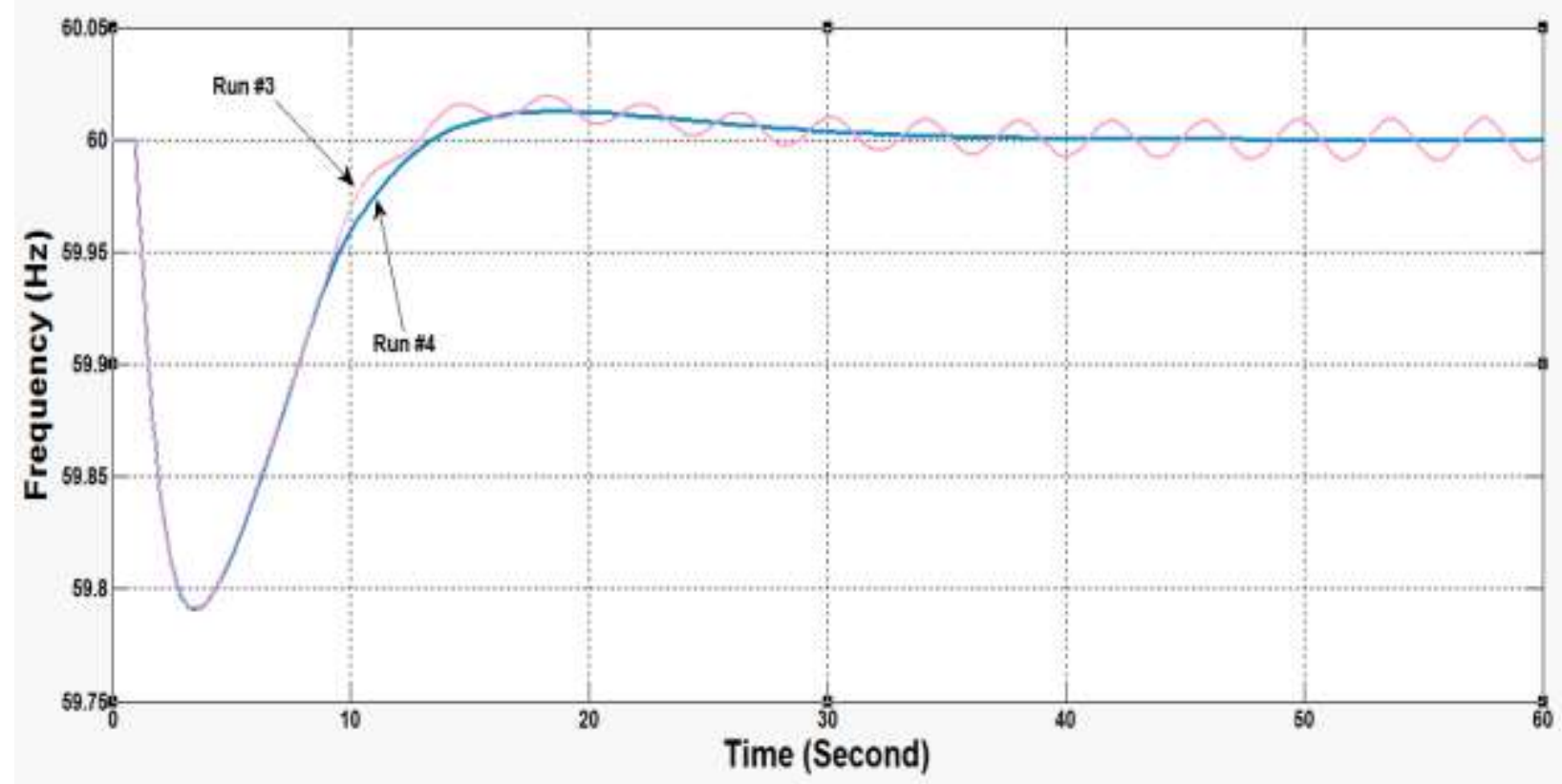

Figure 4.24. Comparing run \#3 and run \#4 (close ISE values)

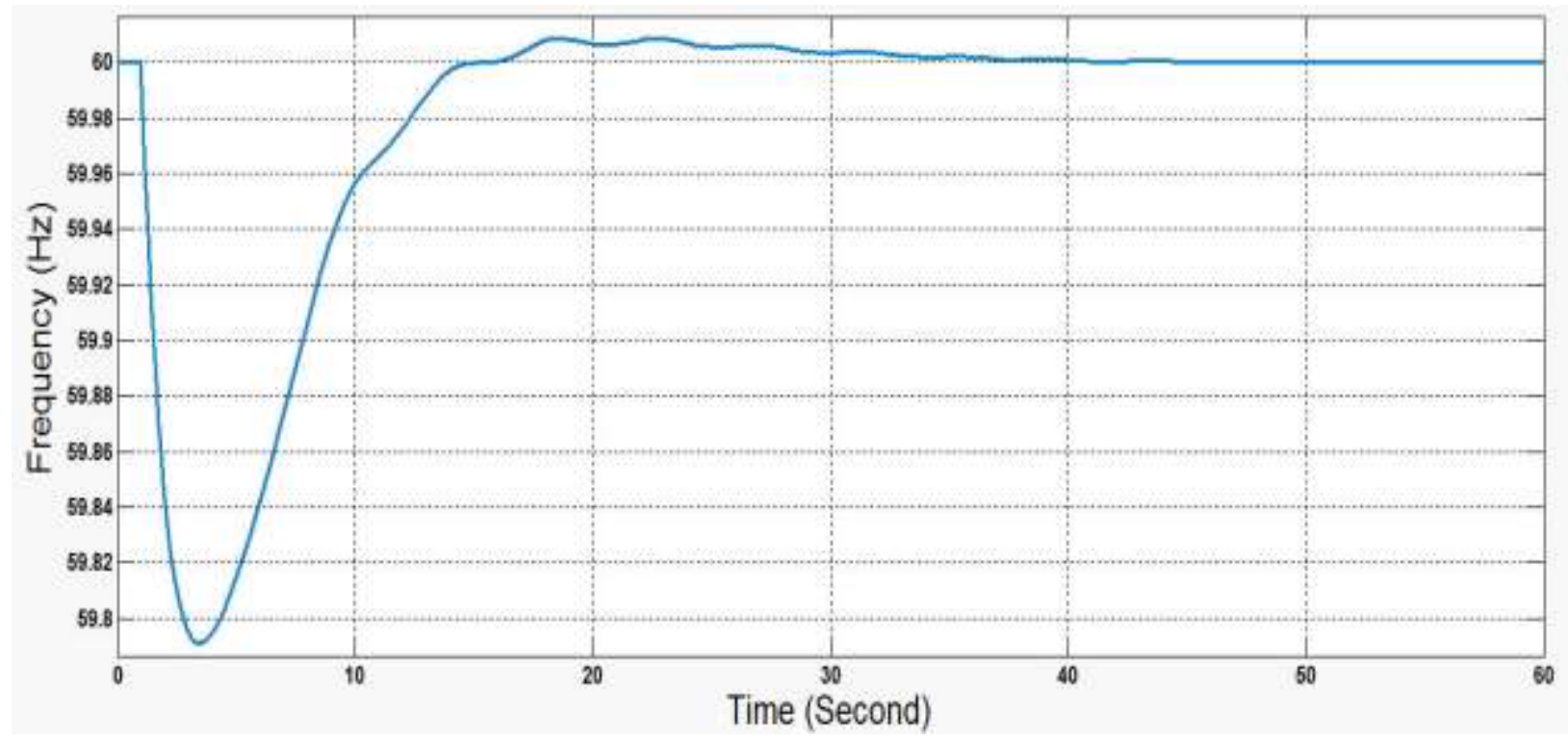

Figure 4.25. Response of PID controller with the least ITAE 
ITSE is the fourth PCI which is assessed. The results of GA runs can be seen in Table 4.10. The response of system to the least ISE found (best solution- run \#6) can be seen in figure 4.26.

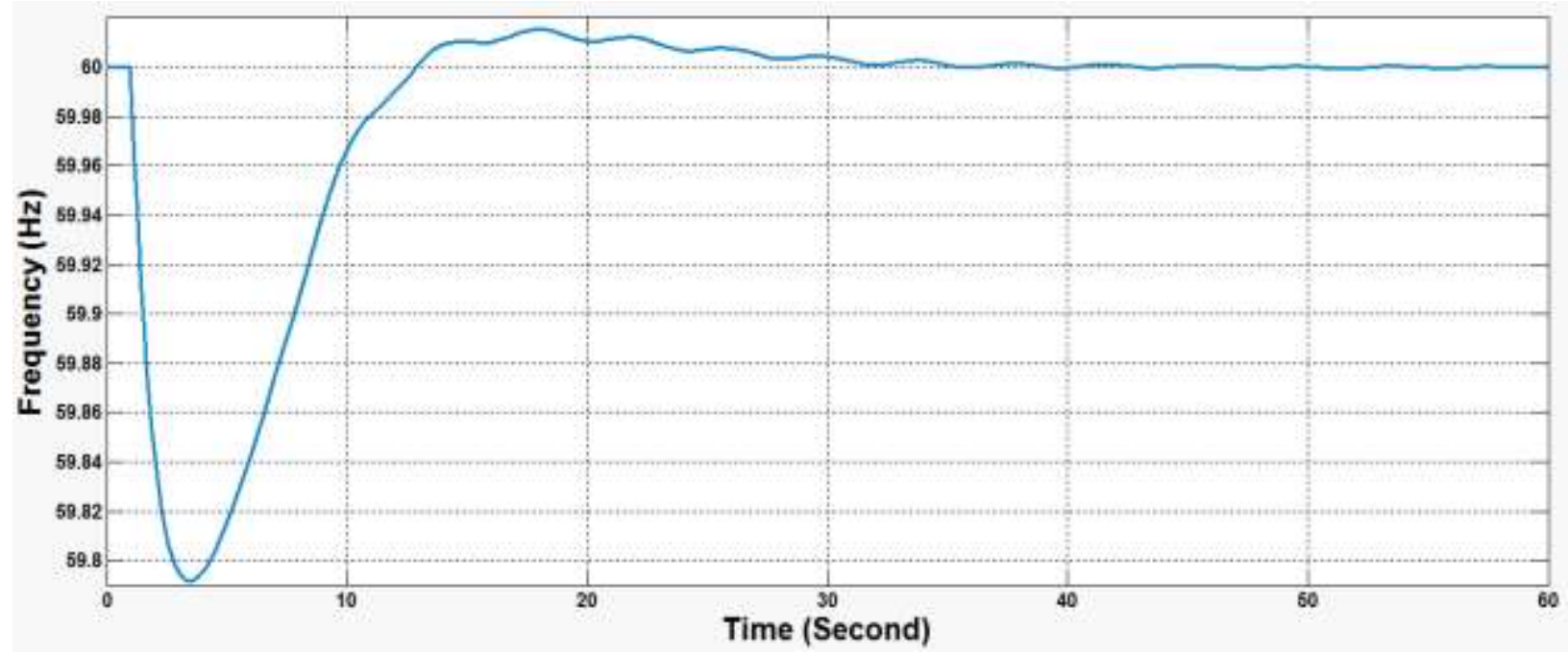

Figure 4.26. Response of PID controller with the least ITSE

In addition to the common performance index criteria, overshoot and settling time are also selected as the performance index criterion. In this way, computed results have very low overshoots and short settling time periods. Tables 4.11 and 4.12 are presenting the computed results. Figure 4.27 shows the best solution found (run \#5) when overshoot is utilized as the PCI. Figure 4.28 also shows the response of the best solution found when settling time is used as the PCI.

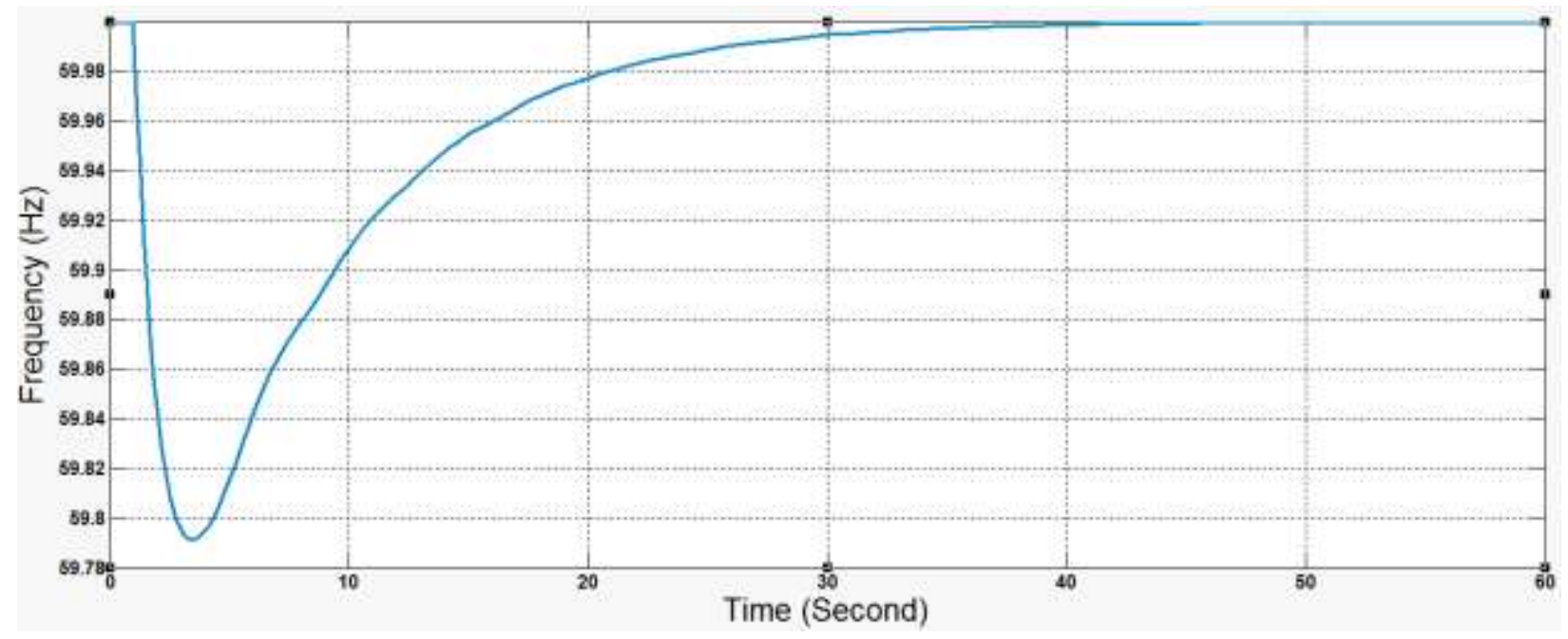

Figure 4. 27. Response of PID controller with overshoot as the PIC 
Table 4. 7. Result of GA runs using IAE as the performance index criterion

\begin{tabular}{|c|c|c|c|c|c|c|c|c|c|c|c|c|c|}
\hline Controller & Run\# & $\begin{array}{c}\text { Load Change } \\
(\mathrm{PU})\end{array}$ & $\begin{array}{c}\text { Delay } \\
(\mathbf{s})\end{array}$ & $\mathrm{Kp}$ & $\mathrm{Ki}$ & $\mathrm{Kd}$ & $\mathrm{IAE}$ & ISE & ITAE & ITSE & $\begin{array}{c}\text { OverShoot } \\
(\%)\end{array}$ & $\begin{array}{c}\text { UnderShoot } \\
(\%)\end{array}$ & $\begin{array}{c}\text { Settling Time } \\
(\mathbf{s})\end{array}$ \\
\hline PID & 1 & 0.04 & 0.50 & 0.201126 & 0.125460 & 0.113504 & 1.459937 & 0.200901 & 10.441437 & 0.938592 & 0.024429 & 0.348190 & 29.049476 \\
\hline PID & 2 & 0.04 & 0.50 & 0.480648 & 0.200796 & 0.043712 & 1.436667 & 0.200259 & 10.201134 & 0.930567 & 0.030746 & 0.348492 & 29.209604 \\
\hline PID & 3 & 0.04 & 0.50 & 0.534351 & 0.191836 & 0.170114 & 1.386186 & 0.187491 & 9.728415 & 0.858722 & 0.020827 & 0.339311 & 30.400356 \\
\hline PID & 4 & 0.04 & 0.50 & 0.549347 & 0.198930 & 0.177055 & 1.387617 & 0.187121 & 9.874934 & 0.856705 & 0.021945 & 0.339175 & 28.389616 \\
\hline PID & 5 & 0.04 & 0.50 & 0.503806 & 0.197408 & 0.038512 & 1.438290 & 0.200181 & 10.293323 & 0.928230 & 0.027327 & 0.348517 & 29.396574 \\
\hline PID & 6 & 0.04 & 0.50 & 0.456283 & 0.198620 & 0.245082 & 1.393821 & 0.185723 & 10.010973 & 0.852824 & 0.026546 & 0.338023 & 29.560978 \\
\hline PID & 7 & 0.04 & 0.50 & 0.417656 & 0.173057 & 0.258181 & 1.388566 & 0.186027 & 9.863979 & 0.853215 & 0.023065 & 0.338015 & 28.967900 \\
\hline PID & 8 & 0.04 & 0.50 & 0.428458 & 0.183211 & 0.002474 & 1.435970 & 0.200724 & 10.117609 & 0.931027 & 0.026832 & 0.348784 & 28.419925 \\
\hline PID & 9 & 0.04 & 0.50 & 0.506346 & 0.185852 & 0.202323 & 1.384730 & 0.186394 & 9.763985 & 0.853512 & 0.021075 & 0.338294 & 29.739746 \\
\hline PID & 10 & 0.04 & 0.50 & 0.458023 & 0.181109 & 0.217407 & 1.385248 & 0.186137 & 9.787744 & 0.852637 & 0.022212 & 0.338112 & 27.763109 \\
\hline & & & & & & Average & 1.409703 & 0.192096 & 10.008354 & 0.885603 & 0.024501 & 0.342491 & 29.089728 \\
\hline
\end{tabular}

Table 4. 8. Result of GA runs using ISE as the performance index criterion

\begin{tabular}{|c|c|c|c|c|c|c|c|c|c|c|c|c|c|}
\hline Controller & Run\# & $\begin{array}{c}\text { Load Change } \\
\text { (PU) }\end{array}$ & $\begin{array}{c}\text { Delay } \\
(\mathbf{s})\end{array}$ & Kp & Ki & Kd & IAE & ISE & ITAE & ITSE & $\begin{array}{c}\text { OverShoot } \\
(\%)\end{array}$ & $\begin{array}{c}\text { UnderShoot } \\
(\%)\end{array}$ & $\begin{array}{c}\text { Settling Time } \\
(\mathbf{s})\end{array}$ \\
\hline PID & 1 & 0.04 & 0.50 & 0.547563 & 0.205445 & 0.136151 & 1.471800 & 0.199817 & 11.651383 & 0.931752 & 0.029783 & 0.347893 & 31.708479 \\
\hline PID & 2 & 0.04 & 0.50 & 0.484860 & 0.218656 & 0.265582 & 1.531149 & 0.200069 & 13.753027 & 0.951963 & 0.039041 & 0.347143 & 58.577592 \\
\hline PID & 3 & 0.04 & 0.50 & 0.573567 & 0.208962 & 0.202323 & 1.591017 & 0.200583 & 17.108438 & 0.980608 & 0.032672 & 0.347381 & 58.712237 \\
\hline PID & 4 & 0.04 & 0.50 & 0.248238 & 0.127118 & 0.131008 & 1.456729 & 0.201039 & 10.396497 & 0.937607 & 0.020899 & 0.348212 & 29.306994 \\
\hline PID & 5 & 0.04 & 0.50 & 0.527114 & 0.200189 & 0.201959 & 1.481495 & 0.199452 & 12.006754 & 0.931878 & 0.030164 & 0.347642 & 42.445751 \\
\hline PID & 6 & 0.04 & 0.50 & 0.434467 & 0.166477 & 0.225969 & 1.451444 & 0.199452 & 10.572584 & 0.926540 & 0.025436 & 0.347633 & 29.695376 \\
\hline PID & 7 & 0.04 & 0.50 & 0.787162 & 0.306664 & 0.505140 & 1.802064 & 0.204716 & 26.640439 & 1.229751 & 0.057144 & 0.346014 & 59.814556 \\
\hline PID & 8 & 0.04 & 0.50 & 0.395373 & 0.170249 & 0.310606 & 1.499818 & 0.199252 & 12.508173 & 0.935698 & 0.031497 & 0.347024 & 58.917159 \\
\hline PID & 9 & 0.04 & 0.50 & 0.422824 & 0.184170 & 0.273212 & 1.474341 & 0.199396 & 11.329506 & 0.933165 & 0.032236 & 0.347215 & 32.925322 \\
\hline PID & 10 & 0.04 & 0.50 & 0.380947 & 0.168930 & 0.310918 & 1.491029 & 0.199238 & 12.047934 & 0.934308 & 0.032067 & 0.346986 & 58.661416 \\
\hline
\end{tabular}


Table 4. 9. Result of GA runs using ITAE as the performance index criterion

\begin{tabular}{|c|c|c|c|c|c|c|c|c|c|c|c|c|c|}
\hline Controller & Run\# & $\begin{array}{c}\text { Load Change } \\
\text { (PU) }\end{array}$ & $\begin{array}{c}\text { Delay } \\
(\mathbf{s})\end{array}$ & Kp & Ki & Kd & IAE & ISE & ITAE & ITSE & $\begin{array}{c}\text { OverShoot } \\
(\%)\end{array}$ & $\begin{array}{c}\text { UnderShoot } \\
(\%)\end{array}$ & $\begin{array}{c}\text { Settling Time } \\
(\mathbf{s})\end{array}$ \\
\hline PID & 1 & 0.04 & 0.50 & 0.456283 & 0.145901 & 0.018363 & 1.442109 & 0.202176 & 9.954147 & 0.940880 & $\mathbf{0 . 0 1 3 6 4 2}$ & 0.348565 \\
\hline PID & 2 & 0.04 & 0.50 & 0.475195 & 0.177480 & 0.029535 & 1.436656 & 0.200338 & 10.077993 & 0.926564 & 0.022693 & 0.348532 & 28.894016 \\
\hline PID & 3 & 0.04 & 0.50 & 0.416138 & 0.189023 & 0.085675 & 1.444013 & 0.200284 & 10.226717 & 0.932825 & 0.029657 & 0.348349 & 28.302904 \\
\hline PID & 4 & 0.04 & 0.50 & 0.366482 & 0.133779 & 0.048481 & 1.447545 & 0.202108 & 10.081854 & 0.941288 & 0.014069 & 0.348507 & 29.022600 \\
\hline PID & 5 & 0.04 & 0.50 & 0.479038 & 0.174663 & 0.080816 & 1.439677 & 0.200197 & 10.126402 & 0.926804 & 0.022714 & 0.348292 & 28.569114 \\
\hline PID & 6 & 0.04 & 0.50 & 0.487719 & 0.151884 & 0.090971 & 1.442319 & 0.201639 & 10.042520 & 0.938233 & 0.015622 & 0.347948 & 27.891279 \\
\hline PID & 7 & 0.04 & 0.50 & 0.493903 & 0.163793 & 0.025914 & 1.437723 & 0.201040 & 9.992843 & 0.931027 & 0.019336 & 0.348560 & 29.209348 \\
\hline PID & 8 & 0.04 & 0.50 & 0.489105 & 0.151609 & 0.006420 & 1.440394 & 0.202166 & 9.939463 & 0.940550 & 0.014864 & 0.348641 & 29.099766 \\
\hline PID & 9 & 0.04 & 0.50 & 0.438750 & 0.143356 & 0.042830 & 1.444626 & 0.202054 & 10.044787 & 0.940561 & 0.013971 & 0.348540 & 28.6778751 \\
\hline PID & 10 & 0.04 & 0.50 & 0.475737 & 0.149152 & 0.041383 & 1.439348 & 0.201992 & 9.919254 & 0.939577 & 0.014188 & 0.348525 & $\$ 28.531830$ \\
\hline & & & & & & Average & 1.441441 & 0.201399 & 10.040598 & 0.935831 & 0.018076 & 0.348446 & 28.739471 \\
\hline
\end{tabular}

Table 4. 10. Result of GA runs using ITSE as the performance index criterion

\begin{tabular}{|c|c|c|c|c|c|c|c|c|c|c|c|c|c|}
\hline Controller & Run\# & $\begin{array}{c}\text { Load Change } \\
(\mathrm{PU})\end{array}$ & $\begin{array}{c}\text { Delay } \\
(\mathbf{s})\end{array}$ & $\mathrm{Kp}$ & $\mathrm{Ki}$ & $\mathrm{Kd}$ & IAE & ISE & ITAE & ITSE & $\begin{array}{c}\text { OverShoot } \\
(\%)\end{array}$ & $\begin{array}{c}\text { UnderShoot } \\
(\%)\end{array}$ & $\begin{array}{c}\text { Settling Time } \\
(\mathbf{s})\end{array}$ \\
\hline PID & 1 & 0.04 & 0.50 & 0.477778 & 0.179829 & 0.179829 & 1.447499 & 0.199572 & 10.458508 & 0.925847 & 0.026153 & 0.347770 & 30.666048 \\
\hline PID & 2 & 0.04 & 0.50 & 0.452065 & 0.185643 & 0.148351 & 1.444496 & 0.199792 & 10.325767 & 0.928109 & 0.026979 & 0.348078 & 27.828884 \\
\hline PID & 3 & 0.04 & 0.50 & 0.423770 & 0.161933 & 0.037331 & 1.440104 & 0.200459 & 10.159316 & 0.927433 & 0.020659 & 0.348558 & 28.950096 \\
\hline PID & 4 & 0.04 & 0.50 & 0.431907 & 0.157133 & 0.265582 & 1.463600 & 0.199812 & 11.147298 & 0.930923 & 0.022701 & 0.347186 & 35.761270 \\
\hline PID & 5 & 0.04 & 0.50 & 0.456283 & 0.173876 & 0.018363 & 1.437965 & 0.200310 & 10.168623 & 0.926074 & 0.022113 & 0.348595 & 29.196822 \\
\hline PID & 6 & 0.04 & 0.50 & 0.458579 & 0.176089 & 0.186841 & 1.446929 & 0.199478 & 10.429577 & 0.925472 & 0.025798 & 0.347529 & 30.299721 \\
\hline PID & 7 & 0.04 & 0.50 & 0.446251 & 0.169330 & 0.100364 & 1.441521 & 0.200036 & 10.182541 & 0.926612 & 0.022996 & 0.348117 & 28.346808 \\
\hline PID & 8 & 0.04 & 0.50 & 0.494219 & 0.175275 & 0.115246 & 1.444972 & 0.200029 & 10.371197 & 0.926658 & 0.023472 & 0.347869 & 28.118703 \\
\hline PID & 9 & 0.04 & 0.50 & 0.481603 & 0.177951 & 0.111857 & 1.441453 & 0.199923 & 10.220572 & 0.925959 & 0.024156 & 0.347975 & 28.242558 \\
\hline PID & 10 & 0.04 & 0.50 & 0.517443 & 0.184254 & 0.087303 & 1.443909 & 0.199934 & 10.432538 & 0.925512 & 0.024532 & 0.348039 & 28.639251 \\
\hline & & & & & & Average & 1.445245 & 0.199935 & 10.389594 & 0.926860 & 0.023956 & 0.347972 & 29.605016 \\
\hline
\end{tabular}


Table 4. 11. Result of GA runs using overshoot as the performance index criterion

\begin{tabular}{|c|c|c|c|c|c|c|c|c|c|c|c|c|c|}
\hline Controller & Run\# & $\begin{array}{c}\text { Load Change } \\
\text { (PU) }\end{array}$ & $\begin{array}{c}\text { Delay } \\
\text { (s) }\end{array}$ & Kp & Ki & $\mathrm{Kd}$ & IAE & ISE & ITAE & ITSE & $\begin{array}{c}\text { OverShoot } \\
(\%)\end{array}$ & $\begin{array}{c}\text { UnderShoot } \\
(\%)\end{array}$ & $\begin{array}{c}\text { Settling Time } \\
\text { (s) }\end{array}$ \\
\hline PID & 1 & 0.04 & 0.50 & 0.345657 & 0.062883 & 0.172564 & 2.112481 & 0.256423 & 20.766956 & 1.583871 & $2.533970 \mathrm{E}-17$ & 0.347704 & 35.153975 \\
\hline PID & 2 & 0.04 & 0.50 & 0.480876 & 0.082509 & 0.010690 & \begin{tabular}{|l|}
1.871181 \\
\end{tabular} & 0.234762 & 16.060088 & 1.318698 & $3.679826 \mathrm{E}-05$ & 0.348616 & 29.165334 \\
\hline PID & 3 & 0.04 & 0.50 & 0.507416 & 0.077481 & 0.029704 & \begin{tabular}{|l|}
2.011421 \\
\end{tabular} & 0.243796 & 19.254720 & 1.441451 & $3.360578 \mathrm{E}-06$ & 0.348578 & 35.461555 \\
\hline PID & 4 & 0.04 & 0.50 & 0.345924 & 0.055580 & 0.265582 & 2.394436 & 0.282268 & 27.210251 & 1.922589 & $9.712644 \mathrm{E}-18$ & 0.347532 & 44.497794 \\
\hline \multirow[t]{2}{*}{ PID } & 5 & 0.04 & 0.50 & 0.284385 & 0.062712 & 0.103980 & 1.992994 & 0.247924 & 18.018381 & 1.467962 & $8.075047 \mathrm{E}-19$ & 0.347915 & 31.714968 \\
\hline & & & & & & Average & \begin{tabular}{|l|}
2.076502 \\
\end{tabular} & 0.253035 & 20.262079 & 1.546914 & 0.000008 & 0.348069 & 35.198725 \\
\hline
\end{tabular}

Table 4. 12. Result of GA runs using settling time as the performance index criterion

\begin{tabular}{|c|c|c|c|c|c|c|c|c|c|c|c|c|c|}
\hline Controller & Run\# & $\begin{array}{c}\text { Load Change } \\
\text { (PU) }\end{array}$ & $\begin{array}{c}\text { Delay } \\
\text { (s) }\end{array}$ & $\mathrm{Kp}$ & Ki & $\mathrm{Kd}$ & IAE & ISE & ITAE & ITSE & $\begin{array}{c}\text { OverShoot } \\
(\%)\end{array}$ & $\begin{array}{c}\text { UnderShoot } \\
(\%)\end{array}$ & $\begin{array}{c}\text { Settling Time } \\
(\mathrm{s})\end{array}$ \\
\hline PID & 1 & 0.04 & 0.50 & 0.349526 & 0.090573 & 0.281823 & 1.634592 & 0.220055 & 12.084929 & 1.127593 & 0.004965 & 0.347331 & 20.433178 \\
\hline PID & 2 & 0.04 & 0.50 & 0.127967 & 0.307469 & 0.293374 & 1.603435 & \begin{tabular}{|l|}
0.213954 \\
\end{tabular} & 11.864132 & 1.130817 & 0.114848 & 0.347449 & 19.411642 \\
\hline PID & 3 & 0.04 & 0.50 & 0.441667 & 0.118388 & 0.061709 & 1.505839 & \begin{tabular}{|l|}
0.207845 \\
\end{tabular} & 10.543714 & 0.998301 & 0.006991 & 0.348449 & 16.859851 \\
\hline PID & 4 & 0.04 & 0.50 & 0.079335 & 0.279545 & 0.297616 & 1.620249 & 0.215317 & 12.110443 & 1.152723 & 0.114865 & 0.347462 & 19.614889 \\
\hline \multirow[t]{2}{*}{ PID } & 5 & 0.04 & 0.50 & 0.327051 & 0.102396 & 0.061709 & 1.521324 & 0.209330 & 10.699710 & 1.012794 & 0.006926 & 0.348493 & 17.312664 \\
\hline & & & & & & Average & 1.577088 & 0.213300 & 11.460585 & 1.084446 & 0.049719 & 0.347837 & 18.726445 \\
\hline
\end{tabular}

Table 4. 13. Result of GA using multi-objective function with weighting coefficients

\begin{tabular}{|c|c|c|c|c|c|c|c|c|c|c|c|c|c|}
\hline Controller & Run\# & $\begin{array}{c}\text { Load Change } \\
\text { (PU) }\end{array}$ & $\begin{array}{c}\text { Delay } \\
\text { (s) }\end{array}$ & Kp & Ki & $\mathrm{Kd}$ & IAE & ISE & ITAE & ITSE & $\begin{array}{c}\text { OverShoot } \\
(\%)\end{array}$ & $\begin{array}{c}\text { UnderShoot } \\
(\%)\end{array}$ & $\begin{array}{c}\text { Settling Time } \\
\text { (s) }\end{array}$ \\
\hline PID & 1 & 0.04 & 0.50 & \begin{tabular}{|l|}
0.323984 \\
\end{tabular} & 0.099576 & \begin{tabular}{|l|}
0.060533 \\
\end{tabular} & \begin{tabular}{|l|}
1.534295 \\
\end{tabular} & \begin{tabular}{|l|}
0.210574 \\
\end{tabular} & \begin{tabular}{|l|}
10.804977 \\
\end{tabular} & 1.025766 & 0.006427 & 0.348499 & 17.894037 \\
\hline
\end{tabular}

Table 4. 14. Result of GA using adaptive performance index ceriterion

\begin{tabular}{|c|c|c|c|c|c|c|c|c|c|c|c|c|c|}
\hline Controller & Run\# & $\begin{array}{c}\text { Load Change } \\
\text { (PU) }\end{array}$ & $\begin{array}{c}\text { Delay } \\
\text { (s) }\end{array}$ & Kp & Ki & $\mathrm{Kd}$ & IAE & ISE & ITAE & ITSE & $\begin{array}{c}\text { OverShoot } \\
(\%)\end{array}$ & $\begin{array}{c}\text { UnderShoot } \\
(\%)\end{array}$ & $\begin{array}{c}\text { Settling Time } \\
(\mathrm{s})\end{array}$ \\
\hline PID & 1 & 0.04 & 0.50 & 0.328262 & 0.083640 & 0.213883 & 1.674900 & 0.224085 & 12.396549 & 1.172220 & 0.002491 & 0.347702 & 22.670840 \\
\hline
\end{tabular}




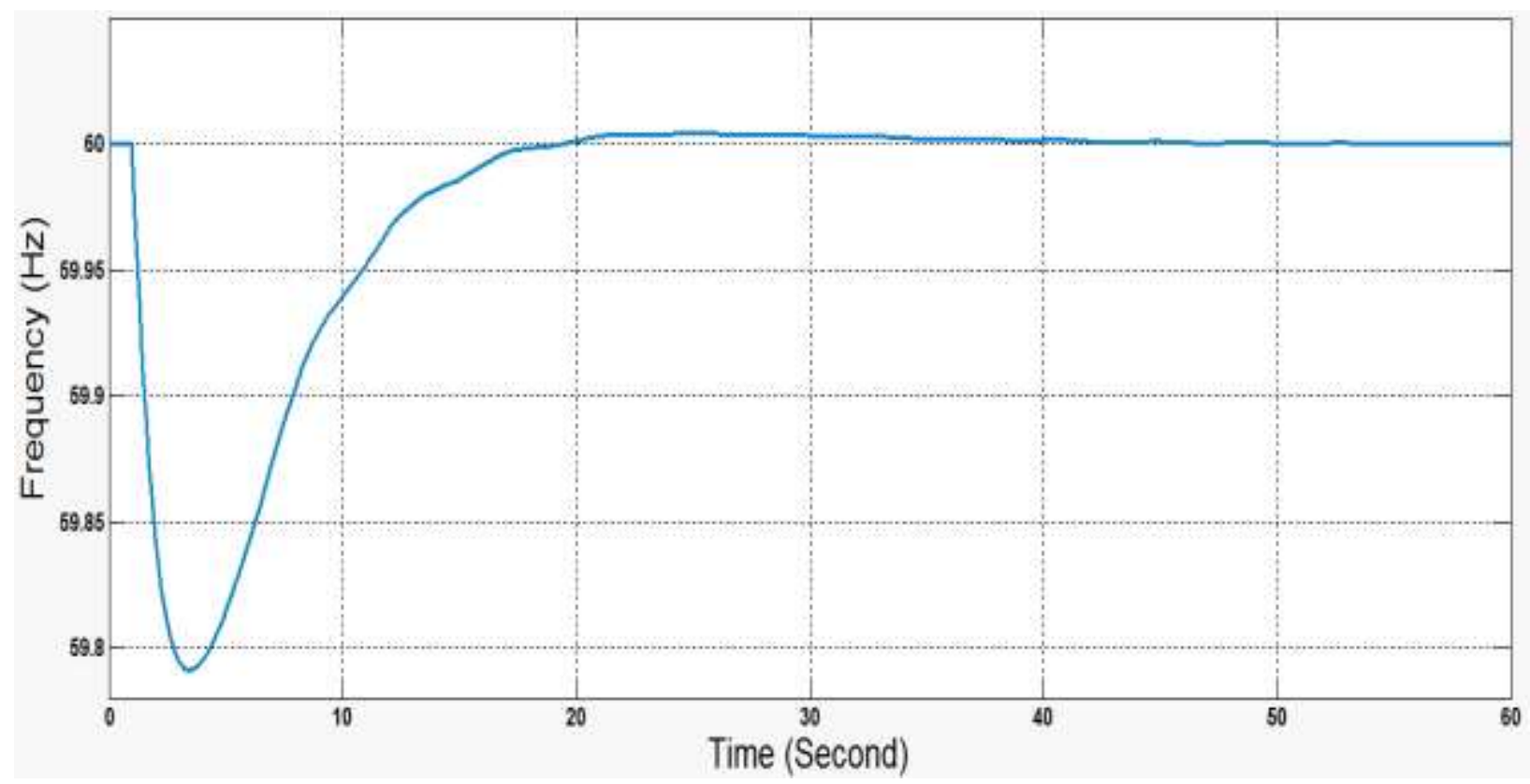

Figure 4.28. Response of PID controller with settling time as the PIC

To take advantage of a performance index criterion with low overshoot and short settling time, a multi-objective function is defined as seen in equation 4.10 and the aim is maximizing the objective function. First objective function competes for lower overshoot and the second objective function competes for shorter settling time. The less they are, the greater objective function is and it means a greater fitness value (better solution).

Objective function $=W_{1}\left(\frac{1}{\operatorname{Max}(\Delta f)}\right)+W_{2}\left(\frac{1}{\text { Settling time }}\right)$

Where $W_{1}$ and $W_{2}$ are the weighting coefficients for overshoot and settling time so that they can compete with each other. By considering the least value found for settling time and a very small value for overshoot, $W_{1}$ and $W_{2}$ are chosen equal to 0.00012 and 100 respectively. By performing the GA, a very impressing result is obtained which can be seen in figure 4.29. Computed controllers gains are presented in table 4.13. The achieved controller had the settling time of $17.9 \mathrm{~s}$ and overshoot of $0.006427 \%$ which is a very efficient performance. 


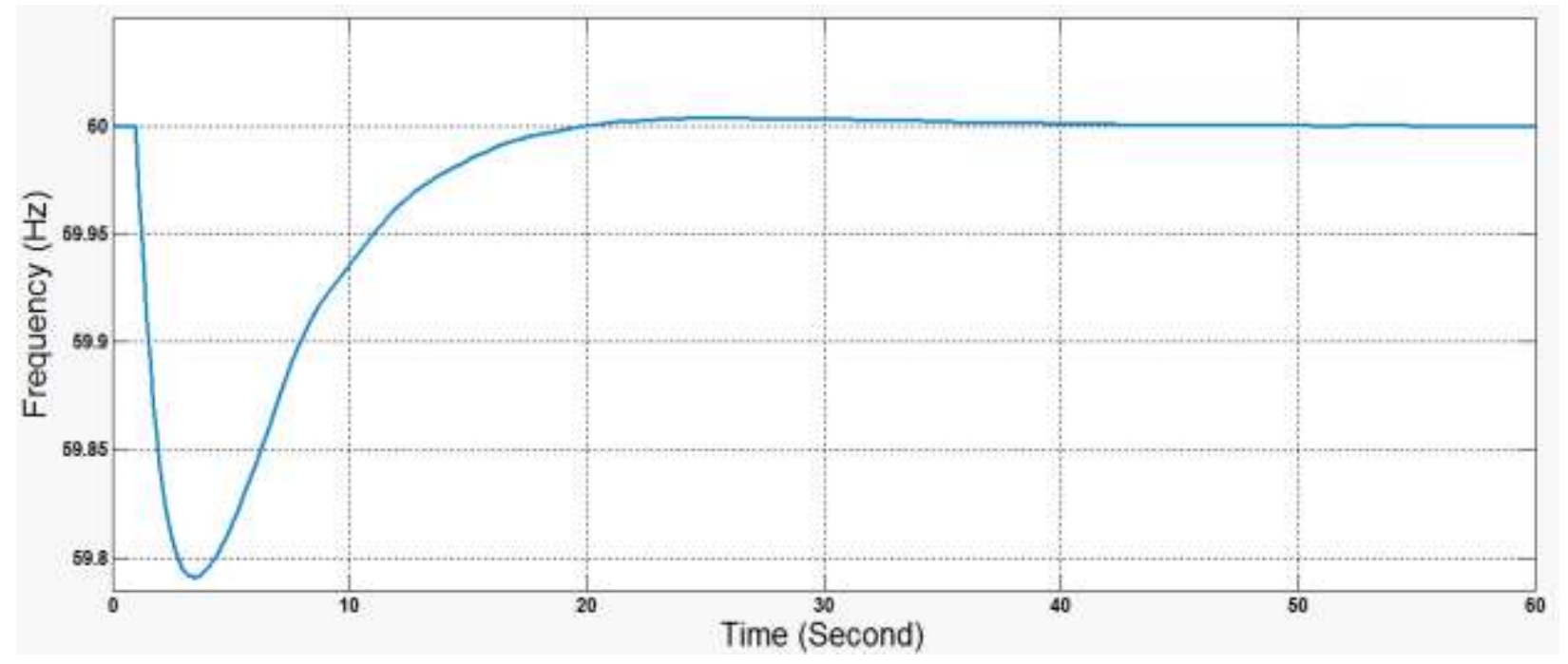

Figure 4. 29. Response of PID controller with multi-objective function

Finally, an adaptive performance index criterion is proposed and developed. This PIC has the ability to define the overshoot and settling time in their possible margins. GA performs the optimization and tries to find solutions having desired overshoot and settling time or less. This adaptive PCI let us define a specific value for overshoot and settling time for the used AGC scheme. The value of $1 \%$ in chosen for the overshoot and 25 seconds for the settling time. GA with the adaptive PIC is run and the result is presented in table 4.14. The response of PID controller can be seen in figure 4. 30. Results show that the overshoot and settling time are in the defined range.

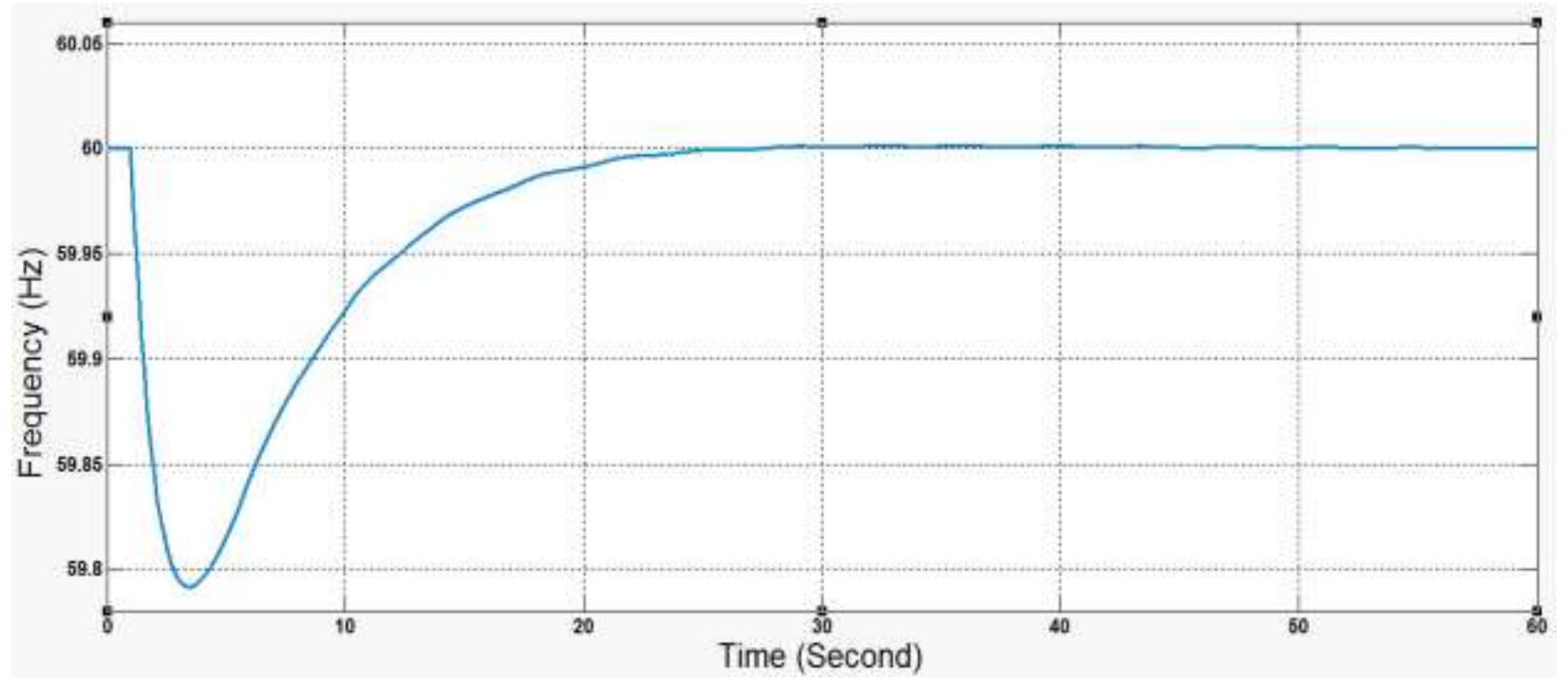

Figure 4. 30. Response of PID controller using developed adaptive PIC 


\section{Chapter 5: Discussion and Future Direction}

Most of the recent LFC studies have not considered the effect of communication link delays on the performance of AGC. This study addresses the importance of considering communication links delay in LFC analysis and shows that the delay can degrade the performance of the control system and even push the system towards instability. Six scenarios are simulated and discussed to evaluate the effect of communication delay on AGC and simulation results for each scenario are presented. Simulation results show that system can stand high amount of communication delay applied to all control areas and still tracks the load change efficiently if the communication delay is considered in the LFC model.

Employing a practical and realistic LFC model is a necessity to study the behavior of control systems to the load deviations and evaluate the efficiency of AGC system. Therefore, a realistic LFC model considering physical constraints such as governor dead band and generation rate limit and communication links delay is developed. By employing the comprehensive LFC model and a robust GA based decentralized AGC scheme, optimal controllers are designed and the simulation results show that the AGC system is able to damp the frequency deviations originated from a load change.

A comparison between conventional controllers used in LFC studies is performed. The simulation results indicate that PID controller has the best performance in the case physical constraints are not considered. On the other hand, in the case where physical constraints are considered, the performance of integrator, PI and PID controllers are very close to each other. However, it is observed that the performance of PID controller is slightly better.

Different performance index criteria have been used to evaluate the performance of different AGC schemes and different controllers employed in those schemes. This study assesses the behavior and effectiveness of different performance index criteria obtained from several GA runs. The averages of overshoot and settling time for each performance index also provide a good evaluation of the examined performance index criterion. It is observed that by employing ISE, there are cases which have the least ISE value (best solution in terms of performance index) but designed controller cannot eliminate steady-state error completely. Moreover, cases are observed which have ISE 
values close to each other but their behavior are different in term of eliminating the steady-state error. Since ISE has been used very widely in control and LFC researches, the mentioned points should be considered when employing the ISE as the performance index criterion.

Finally, an adaptive and effective performance index criterion is introduced and developed. First in term of a multi-objective function which provides an acceptable response with short settling time and low overshoot. The multi-objective function can perform the trade of between settling time and overshoot if appropriate weighting coefficients are defined. Second in term of an adaptive performance index criterion which has the ability to define the settling time and overshoot. The developed performance index criterion let the utilized GA design controllers with overshoot and settling time equal to or less than desire overshoot and settling time.

The triangle of optimality (GA), best performance (PID controllers and adaptive performance index) and accuracy (comprehensive model) makes the load frequency control model and automatic generation control scheme employed in this study a novel and practical method in LFC studies.

As for future directions, comparison of different optimization methods in term of computation speed can be a valuable work through LFC studies. Since a real-time or very quick optimization method can be employed to design an adaptive control scheme which can deal with various and fast load changes. Developing automatic generation control schemes for renewable energy integration is also an emerging research filed. Moreover, a detailed discrete LFC model which utilizing optimal sampling rate in its control loops can be a good topic for the future works. Since smart grid and future of power system has tied with open communication infrastructures, every research trying to discretize continuous power system and combine it with discrete communication systems will be valuable. 


\section{References}

[1] P. Kundur, Power System Stability and Control, 1994 :McGraw-Hill

[2] JALEELI N., EWART D.N., FINK L.H, "Understanding automatic generation control," IEEE Trans. Power Syst., 1992, 7, (3), pp. 1106-1112

[3] Glover, J. Duncan., Mulukutla S. Sarma, and Thomas J. Overbye. Power System Analysis and Design. Stamford, CT: Cengage Learning, 2012. Print.

[4] Ibraheem, I.; Kumar, P.; Kothari, D.P., "Recent philosophies of automatic generation control strategies in power systems," Power Systems, IEEE Transactions on, vol.20, no.1, pp.346,357, Feb. 2005

[5] Chidambaram, I.A.; Velusami, S., "Decentralized Biased Controllers for Load Frequency Control of Interconnected Power Systems Considering Governor Dead Band Non-Linearity," INDICON, 2005 Annual IEEE, vol., no., pp.521,525, 11-13

[6] Xiangjie Liu; Xiaolei Zhan; Dianwei Qian, "Load frequency control considering generation rate constraints," Intelligent Control and Automation (WCICA), 2010 8th World Congress on, vol., no., pp.1398,1401, 7-9 July 2010

[7] Bhowmik, S.; Tomsovic, K.; Bose, A., "Communication models for third party load frequency control," Power Systems, IEEE Transactions on, vol.19, no.1, pp.543,548, Feb. 2004

[8] Heon-Su Ryu; Ki-Young Jung; Jeong-Do Park; Young-Hyun Moon; Hong-Woo Rhew, "Extended integral control for load frequency control with the consideration of generationrate constraints," Power Engineering Society Summer Meeting, 2000. IEEE , vol.3, no., pp. 1877,1882 vol. 3,2000

[9] Prakash, S.; Sinha, S.K., "Intelligent PI control technique in four area Load Frequency Control of interconnected hydro-thermal power system," Computing, Electronics and 
Electrical Technologies (ICCEET), 2012 International Conference on , vol., no., pp.145,150, 21-22 March 2012

[10] Hamedrahmat, E.; Yazdizadeh, A.; Ramezani, M.H., "Decentralized optimal PID controller based on characteristic matrix eigenvalues and Lyapunov function for load frequency control in KHOZESTAN area," Industrial Electronics and Applications (ICIEA), 2011 6th IEEE Conference on, vol., no., pp.2493,2498, 21-23 June 20

[11] Birch, A. P.; Sapeluk, A.T.; Ozveren, C.S., "An enhanced neural network load frequency control technique," Control, 1994. Control '94. International Conference on , vol.1, no., pp.409,415 vol.1, 21-24 March 1994

[12] Bevrani, H.; Daneshmand, P.R., "Fuzzy Logic-Based Load-Frequency Control Concerning High Penetration of Wind Turbines," Systems Journal, IEEE , vol.6, no.1, pp.173,180, March 2012

[13] Rerkpreedapong, D.; Hasanovic, A.; Feliachi, A., "Robust load frequency control using genetic algorithms and linear matrix inequalities," Power Systems, IEEE Transactions on, vol.18, no.2, pp.855,861, May 2003

[14] Saxena, A.; Gupta, M.; Gupta, V., "Automatic generation control of two area interconnected power system using Genetic algorithm," Computational Intelligence \& Computing Research (ICCIC), 2012 IEEE International Conference on , vol., no., pp.1,5, 18-20 Dec. 2012

[15] Zhang, C.-K.; Jiang, L.; Wu, Q.H.; He, Y.; Wu, M., "Delay-dependent robust load frequency control for time delay power systems," Power Systems, IEEE Transactions on, vol.PP, no.99, pp.1,10

[16] Sathans, S.; Swarup, A., "Intelligent Load Frequency Control of Two-Area Multi Unit Power System with SMES," Systems Engineering (ICSEng), 201121 st International Conference on, vol., no., pp.147,152, 16-18 Aug. 2011 
[17] Abdel-Magid, Y.L.; Dawoud, M.M., "Genetic algorithms applications in load frequency control," Genetic Algorithms in Engineering Systems: Innovations and Applications, 1995. GALESIA. First International Conference on (Conf. Publ. No. 414), vol., no., pp.207,213, 12-14 Sep 1995

[18] Srinivas, M.; Patnaik, L.M., "Genetic algorithms: a survey," Computer , vol.27, no.6, pp.17,26, June 1994

[19] John Holland, Adaptation in Natural and Artificial Systems, University of Michigan Press, Ann Arbon, MI; 1975; 2nd ed., MIT Press, Cambridge, MA, 1992.

[20] Kantardzic, M. (2011) Genetic Algorithms, in Data Mining: Concepts, Models, Methods, and Algorithms, Second Edition, John Wiley \& Sons, Inc., Hoboken, NJ, USA. doi: 10.1002/9781118029145.ch13

[21] Frenzel, J.F., "Genetic algorithms," Potentials, IEEE, vol.12, no.3, pp.21,24, Oct. 1993

[22] Chih-Hsun Chou; Jou-Nan Chen, "Genetic algorithms: initialization schemes and genes extraction," Fuzzy Systems, 2000. FUZZ IEEE 2000. The Ninth IEEE International Conference on , vol.2, no., pp.965,968 vol.2, 2000

[23] Petridis, V.; Kazarlis, S.; Bakirtzis, A., "Varying fitness functions in genetic algorithm constrained optimization: the cutting stock and unit commitment problems," Systems, Man, and Cybernetics, Part B: Cybernetics, IEEE Transactions on , vol.28, no.5, pp.629,640, Oct 199

[24] Patalia, T.P.; Kulkarni, G.R., "Behavioral analysis of genetic algorithm for function optimization," Computational Intelligence and Computing Research (ICCIC), 2010 IEEE International Conference on , vol., no., pp.1,5, 28-29 Dec. 2010

[25] Ramirez, u oz Adalberto., Rodriguez Ignacio. Garza. Handbook of Genetic Algorithms: New Research. New York: Nova Science, 2012. Print.

[26] Mitchell, Melanie. An Introduction to Genetic Algorithms. Cambridge, MA: MIT, 1998. Print. 
[27] Chambers, Lance. Practical Handbook of Genetic Algorithms. Boca Raton, FL: CRC, 1995. Print.

[28] Bevrani H. "Intelligent Automatic Generation Control," CRC Press, 2011, ch.2, pp. 241262

[29] Kristinsson, K.; Dumont, G.A., "System identification and control using genetic algorithms," Systems, Man and Cybernetics, IEEE Transactions on , vol.22, no.5, pp.1033,1046, Sep/Oct 1992

[30] Reformat, M.; Kuffel, E.; Woodford, D.; Pedrycz, W., "Application of genetic algorithms for control design in power systems," Generation, Transmission and Distribution, IEE Proceedings- , vol.145, no.4, pp.345,354, Jul 1998

[31] Anupama Huddar; P. S. Kulkarni A., "Robust ethod of Tuning the Feedback Gains of a Variable Structure Load Frequency Controller Using Genetic Algorithm Optimization" ,Electric Power Components and systems, Vol 36, Iss. 12, 2008

[32] Y. L. Abdel-Magid, M. M. Dawoud. 1996. Optimal AGC tuning with genetic algorithms. Elect. Power Syst. Res. 38(3):231-38.

[33] A. Abdennour. 2002. Adaptive optimal gain scheduling for the load frequency control problem. Elect. Power Components Syst. 30(1):45-56.

[34] S. K. Aditya, D. Das. 2003. Design of load frequency controllers using genetic algorithm for two area interconnected hydro power system. Elect. Power Components Syst. 31(1):8194.

[35] Z. M. Al-Hamouz, H. N. Al-Duwaish. 2000. A new load frequency variable structure controller using genetic algorithm. Elect. Power Syst. Res. 55:1-6. 
[36] Calovic, M., "Linear Regulator Design for a Load and Frequency Control," Power Apparatus and Systems, IEEE Transactions on, vol.PAS-91, no.6, pp.2271,2285, Nov. 1972

[37] Premakumaran, N.; Parthasarathy, K.; Khincha, H. P.; Chidambara, M. R., "Some aspects of multilevel load-frequency control of a power system," Generation, Transmission and Distribution, IEE Proceedings C, vol.129, no.6, pp.290,294, November 1982

[38] Athay, T.M., "Generation scheduling and control," Proceedings of the IEEE , vol.75, no.12, pp.1592,1606, Dec. 1987

[39] Shoults, R.R.; Jativa Ibarra, J.A., "Multi-area adaptive LFC developed for a comprehensive AGC simulator," Power Systems, IEEE Transactions on , vol.8, no.2, pp.541,547, May 1993

[40] Bakken, B.H.; Grande, O.S., "Automatic generation control in a deregulated power system," Power Systems, IEEE Transactions on , vol.13, no.4, pp.1401,1406, Nov 1998

[41] Liu, F.; Song, Y. -H; Ma, J.; Mei, S.; Lu, Q., "Optimal load-frequency control in restructured power systems," Generation, Transmission and Distribution, IEE Proceedings- , vol.150, no.1, pp.87,95, Jan. 2003

[42] Wen Tan, "Unified Tuning of PID Load Frequency Controller for Power Systems via IMC," Power Systems, IEEE Transactions on, vol.25, no.1, pp.341,350, Feb. 2010

[43] Masuta, T.; Yokoyama, A., "Supplementary Load Frequency Control by Use of a Number of Both Electric Vehicles and Heat Pump Water Heaters," Smart Grid, IEEE Transactions on , vol.3, no.3, pp.1253,1262, Sept. 2012

[44] Bevrani H. "Robust power system frequency control," 1st ed. New York: Springer, pp. 1537,2009

[45] Report, I.C., "Dynamic Models for Steam and Hydro Turbines in Power System Studies," Power Apparatus and Systems, IEEE Transactions on, vol.PAS-92, no.6, pp.1904,1915, Nov. 1973 
[46] Kwatny, H.G.; Kalnitsky, K. C.; Bhatt, A., "An optimal tracking approach to loadfrequency control," Power Apparatus and Systems, IEEE Transactions on, vol.94, no.5, pp. 1635,1643 , Sept. 1975

[47] Kumar, A.; Malik, O. P.; Hope, G.S., "Discrete variable structure controller for load frequency control of multiarea interconnected power systems," Generation, Transmission and Distribution, IEE Proceedings C , vol.134, no.2, pp.116,122, March 1987

[48] Report, I.C., "Dynamic Models for Steam and Hydro Turbines in Power System Studies," Power Apparatus and Systems, IEEE Transactions on, vol.PAS-92, no.6, pp.1904,1915, Nov. 1973

[49] Sadeh, J.; Rakhshani, E., "Multi-area load frequency control in a deregulated power system using optimal output feedback method," Electricity Market, 2008. EEM 2008. 5th International Conference on European, vol., no., pp.1,6, 28-30 May 2008

[50] Shoults, R.R.; Jativa Ibarra, J.A., "Multi-area adaptive LFC developed for a comprehensive AGC simulator," Power Systems, IEEE Transactions on, vol.8, no.2, pp.541,547, May 1993

[51] Shafiee, Q.; Morattab, A.; Bevrani, H., "Decentralized model predictive load-frequency control for multi-area interconnected power systems," Electrical Engineering (ICEE), 2011 19th Iranian Conference on, vol., no., pp.1,1, 17-19 May 2011

[52] Thirukkovulur, Ateeth Kumar; Nandagopal, Harikrishna; Parivallal, Vigneesh, "Decentralized control of multi-area power system restructuring for LFC optimization," Computational Intelligence \& Computing Research (ICCIC), 2012 IEEE International Conference on , vol., no., pp.1,6, 18-20 Dec. 2012

[53] Lili Dong; Yao Zhang, "On design of a robust load frequency controller for interconnected power systems," American Control Conference (ACC), 2010 , vol., no., pp.1731,1736, June 30 2010-July 22010 
[54] Reddoch, T. W.; Julich, P.M.; Tan, T. O.; Tacker, E.C., "Models and performance functionals for load frequency control in interconnected power systems," Decision and Control, 1971 IEEE Conference on, vol.10, no., pp.492,493, Dec. 1971

[55] Concordia, C.; Kirchmayer, L. K., "Tie-Line Power and Frequency Control of Electric Power Systems [includes discussion]," Power apparatus and systems, part iii. transactions of the american institute of electrical engineers , vol.72, no.2, pp.,, Jan. 1953

[56] Cohn, Nathan, "Some Aspects of Tie-Line Bias Control on Interconnected Power Systems [includes discussion]," Power apparatus and systems, part iii. transactions of the american institute of electrical engineers, vol.75, no.3, pp.,, Jan. 1956

[57] O.I. Elgerd, Electric Energy Systems Theory: An Introduction, McGraw-Hill, 1971.

[58] Qudaih, Yaser Soliman; Bernard, M.; Mitani, Y.; Mohamed, T.H., "Model predictive based load frequency control design in the presence of DFIG wind turbine," Electric Power and Energy Conversion Systems (EPECS), 2011 2nd International Conference on, vol., no., pp.1,5, 15-17 Nov. 2011

[59] IEEE Committee Report, Standard definitions of terms for automatic generation control on electric power systems, IEEE Trans. Power App. Syst., vol. PAS-89, 1970.

[60] L.K. Kirchmayer, Economic Contorl of Interconnected Systems, John Wiley \& Sons, 1959.

[61] Concordia, Charles, "Effect of Prime-Mover Speed Control Characteristics on Electric Power System Performance," Power Apparatus and Systems, IEEE Transactions on , vol.PAS-88, no.5, pp.752,756, May 1969

[62] IEEE Standard 122-1991, Recommended practice for functional and performance characteristics of control systems for steam turbine-generator units, 1992.

[63] Eilts, L. E.; Schleif, F.R., "Governing features and performance of the first 600-MW drogenerating unit at grand coulee," Power Apparatus and Systems, IEEE Transactions on, vol.96, no.2, pp.457,466, Mar 1977 
[64] Kothari, M. L.; Satsangi, P. S.; Nanda, J., "Sampled-Data Automatic Generation Control of Interconnected Reheat Thermal Systems Considering Generation Rate Constraints," Power Apparatus and Systems, IEEE Transactions on , vol.PAS-100, no.5, pp.2334,2342, May 1981

[65] Nanda, J.; Kothari, M. L.; Satsang, P.S., "Automatic generation control of an interconnected hydrothermal system in continuous and discrete modes considering generation rate constraints," Control Theory and Applications, IEE Proceedings D, vol.130, no.1, pp.17,27, January 1983

[66] Hiyama, T., "Optimisation of discrete-type load-frequency regulators considering generation-rate constraints," Generation, Transmission and Distribution, IEE Proceedings C, vol.129, no.6, pp.285,289, November 1982

[67] Bhowmik, S.; Tomsovic, K.; Bose, A., "Communication models for third party load frequency control," Power Systems, IEEE Transactions on, vol.19, no.1, pp.543,548, Feb. 2004

[68] Bevrani, H.; Hiyama, T., "On Load-Frequency Regulation With Time Delays: Design and Real-Time Implementation," Energy Conversion, IEEE Transactions on , vol.24, no.1, pp.292,300, March 2009

[69] Mathur, H. D.; Manjunath, H. V., "Extended Fuzzy Logic Based Integral Controller for Three Area Power System with Generation Rate Constraint," Industrial Technology, 2006. ICIT 2006. IEEE International Conference on, vol., no., pp.917,921, 15-17 Dec. 2006

[70] Kumar, Narendra; Kumar, Narendra; Gupta, Vipul; Kakkar, Shitij; Tanwar, Astha; Goyal, Subhanshu; Upma, "Integral and optimal AGC of 3 area Interconnected Power Systems and modifications in UI Mechanism," Power India Conference, 2012 IEEE Fifth, vol., no., pp.1,6, 19-22 Dec. 2012

[71] Yao Zhang; Lili Dong; Zhiqiang Gao, "Load frequency control for multiple-area power systems," American Control Conference, 2009. ACC '09. , vol., no., pp.2773,2778, 10-12 June 2009 


\section{Appendix A: GA MATLAB Code (Multi-Area, PID Controller)}

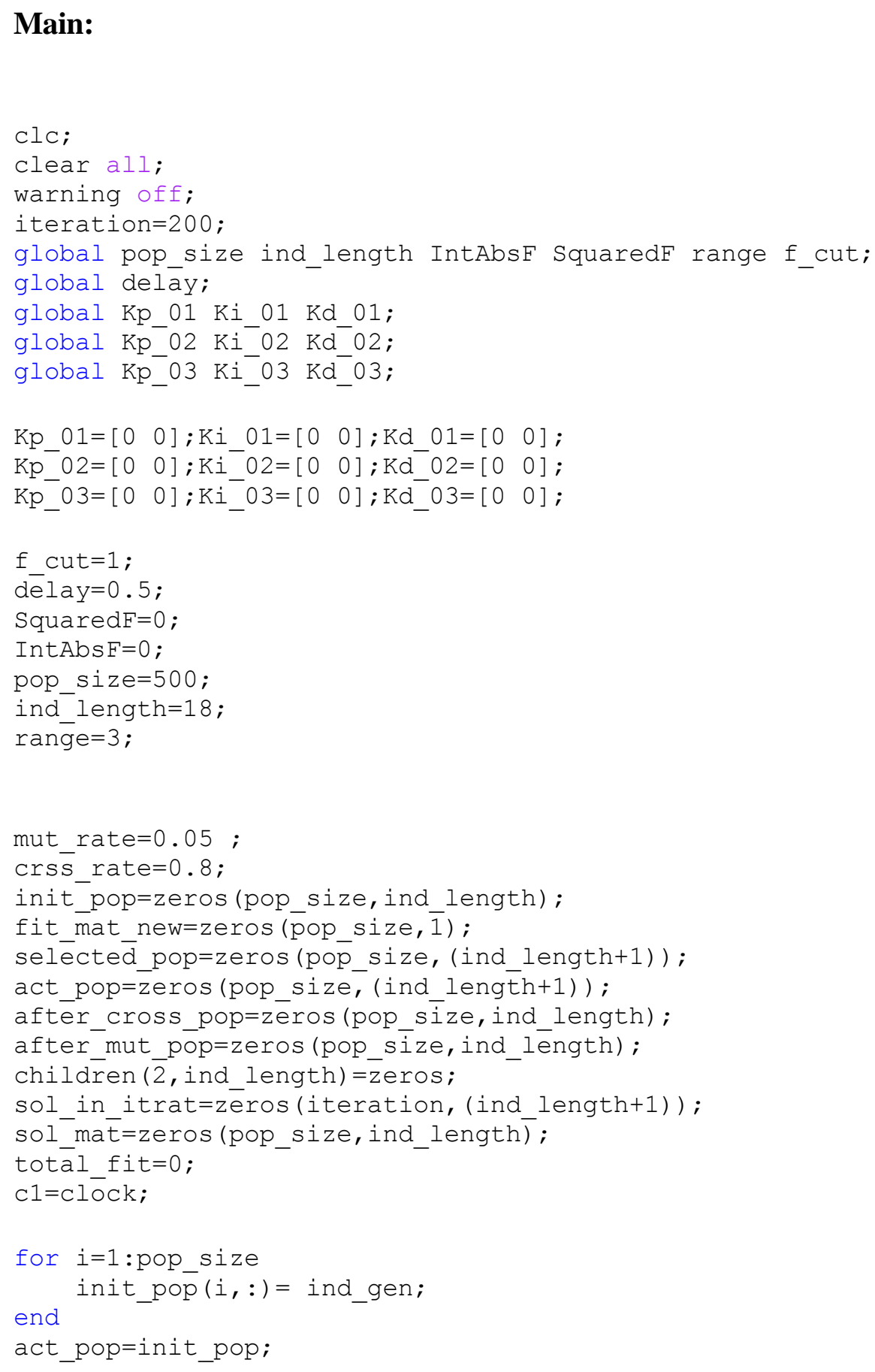




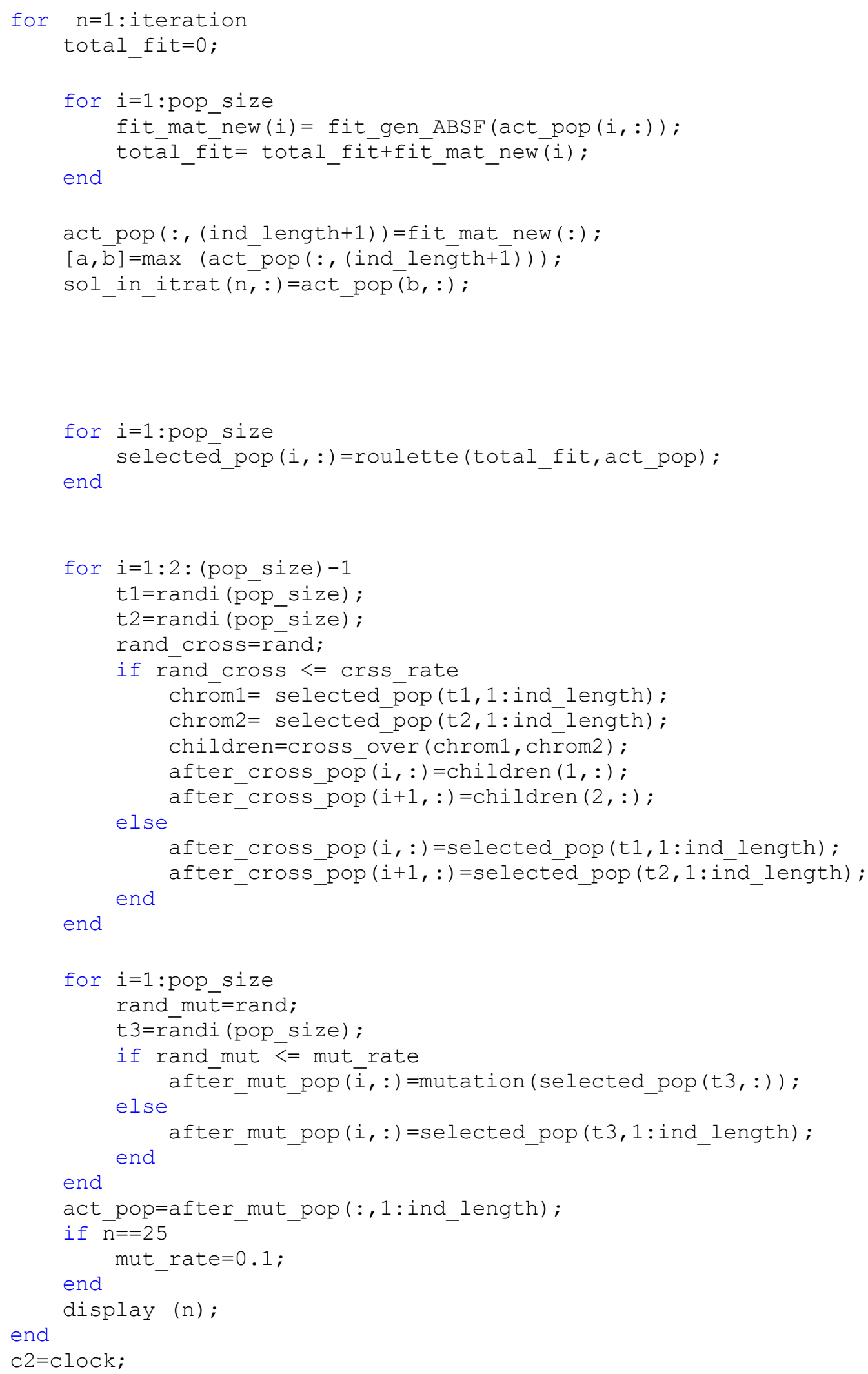




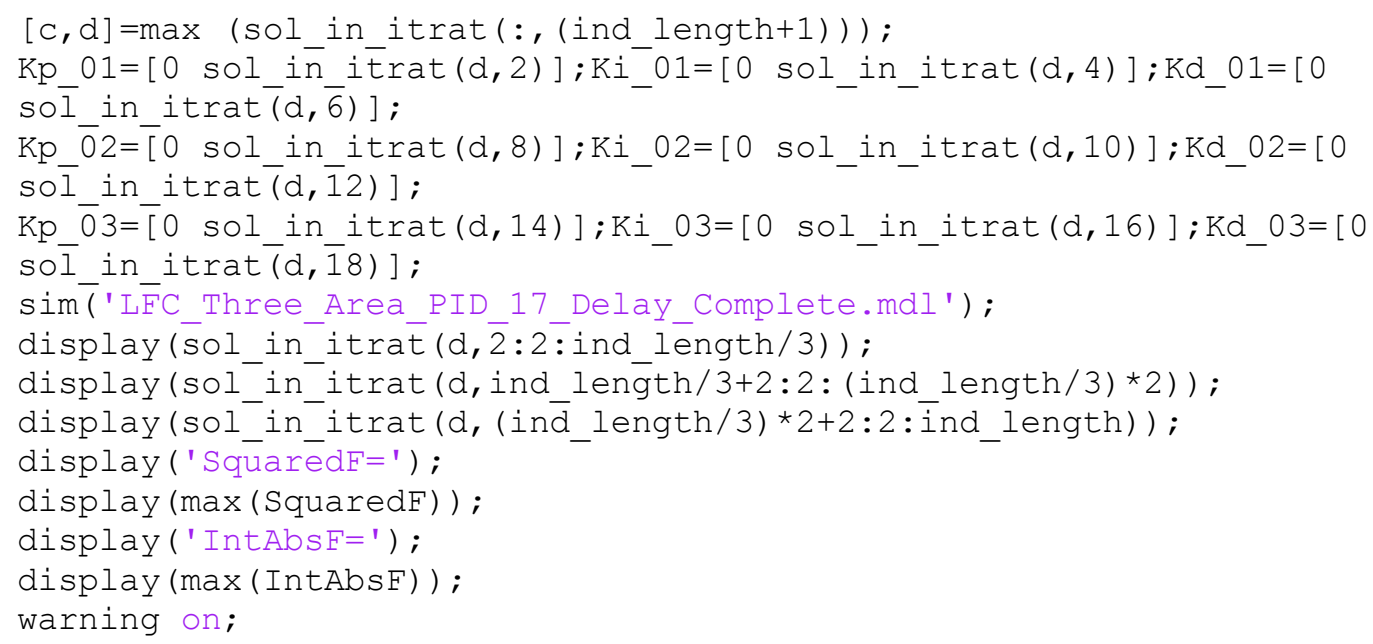

\section{ind_gen Function:}

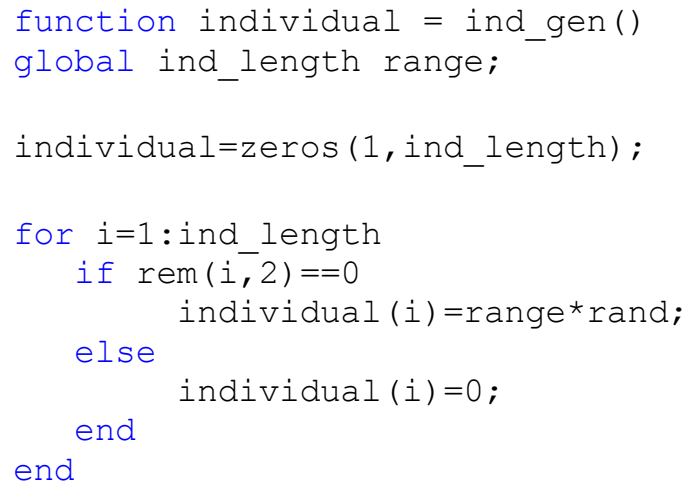

\section{fit_gen_ABSF Function:}

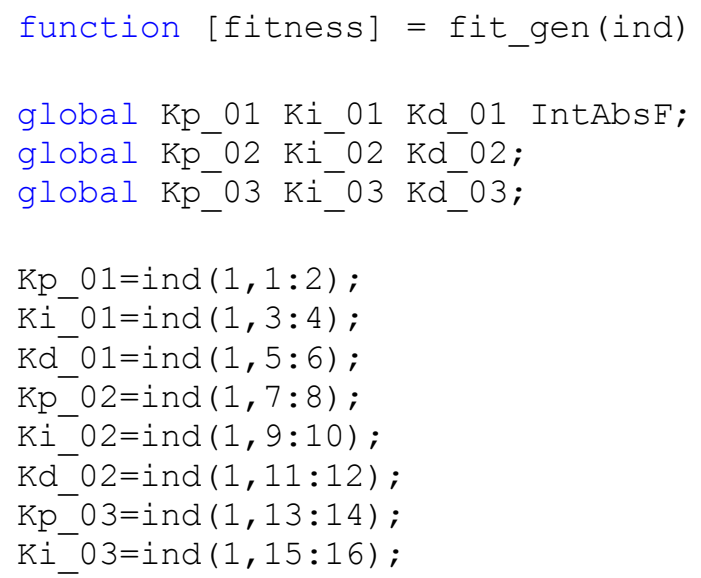


Kd_03=ind $(1,17: 18)$;

sīm('LFC Three Area PID 17 Delay Complete.mdl');

fitness $=\overline{1} / \operatorname{IntA\overline {b}} \mathrm{F}($ length $(\operatorname{In} t A b s F \overline{)})$;

end

roulette Function:

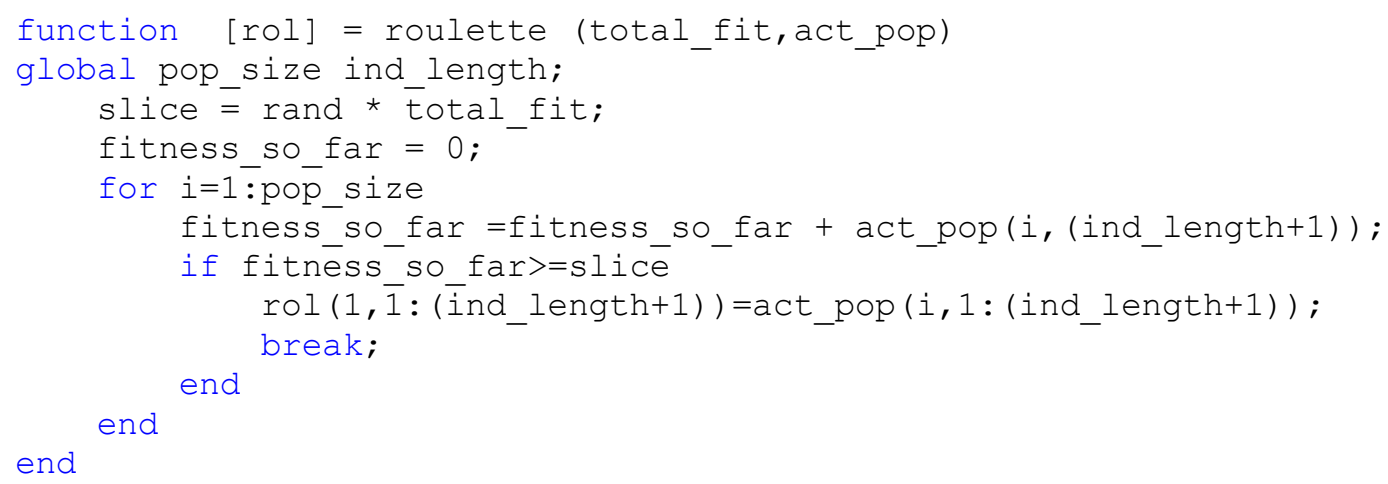

\section{cross_over Function:}

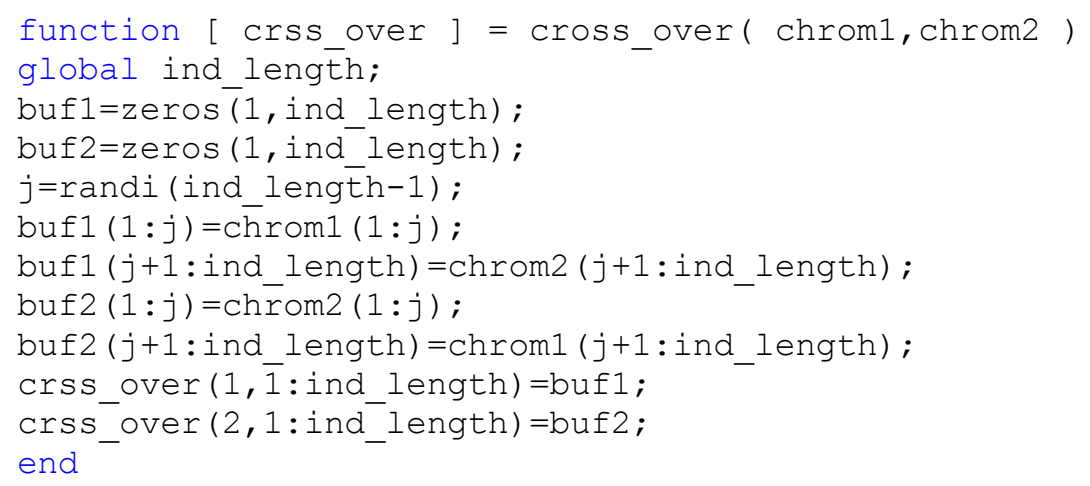

mutation Function:

function [ after mut ] = mutation ( chrom )

global ind lengt $\bar{h}$ range;

$\mathrm{mp}=($ randi (ind_length/2) $) * 2$;

chrom (mp) =range* rand ( ) ;

after_mut $=$ chrom (1:ind_length $)$;

end 


\section{Appendix B: GA MATLAB Code (Single-Area, PID Controller)}

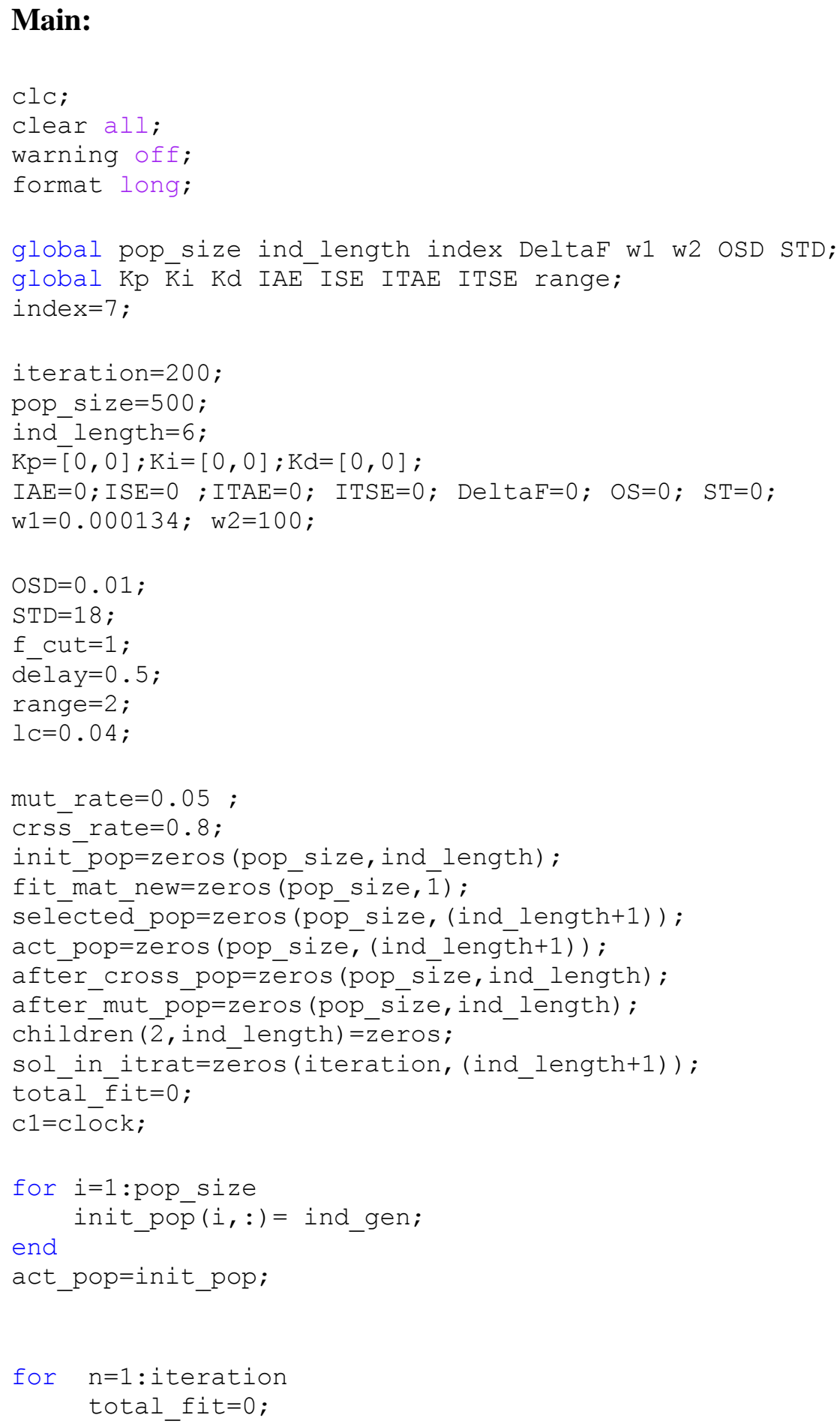




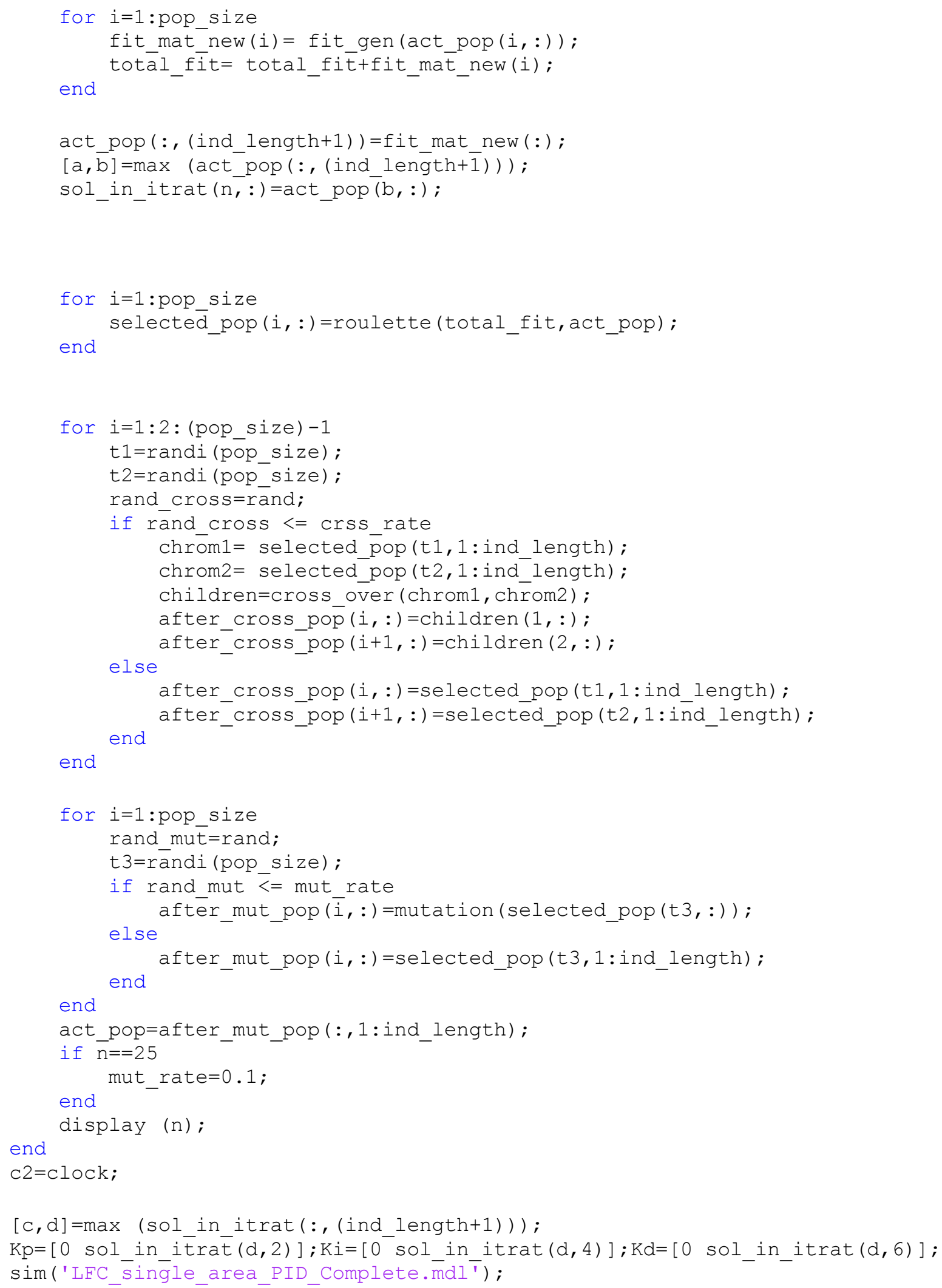




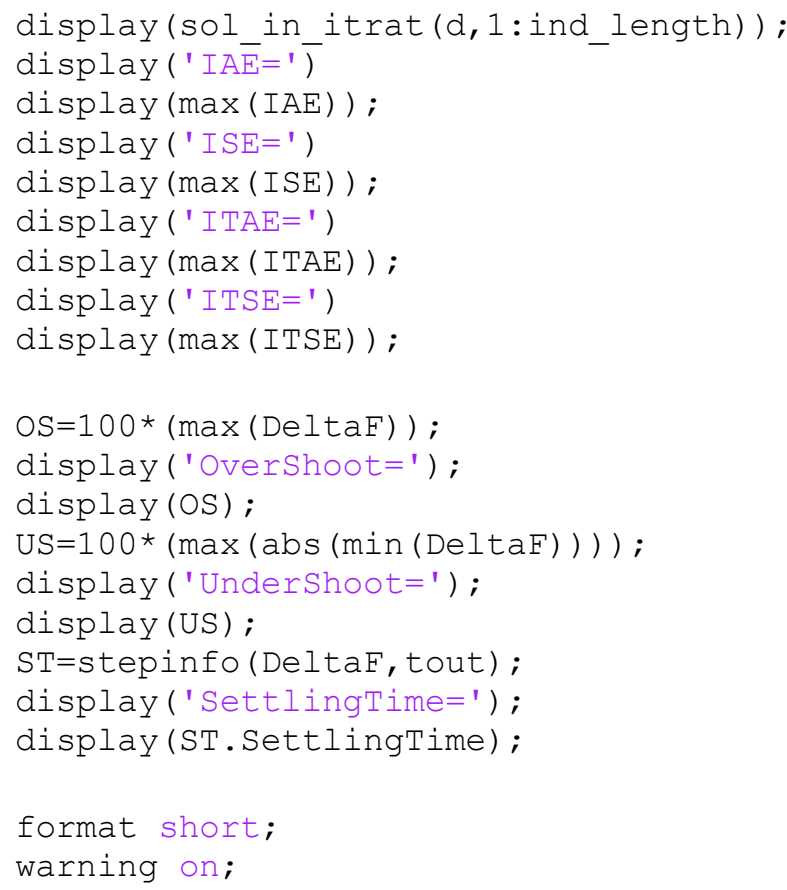

\section{ind_gen Function:}

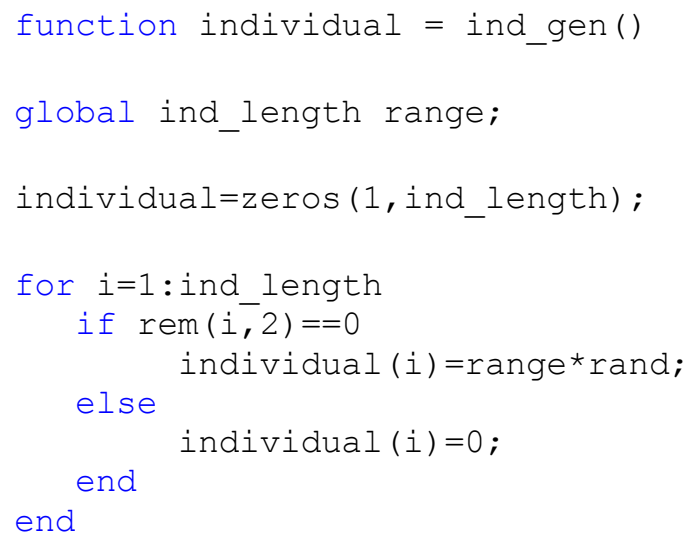

\section{fit_gen Function:}

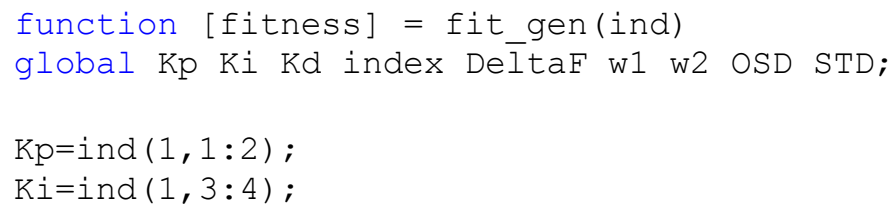




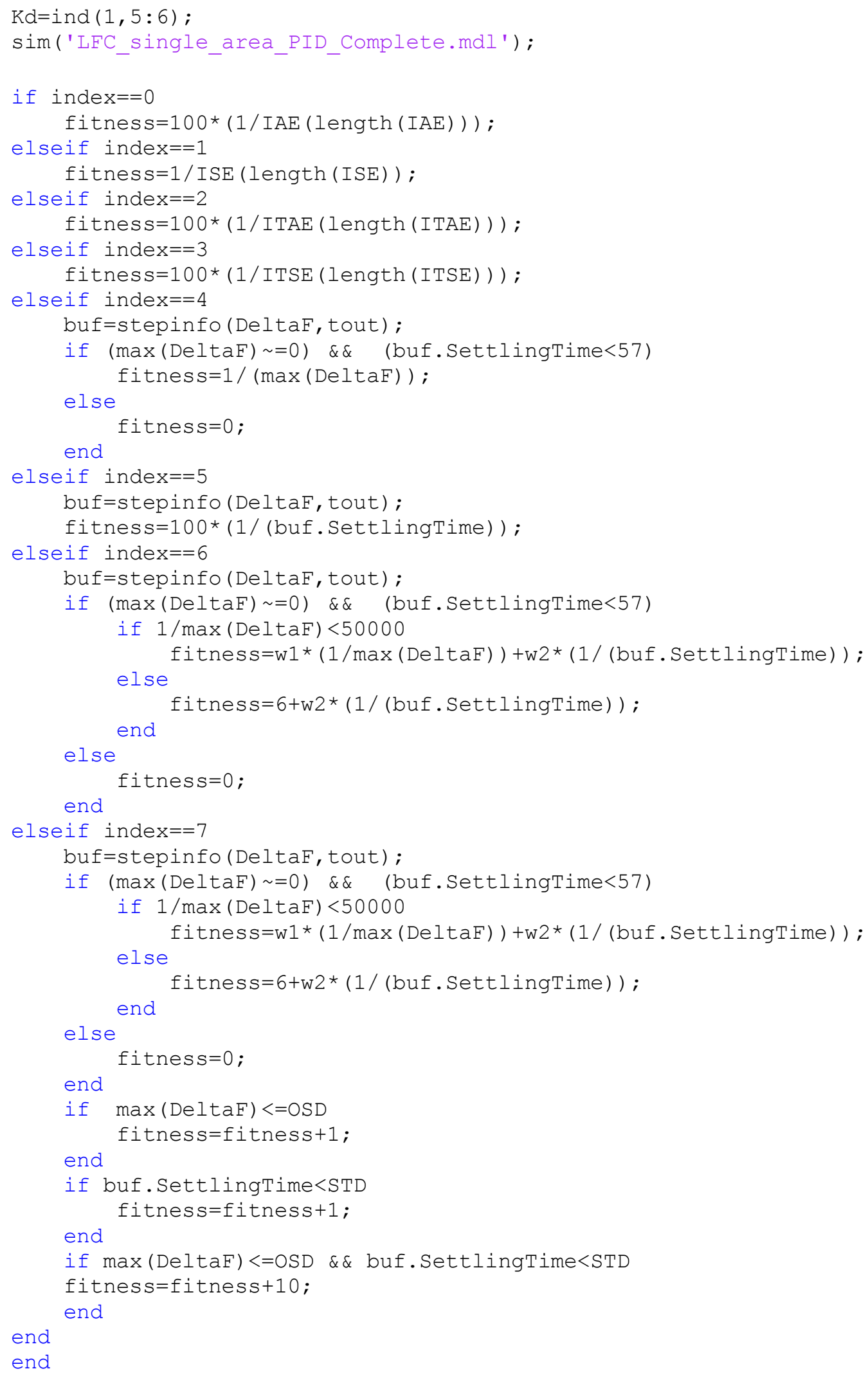




\section{roulette Function:}

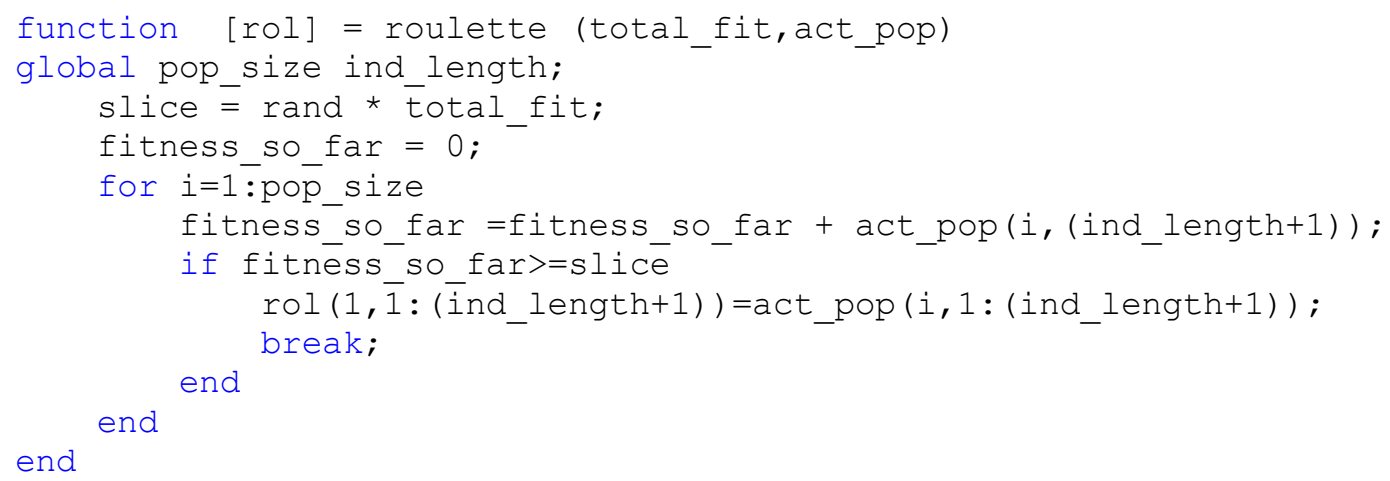

\section{cross_over Function:}

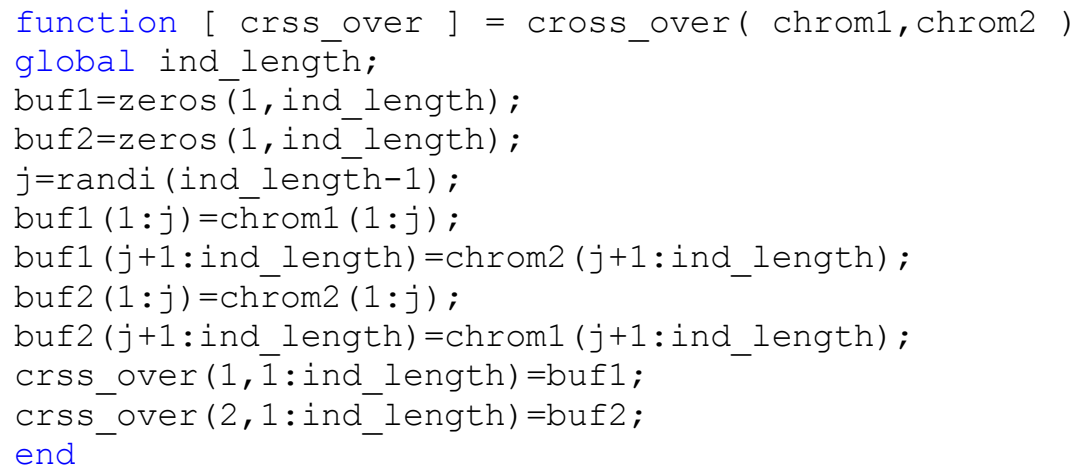

\section{mutation Function:}

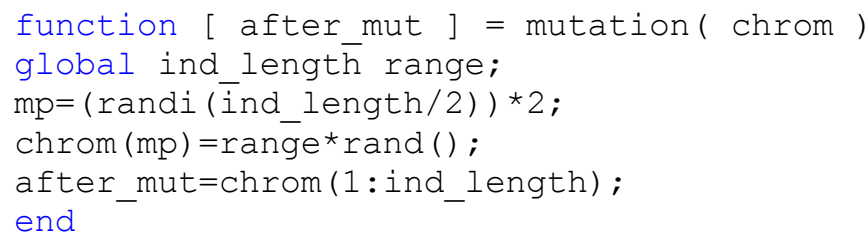




\section{Appendix C: System parameters for three-area \& single-area power systems}

Three-area:

$\mathrm{D}_{1}=0.1, \mathrm{D}_{2}=0.2, \mathrm{D}_{3}=0.15$ [p.u. $\left./ \mathrm{Hz}\right] ;$

$\mathrm{H}_{1}=\mathrm{H}_{2}=\mathrm{H}_{3}=5[\mathrm{~s}]$;

$\mathrm{R}_{1}=\mathrm{R}_{3}=3, \mathrm{R}_{2}=4[\mathrm{~Hz} /$ p.u. $]$;

$\mathrm{T}_{\mathrm{g} 1}=0.2, \mathrm{~T}_{\mathrm{g} 2}=0.25, \mathrm{~T}_{\mathrm{g} 3}=0.3[\mathrm{~s}]$;

$\mathrm{T}_{\mathrm{t} 1}=\mathrm{T}_{\mathrm{t} 2}=\mathrm{T}_{\mathrm{t} 3}=0.3[\mathrm{~s}] ;$

$\beta 1=0.25, \beta 2=0.3, \beta 3=0.28[$ p.u. $/ \mathrm{Hz}] ;$

$\mathrm{T}_{12}=0.20, \mathrm{~T}_{13}=0.22, \mathrm{~T}_{23}=0.15[$ p.u. $/ \mathrm{Hz}] ;$

$\mathrm{T}_{\mathrm{r}} 1=\mathrm{T}_{\mathrm{r} 2}=\mathrm{T}_{\mathrm{r} 3}=0.5[\mathrm{~s}]$;

$\mathrm{K}_{\mathrm{t} 1}=\mathrm{K}_{\mathrm{t} 2}=\mathrm{K}_{\mathrm{t} 3}=1$;

$\mathrm{K}_{\mathrm{g} 1}=\mathrm{K}_{\mathrm{g} 2}=\mathrm{K}_{\mathrm{g} 3}=1$;

$\mathrm{K}_{\mathrm{r} 1}=\mathrm{K}_{\mathrm{r} 2}=\mathrm{K}_{\mathrm{r} 3}=0.5$

\section{Single-area:}

$\mathrm{D}=0.15$ [p.u./Hz];

$\mathrm{H}=5[\mathrm{~s}]$;

$\mathrm{R}=3$ [Hz/p.u.];

$\mathrm{T}_{\mathrm{g}}=0.2[\mathrm{~s}] ;$

$\mathrm{T}_{\mathrm{t}}=0.3[\mathrm{~s}] ;$

$\mathrm{T}_{\mathrm{r}}=0.5[\mathrm{~s}]$;

$\mathrm{K}_{\mathrm{t}}=1$;

$\mathrm{K}_{\mathrm{g}}=1$;

$\mathrm{K}_{\mathrm{r}}=0.5$; 